Utah State University

DigitalCommons@USU

\title{
$5-2018$
}

\section{Assessing the Effects of Local Turbulence and Velocity Profiles on Electromagnetic Flow Meter Accuracy}

Kade J. Beck

Utah State University

Follow this and additional works at: https://digitalcommons.usu.edu/etd

Part of the Civil and Environmental Engineering Commons

\section{Recommended Citation}

Beck, Kade J., "Assessing the Effects of Local Turbulence and Velocity Profiles on Electromagnetic Flow Meter Accuracy" (2018). All Graduate Theses and Dissertations. 7033.

https://digitalcommons.usu.edu/etd/7033

This Thesis is brought to you for free and open access by the Graduate Studies at DigitalCommons@USU. It has been accepted for inclusion in All Graduate Theses and Dissertations by an authorized administrator of DigitalCommons@USU. For more information, please contact digitalcommons@usu.edu.

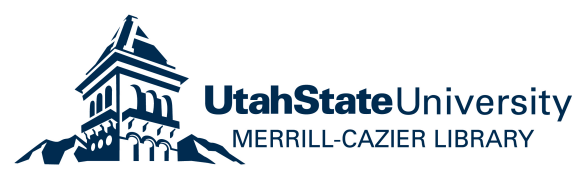


ASSESSING THE EFFECTS OF LOCAL TURBULENCE AND VELOCITY

PROFILES ON ELECTROMAGNETIC FLOW METER ACCURACY

by

Kade J. Beck

A thesis submitted in partial fulfillment

of the requirements for the degree

of

MASTER OF SCIENCE

in

Civil and Environmental Engineering

Approved:

Steven L. Barfuss, M.S., P.E.

Michael C. Johnson, Ph.D., P.E.

Major Professor

Committee Member

Reyhan Baktur, Ph.D.

Mark R. McLellan, Ph.D.

Committee Member

Vice President for Research and

Dean of the School of Graduate Studies

UTAH STATE UNIVERSITY

Logan, Utah 
Copyright () Kade J. Beck 2018

All Rights Reserved 


\author{
ABSTRACT \\ Profiles on Electromagnetic Flow Meter Accuracy \\ by \\ Kade J. Beck, Master of Science \\ Utah State University, 2018
}

Assessing the Effects of Local Turbulence and Velocity

Major Professor: Steven L. Barfuss

Department: Civil and Environmental Engineering

The purpose of this research was to assess the effects of local turbulence and velocity profiles on electromagnetic (magnetic) flow meters. According to the American Water Works Association, "No tool available to water utilities has played a greater part in the conservation of water than the water meter (AWWA 2002)." Consequently, it is imperative to understand what variables may influence magnetic flow meter accuracy.

Even though other researchers have explored the effects of turbulence profile development on orifice plates, the literature is not clear how magnetic flow meters respond to the effect of local turbulence. Accordingly, this study investigated the effects of local turbulence and velocity profiles on magnetic flow meter accuracy.

Using five magnetic flow meters from five different manufacturers, laboratory tests were conducted with a CPA 65E flow conditioner located at different distances upstream of the meter. Numerical modeling using commercially available 
computational fluid dynamics software provided additional insight regarding the effects of local turbulence and velocity profiles on magnetic flow meter accuracy.

The results of the computational fluid dynamics showed local turbulence levels in the pipe to be four times greater at one diameter downstream of a flow conditioner than the local turbulence levels without a flow conditioner installed. Interestingly, the associated differences in flow meter accuracy were not significant. Computational fluid dynamics also showed that the deviations in flow meter accuracy were not proportional to the levels of local turbulence. It appears that magnetic flow meters may only be influenced by local turbulence to the degree that the upstream disturbance that distorts the velocity profile also increases local turbulence. 
PUBLIC ABSTRACT

\author{
Assessing the Effects of Local Turbulence and Velocity \\ Profiles on Electromagnetic Flow Meter Accuracy
}

Kade J. Beck

The purpose of this research was to assess the effects of local turbulence and velocity profiles on electromagnetic (magnetic) flow meters. According to the American Water Works Association, "No tool available to water utilities has played a greater part in the conservation of water than the water meter (AWWA 2002)." Consequently, it is imperative to understand what variables may influence magnetic flow meter accuracy.

Even though other researchers have explored the effects of turbulence profile development on orifice plates, the literature is not clear how magnetic flow meters respond to the effect of local turbulence. Accordingly, this study investigated the effects of local turbulence and velocity profiles on magnetic flow meter accuracy.

Using five magnetic flow meters from five different manufacturers, laboratory tests were conducted with a CPA 65E flow conditioner located at different distances upstream of the meter. Numerical modeling using commercially available computational fluid dynamics software indicated that the deviations in flow meter accuracy were not proportional to the levels of local turbulence. It appears that magnetic flow meters may only be influenced by local turbulence to the degree that the upstream disturbance that distorts the velocity profile also increases local turbulence. 


\section{ACKNOWLEDGMENTS}

Professor Steven Barfuss provided direction, support, and guidance for the completion of this project. His mentorship has been appreciated and greatly enjoyed. Dr.'s Michael Johnson and Reyhan Baktur provided instrumental feedback and suggestions. Zac Sharp mentored the efforts to apply computational fluid dynamics and interpret the results. Ryan Weller and John Chadwick provided perspective and suggestions throughout the research process that were greatly appreciated. Danny Sawchuk from Canada Pipelines Accessories donated the CPA 65E liquid flow conditioner that was used in this study. Mark Cannon and Andy Lee helped with the laboratory equipment.

I am grateful for my wife, Megan, and the support and encouragement she provided throughout this process.

Kade J. Beck 
CONTENTS

Page

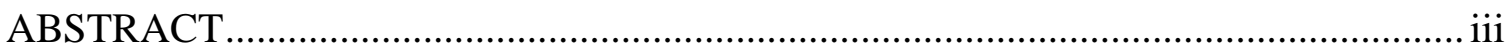

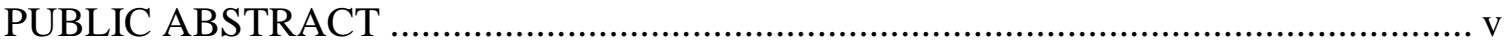

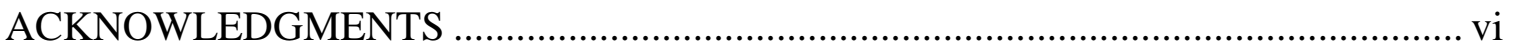

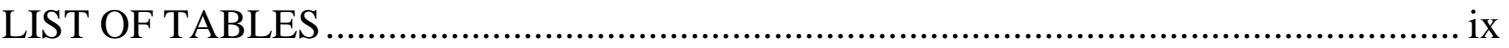

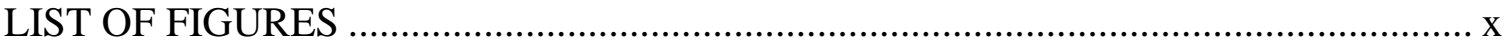

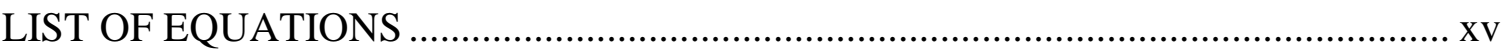

CHAPTER

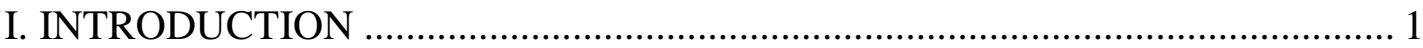

Magnetic Flow Metering Overview ............................................................. 1

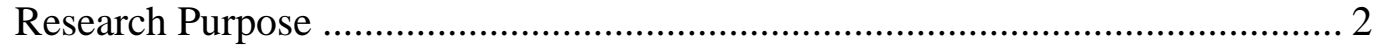

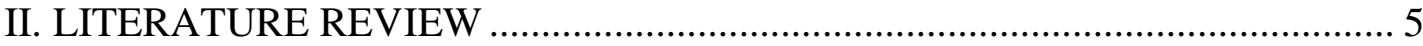

Meter Sensitivity to Velocity Profile.................................................................... 5

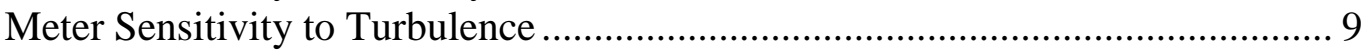

III. PHYSICAL TEST SETUP AND PROCEDURE ............................................. 12

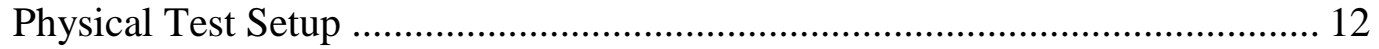

Physical Test Procedure ................................................................................. 14

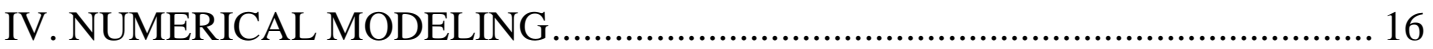

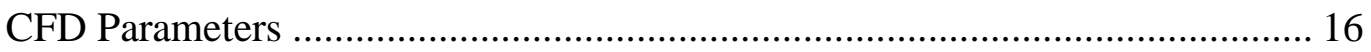

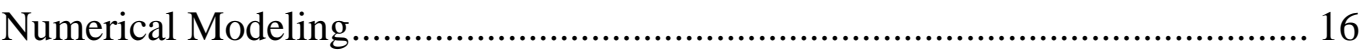

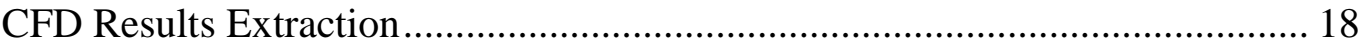

Discussion of Fully Developed Flow ......................................................... 19

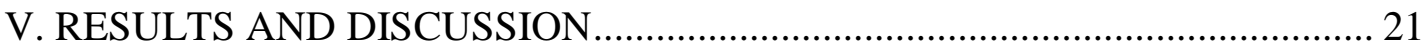

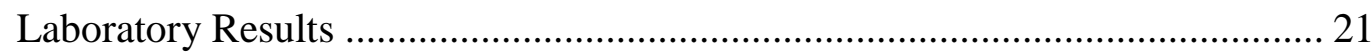

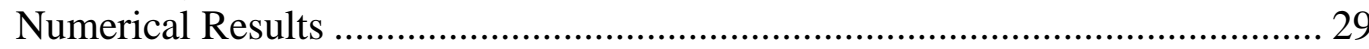

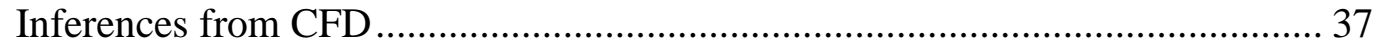

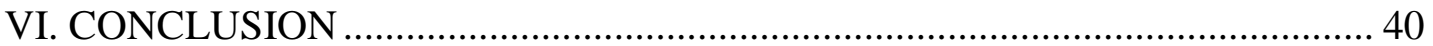

Need for Further Research ................................................................... 40 


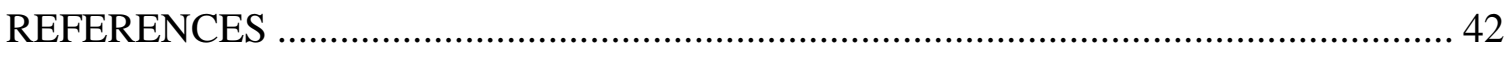

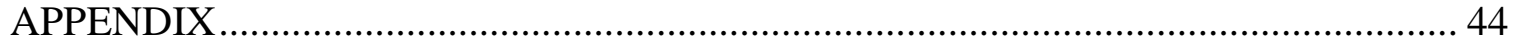

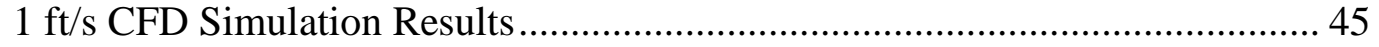

$3 \mathrm{ft} / \mathrm{s}$ CFD Simulation Results ...................................................................... 51

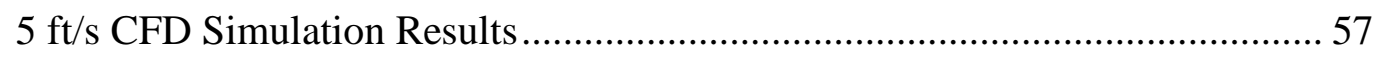

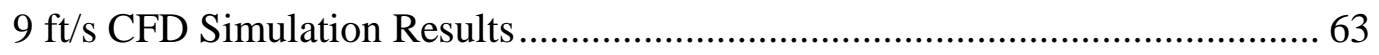

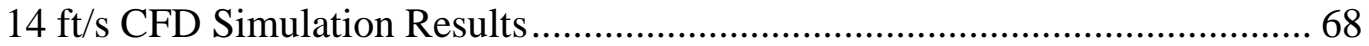


LIST OF TABLES

Table

Page

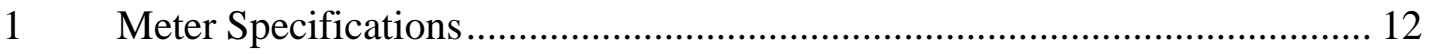

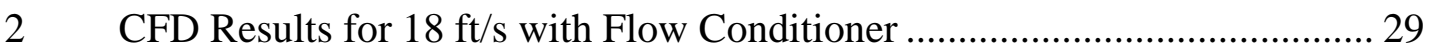

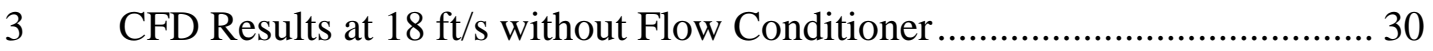

4 TKE vs Percent Deviation from Straight Pipe Performance at $18 \mathrm{ft} / \mathrm{s}$.......... 36

5 TKE vs Percent Deviation from Straight Pipe Performance at $1 \mathrm{ft} / \mathrm{s}$............ 36

$6 \quad$ CFD Results for $1 \mathrm{ft} / \mathrm{s}$ with Flow Conditioner ............................................ 45

$7 \quad$ CFD Results for $1 \mathrm{ft} / \mathrm{s}$ without Flow Conditioner ....................................... 45

$8 \quad$ CFD Results for $3 \mathrm{ft} / \mathrm{s}$ with Flow Conditioner ......................................... 51

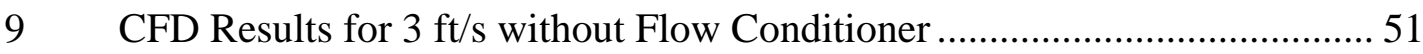

10 CFD Results for $5 \mathrm{ft} / \mathrm{s}$ with Flow Conditioner ......................................... 57

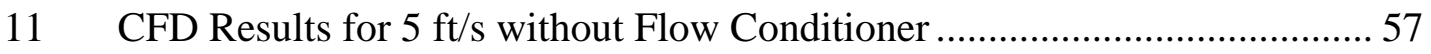

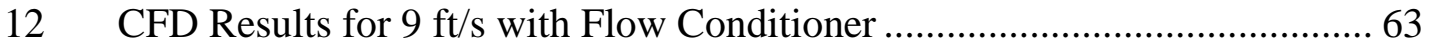

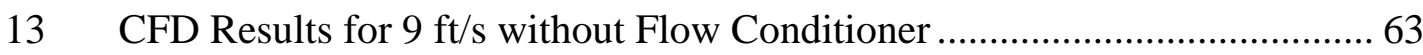




\section{LIST OF FIGURES}

Figure

Page

1 Magnetic Flow Meter Schematic ..................................................... 2

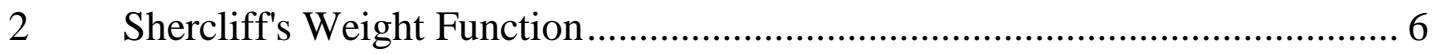

3 Magnetic Meter Installation Schematic................................................... 7

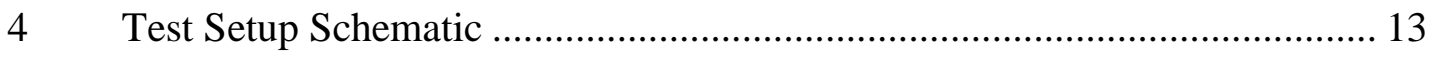

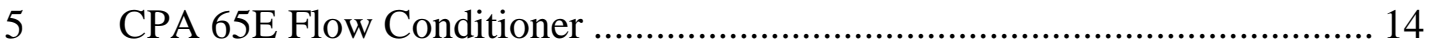

6 Fully Developed Flow TKE Variations with Simulated Pipe Length ............ 18

7 Electrode Location and Corresponding Distance for CFD Extraction........... 19

$8 \quad$ Meter \#1 Laboratory Test Results $1 \mathrm{ft} / \mathrm{s}$ Included ..................................... 22

$9 \quad$ Meter \#2 Laboratory Test Results 1 ft/s Included...................................... 23

10 Meter \#3 Laboratory Test Results 1 ft/s Included ..................................... 23

11 Meter \#4 Laboratory Test Results 1 ft/s Included..................................... 24

12 Meter \#5 Laboratory Test Results $1 \mathrm{ft} / \mathrm{s}$ Included ...................................... 24

13 Meter \#1 Laboratory Test Results ........................................................ 26

14 Meter \#2 Laboratory Test Results ......................................................... 26

15 Meter \#3 Laboratory Test Results ................................................................ 27

16 Meter \#4 Laboratory Test Results .......................................................... 27

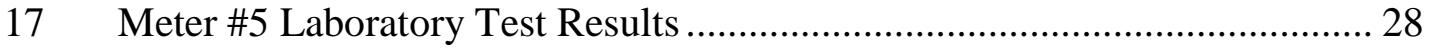

$1818 \mathrm{ft} / \mathrm{s}$ Velocity at 1D with and without Flow Conditioner .......................... 30

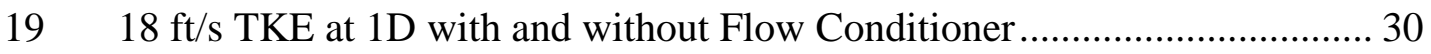

$2018 \mathrm{ft} / \mathrm{s}$ TDR at 1D with and without Flow Conditioner................................... 31 
Figure

$21 \quad 18 \mathrm{ft} / \mathrm{s}$ Velocity at 3D with and without Flow Conditioner........................... 31

$2218 \mathrm{ft} / \mathrm{s}$ TKE at 3D with and without Flow Conditioner................................ 31

$2318 \mathrm{ft} / \mathrm{s}$ TDR at 3D with and without Flow Conditioner.................................... 32

$24 \quad 18 \mathrm{ft} / \mathrm{s}$ Velocity at 5D with and without Flow Conditioner........................... 32

$2518 \mathrm{ft} / \mathrm{s}$ TKE at 5D with and without Flow Conditioner............................... 32

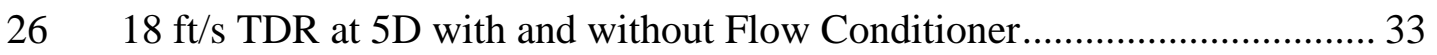

$2718 \mathrm{ft} / \mathrm{s}$ Velocity at 10.4D with and without Flow Conditioner ...................... 33

$2818 \mathrm{ft} / \mathrm{s}$ TKE at 10.4D with and without Flow Conditioner ............................. 33

$2918 \mathrm{ft} / \mathrm{s}$ TDR at 10.4D with and without Flow Conditioner............................ 34

$30 \quad 18 \mathrm{ft} / \mathrm{s}$ Velocity Profiles with Flow Conditioner ......................................... 34

$31 \quad 18 \mathrm{ft} / \mathrm{s}$ Velocity Profiles without Flow Conditioner .................................... 35

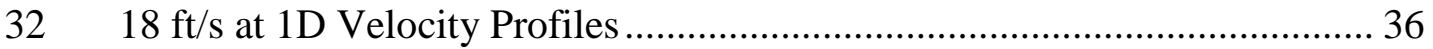

$331 \mathrm{ft} / \mathrm{s}$ Velocity at 1D with and without Flow Conditioner............................. 46

$341 \mathrm{ft} / \mathrm{s}$ TKE at 1D with and without Flow Conditioner ................................. 46

$351 \mathrm{ft} / \mathrm{s}$ TDR at 1D with and without Flow Conditioner..................................... 46

$361 \mathrm{ft} / \mathrm{s}$ Velocity at 3D with and without Flow Conditioner ........................... 47

$371 \mathrm{ft} / \mathrm{s}$ TKE at 3D with and without Flow Conditioner ................................ 47

$381 \mathrm{ft} / \mathrm{s}$ TDR at 3D with and without Flow Conditioner............................... 47

$391 \mathrm{ft} / \mathrm{s}$ Velocity at 5D with and without Flow Conditioner ............................ 48

$40 \quad 1 \mathrm{ft} / \mathrm{s}$ TKE at 5D with and without Flow Conditioner..................................... 48

$411 \mathrm{ft} / \mathrm{s}$ TDR at 5D with and without Flow Conditioner................................. 48

$421 \mathrm{ft} / \mathrm{s}$ Velocity at 10.4D with and without Flow Conditioner ........................ 49 
Figure

$431 \mathrm{ft} / \mathrm{s}$ TKE at 10.4D with and without Flow Conditioner ............................... 49

$441 \mathrm{ft} / \mathrm{s}$ TDR at 10.4D with and without Flow Conditioner............................ 49

$45 \quad 1 \mathrm{ft} / \mathrm{s}$ Velocity Profiles with Flow Conditioner ...................................... 50

$46 \quad 1 \mathrm{ft} / \mathrm{s}$ Velocity Profiles without Flow Conditioner ...................................... 50

$473 \mathrm{ft} / \mathrm{s}$ Velocity at 1D With and Without Flow Conditioner ........................... 52

$48 \quad 3 \mathrm{ft} / \mathrm{s}$ TKE at 1D With and Without Flow Conditioner ................................ 52

$493 \mathrm{ft} / \mathrm{s}$ TDR at 1D With and Without Flow Conditioner............................... 52

$50 \quad 3 \mathrm{ft} / \mathrm{s}$ Velocity at 3D With and Without Flow Conditioner ............................ 53

$513 \mathrm{ft} / \mathrm{s}$ TKE at 3D With and Without Flow Conditioner ............................... 53

$523 \mathrm{ft} / \mathrm{s}$ TDR at 3D With and Without Flow Conditioner............................... 53

$53 \quad 3 \mathrm{ft} / \mathrm{s}$ Velocity at 5D With and Without Flow Conditioner ............................. 54

$543 \mathrm{ft} / \mathrm{s}$ TKE at 5D With and Without Flow Conditioner ................................. 54

$553 \mathrm{ft} / \mathrm{s}$ TDR at 5D With and Without Flow Conditioner............................... 54

$563 \mathrm{ft} / \mathrm{s}$ Velocity at 10.4D With and Without Flow Conditioner ...................... 55

$573 \mathrm{ft} / \mathrm{s}$ TKE at 10.4D With and Without Flow Conditioner ........................... 55

$583 \mathrm{ft} / \mathrm{s}$ TDR at 10.4D With and Without Flow Conditioner .......................... 55

$59 \quad 3 \mathrm{ft} / \mathrm{s}$ Velocity Profiles with Flow Conditioner ......................................... 56

$60 \quad 3 \mathrm{ft} / \mathrm{s}$ Velocity Profiles without Flow Conditioner ...................................... 56

$615 \mathrm{ft} / \mathrm{s}$ Velocity at 1D with and without Flow Conditioner............................ 58

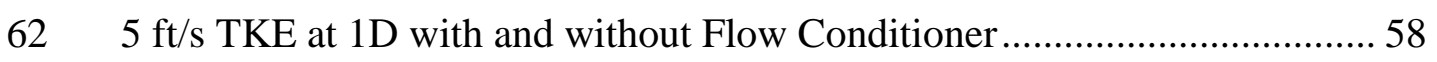

$635 \mathrm{ft} / \mathrm{s}$ TDR at 1D with and without Flow Conditioner................................. 58

$645 \mathrm{ft} / \mathrm{s}$ Velocity at 3D with and without Flow Conditioner ............................ 59 
$655 \mathrm{ft} / \mathrm{s}$ TKE at 3D with and without Flow Conditioner................................ 59

$665 \mathrm{ft} / \mathrm{s}$ TDR at 3D with and without Flow Conditioner................................. 59

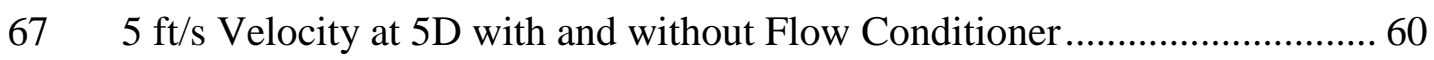

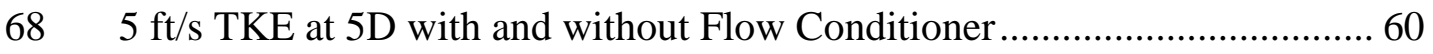

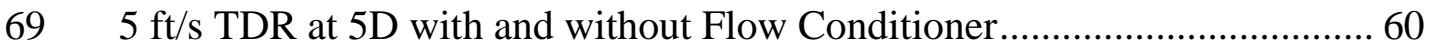

$70 \quad 5 \mathrm{ft} / \mathrm{s}$ Velocity at 10.4D with and without Flow Conditioner ......................... 61

$715 \mathrm{ft} / \mathrm{s}$ TKE at 10.4D with and without Flow Conditioner ............................ 61

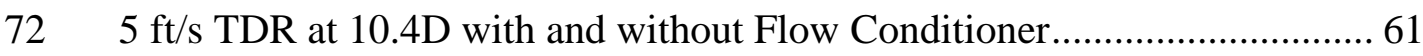

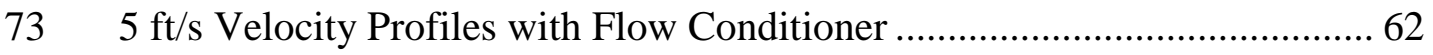

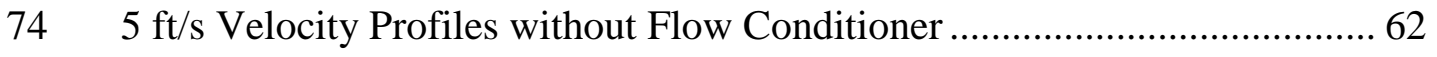

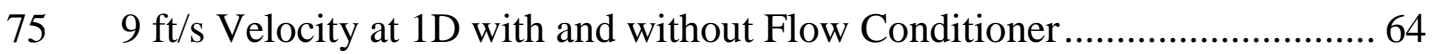

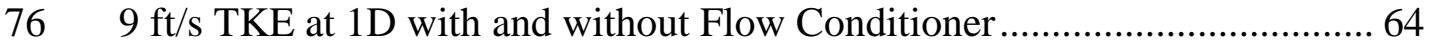

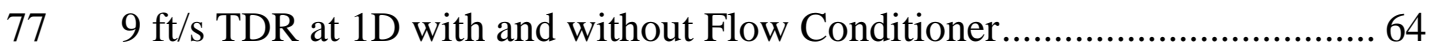

$789 \mathrm{ft} / \mathrm{s}$ Velocity at 3D with and without Flow Conditioner ............................. 65

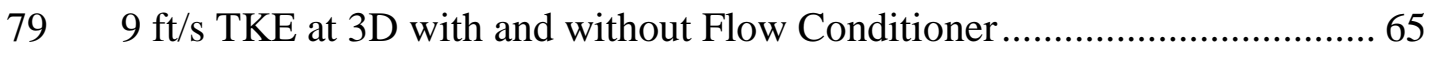

$809 \mathrm{ft} / \mathrm{s}$ TDR at 3D with and without Flow Conditioner................................. 65

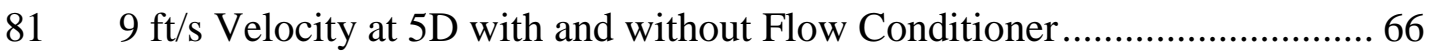

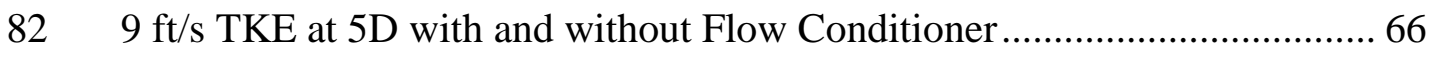

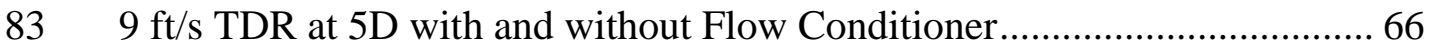

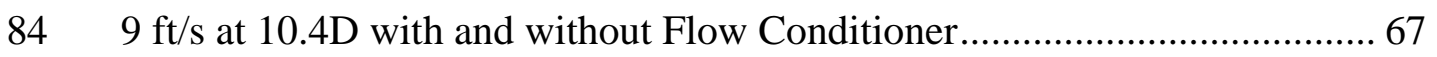

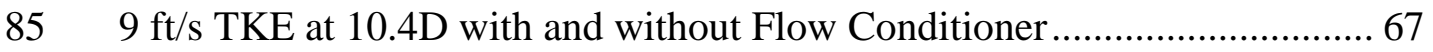

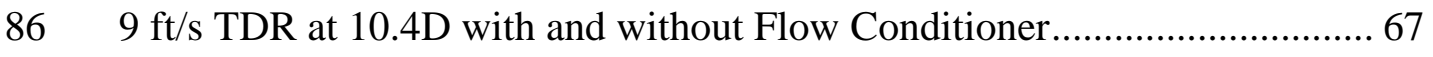


Figure

Page

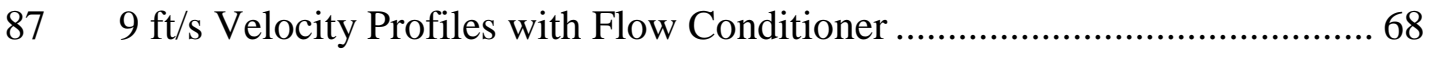

889 ft/s Velocity Profiles without Flow Conditioner ...................................... 68 


\section{LIST OF EQUATIONS}

Equation $\quad$ Page

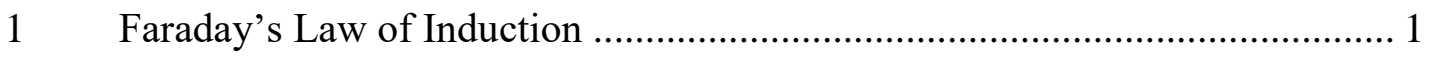

2 Reynolds Number.............................................................................. 3

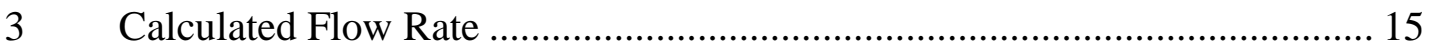

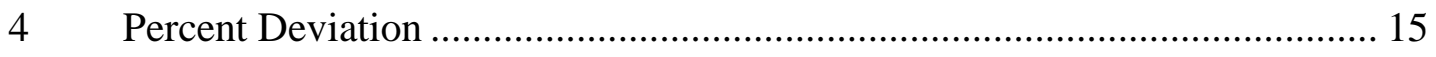




\section{CHAPTER I}

\section{INTRODUCTION}

\section{Magnetic Flow Metering Overview}

A recent study found that electromagnetic (magnetic) flow meters generate more revenue than any other type of flow meter worldwide ( $\$ 1.4$ billion/year) (Flow Research 2017). This same study noted that the water and wastewater industry is responsible for $25 \%$ of all magnetic flow meter sales and has the highest percentage of magnetic flow meter sales of all the process industries.

According to the American Water Works Association (AWWA), "No tool available to water utilities has played a greater part in the conservation of water than the water meter" (AWWA 2002). With magnetic flow meters composing such a high number of metering devices in the water industry, improved understanding of factors that influence magnetic meter accuracy directly affects water conservation (Flow Research 2017).

"Magnetic flow meters are a type of fluid flow meter that employ Faraday's law of induction to measure volumetric flow rates. Faraday's law of induction states that as a conductor of width $D$ with velocity $V$ passes through a magnetic field $B$, a flux $e$ is created (Equation 1).

$$
e=D V B
$$

\section{Equation 1. Faraday's Law of Induction}

For magnetic flow meters, two magnets in the meter spool generate a magnetic 
field. The fluid passing through the meter spool is the conductor, and the conductor width is the inner diameter of the meter spool. Consequently, the velocity of the fluid is directly proportional to the magnetic flux produced. Magnetic flow meters measure this flux as a voltage using two or more electrodes. Figure 1 is a schematic of a magnetic flow meter" (Beck et al. 2018).

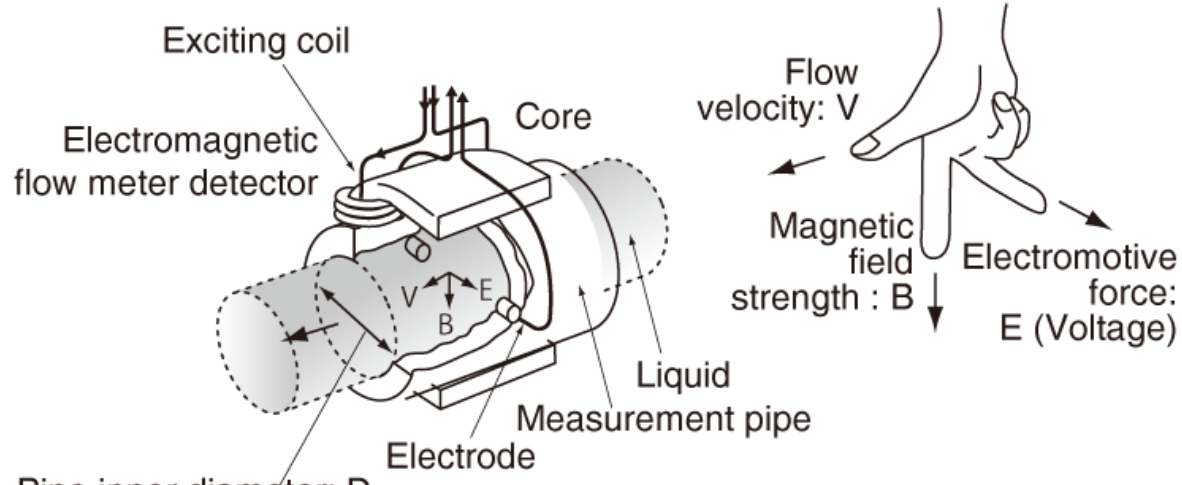

Pipe inner diameter: D

Source: Keyence.com

\section{Figure 1. Magnetic Flow Meter Schematic}

There are over 50 magnetic flow meter manufacturers worldwide (Jesse Yoder, Founder of Flow Research, personal communication, March 7, 2018). Manufacturer specified accuracy often ranges from $\pm 0.2 \%$ to $\pm 1.0 \%$, depending on the application of the meter. Magnetic flow meters have several distinct advantages over differential head flow meters. They are often quite affordable, provide a user-friendly output, and are nonintrusive, which minimizes system head losses.

\section{Research Purpose}

Significant research over many years has been performed on the accuracy of magnetic flow meters. Most of that research has been conducted to analyze and evaluate 
the effect of distorted velocity profiles caused by upstream piping disturbances (e.g., valves, elbows, etc.) on magnetic flow meter accuracy. The literature is unclear if there are other hydraulic phenomena, such as turbulence, that also contribute to magnetic flow metering inaccuracies.

The Reynolds number, named after Osborne Reynolds, is an index used to determine whether flow is laminar or turbulent. The Reynolds number $\left(R_{e}\right)$ is calculated by multiplying the velocity $V$ by the diameter $D$ and dividing by the kinematic viscosity $v$ (Equation 2).

$$
R e=\frac{V D}{v}
$$

Equation 2. Reynolds Number

Laminar flow is defined as flow with streamlines that are parallel, whereas turbulent flow is characterized by streamlines that are no longer parallel and instead demonstrate a random and irregular behavior (Flammer, Jeppson, and Keedy 1982). The irregularities of turbulent flow are often in the form of localized accelerations, also known as eddies. These local accelerations create variations in the velocity and pressure with respect to time.

According to Faraday's law, only variations in the longitudinal velocity - the velocity perpendicular to the magnetic field — influence the magnitude of the voltage produced. Therefore, in theory, Faraday's law would indicate that magnetic flow meter accuracy is not influenced by turbulence. However, the limitations of Faraday's law when employed in magnetic flow meter design are unclear due to variation in sampling rate, magnetic field strength, electrode material, and manufacturer algorithms. Given these 
uncertainties, the purpose of this research was to assess effects of local turbulence and velocity profiles on magnetic flow meter accuracy.

The research in this study was limited to common operating conditions of magnetic flow meters. Consequently, no tests were conducted in laminar flow. For the basis of this research, the turbulence as indicated by the Reynolds number is used as a baseline reference for turbulence. Additional eddies or local accelerations were created by a flow conditioner to provide perspective on how magnetic flow meters respond to the additional local turbulence induced by piping configurations other than those in straight pipe conditions. 


\section{CHAPTER II}

\section{LITERATURE REVIEW}

The purpose of this chapter is to present a brief review of research in the academic literature on the accuracy and sensitivity of magnetic flow meters to velocity profiles and discuss the limitations of the published research. This chapter concludes by outlining why the research conducted in this study is relevant for the magnetic flow metering industry.

\section{Meter Sensitivity to Velocity Profile}

In 1954, John Shercliff published an article where he noted that magnetic flow meter accuracy is sensitive to velocity profiles (Shercliff 1954). Shercliff also clarified that "It has often been stated that the circular [magnetic] flow meter is insensitive to the form of the velocity profile, and hence to the presence of upstream disturbances. This is now seen to be erroneous except in the case of axially symmetric flow" (Shercliff 1954). Consequently, Shercliff (1962) was the first to suggest using a weighted calculation of the velocity to compensate for the effect of distorted velocity profiles. Figure 2 is a presentation of the weighted velocity profile for flow in a pipe using Shercliff's weight function (Baker 1982). The points labeled "B" and "C" at the top and bottom of the figure, respectively, represent the location of the electrodes.

Bevir (1970) expanded Shercliff's function from 2-D to 3-D. Shercliff (1962), Bevir (1970), and Baker (1982) provided a comprehensive theoretical explanation of the weight function, which is beyond the scope of this literature review. However, the significance of their research is understanding that magnetic flow meters do not weight 


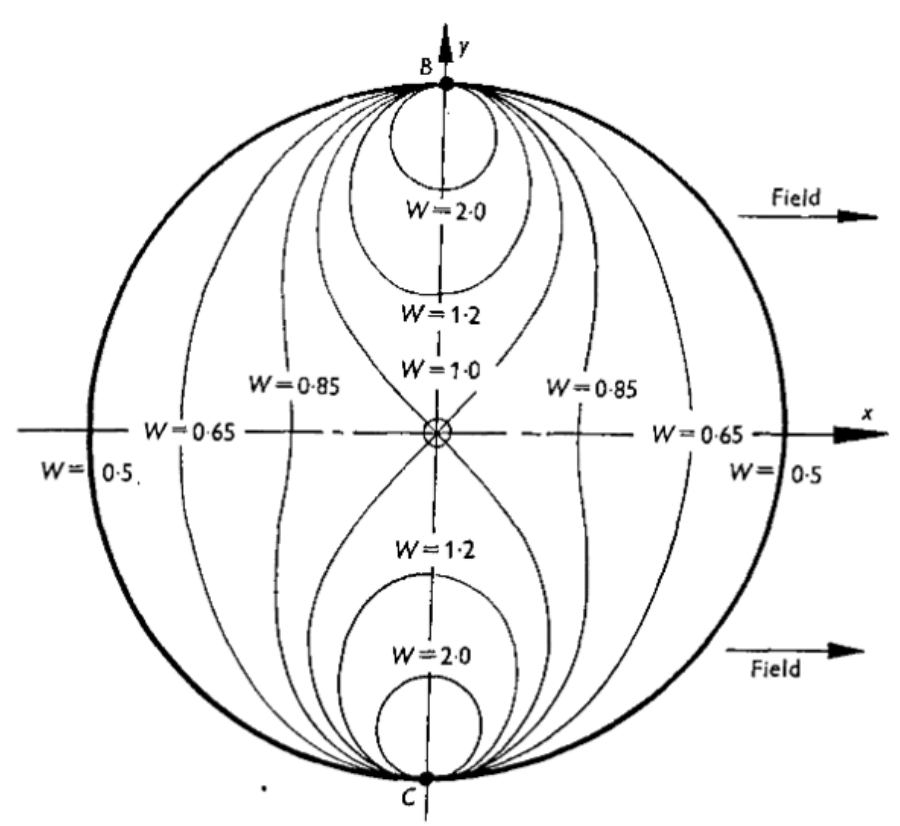

\section{Figure 2. Shercliff's Weight Function}

the entire cross section of measurement uniformly or equally. Rather, the electrodes measure the voltage produced and, using manufacturer-dependent algorithms, the meter head employs the weight function to calculate a flow rate.

Many researchers have sought to quantitatively determine through laboratory experiments the sensitivity of magnetic flow meters to velocity profile distortions caused by upstream piping. In a review of magnetic flow meters, Hemp and Sanderson (1981) asserted that the sensitivity of magnetic flow meters is not possible to predict and that random variations can be as large as $10 \%$. They concluded the difficulties in predicting sensitivities were due to design variations in geometry, electrical properties of the [meter spool], electrical properties of the magnet core, and current supply to the magnet. Hemp and Sanderson also postulated that future magnetic flow meter designs would have a means of self-checking accuracy, thereby removing the need for individual calibrations. 
To assist the reader in understanding this section, it is important to note that distances between the flange of the meter and the flange of the disturbance are often referred to in terms of diameters. This value is obtained by dividing the distance by the diameter of the meter. For example, 30 inches for a ten-inch diameter is referred to as $3 \mathrm{D}$ (Figure 3).

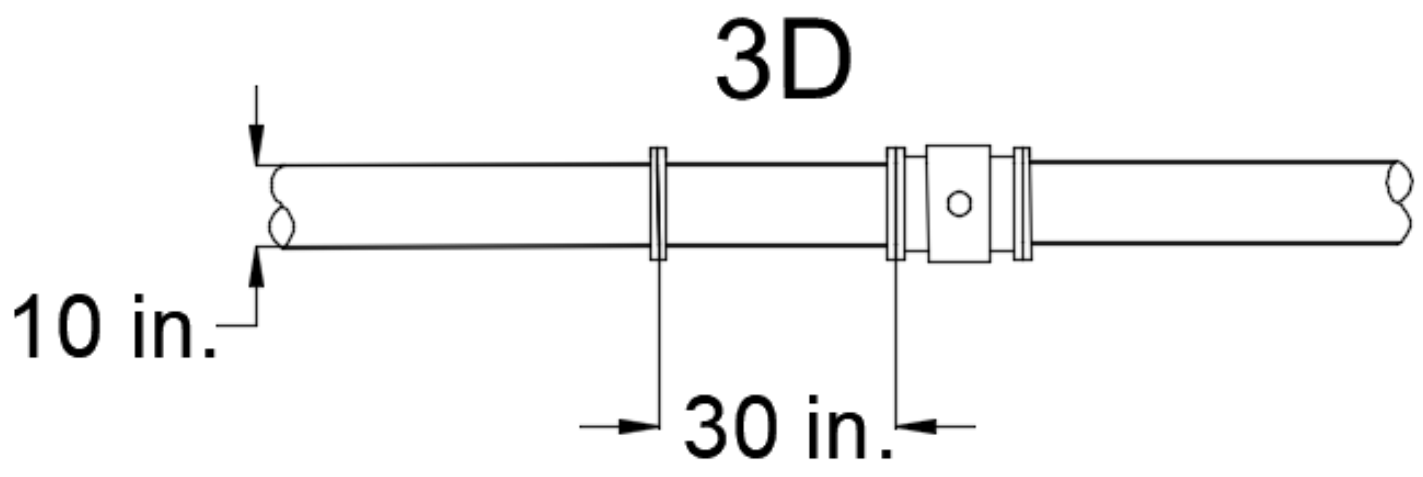

\section{Figure 3. Magnetic Meter Installation Schematic}

Using a total of eight magnetic flow meters (two meters for each of four unique designs), Deacon (1983) explored the results of several upstream disturbances on the accuracy of the eight meters. The upstream disturbances were a gate valve at $50 \%$ and $25 \%$ closed, a single long-radius elbow and two long-radius elbows in perpendicular planes, and a straight-sided reducer. The test fluid was water. Deacon concluded that the single elbow caused the greatest error among the disturbances with the worst error magnitudes equal to $-1.92 \%$ and $-2.79 \%$ at a downstream distance of $5 \mathrm{D}$ and $2.5 \mathrm{D}$, respectively.

Luntta and Halttunen (1989), created a model for a magnetic flow meter and computed the expected error. Four distinct types of magnetic flow meters were tested 
with an orifice plate used as the upstream disturbance. They found that each of the four meters responded differently to the same distorted velocity profile. Luntta and Halttunen concluded that if the disturbance is at least $5 \mathrm{D}$ upstream of the meter, the error would be less than $0.5 \%$.

Later, Halttunen and Luntta (1993) investigated the effects of a single and double $1.5 \mathrm{D}$ radius elbow out of plane using numerical and laboratory methods on magnetic and ultrasonic flow meters. Based on the deviation of accuracy determined from modeling magnetic flow meters, Halttunen and Luntta claimed that a generic type of magnetic flow meter didn't exist. Summarizing their findings, they stated "the general behavior of [magnetic flow meters] can be estimated, but if the accuracy of the meter is important, the estimation must be based on individual knowledge of the meter." Halttunen and Luntta also concluded that combining numerical modeling and experimental data was a valuable tool for optimizing meter performance.

Bates (1999) studied the effect of misalignment of three different sized pipes coupled to a modified magnetic flow meter. The results indicated that the smallest pipe diameter created the largest error for the magnetic flow meter. Bates used Laser Doppler Anemometry (LDA) to measure the velocity and root-mean-square (RMS) velocity profiles. The RMS velocity profile is a physical representation of turbulent kinetic energy (TKE) in the fluid. Bates noted that the highest RMS values corresponded to turbulence intensity values that are significantly higher than typical values associated with fully developed flow. No direct conclusions were stated relating RMS values to observed errors.

Perry (2014) conducted a study evaluating the results of rotating a magnetic flow 
meter to reduce the effect of the distorted velocity profile on the weight function. He stated that "typical magnetic flow meters do not have uniform weight functions and are sensitive to the locations of flow distortions" (Perry 2014). Perry concluded that rotating the magnetic flow meter to minimize the effect of the velocity profile on the weight function was one viable way to produce more accurate measurements.

Most magnetic flow meter manufacturers specify a required length of straight pipe that should be installed upstream of the meter in order for the meter to perform at its specified accuracy. In other words, it is generally assumed that if the magnetic flow meter is installed with enough piping between the upstream disturbance and the flow meter, the flow meter will perform as specified by the manufacturer.

However, Beck et al. (2018) showed that for 17 unique magnetic flow meters tested 3D downstream of a short-radius elbow, most meters did not meet their own manufacturer's specified accuracy claims. The results from their study showed that general statements about upstream and downstream piping recommendations may not always produce the expected accuracy. Like Haltunnen and Luntta, they claimed an "individual knowledge of the meter" was necessary. This means that to produce the expected accuracy, the meter should be laboratory calibrated in a field piping configuration.

\section{Meter Sensitivity to Turbulence}

At the completion of a thorough search, the author is unaware of any literature regarding the sensitivity of magnetic flow meters to turbulence. Consequently, the following section presents the research conducted regarding the sensitivity of orifice plate 
accuracy to turbulence. The oil and gas industry's custody transfer standards stimulated much of the research for orifice plate and flow conditioning devices. A flow conditioner is a device designed to rectify a flow profile, thereby reducing the amount of upstream piping required for more accurate measurements. Yet, even though the velocity profile is conditioned and improved, immediately downstream of a flow conditioner is an increased level of local turbulence.

Morrow et al. (1991) used a single $90^{\circ}$ elbow at varying distances upstream of an orifice plate with nitrogen gas to determine the effects of a flow straightener on the coefficient of discharge $\left(\mathrm{C}_{\mathrm{d}}\right)$. They found that although velocity profiles were nearly fully developed at 20D, the $C_{d}$ for an orifice plate was shifted $+0.45 \%$ for a $\beta=0.75$. Whereas, at $42.5 \mathrm{D}$, the profile was "significantly distorted but the $\mathrm{C}_{\mathrm{d}}$ shift was zero" (Morrow et al. 1991). Thus, they concluded that the flow profile (including the mean velocity and turbulent levels at a given location) was not yet fully developed.

Park et al. (1992) further investigated the sensitivity of $C_{d}$ to velocity profiles distorted by a tee with a flow straightener installed upstream of the orifice plate at two separate facilities using different measurement techniques and compared results. It was found that each of the mean velocity profiles at 11D satisfied the criteria of ISO 5167, yet the $C_{d}$ was shifted by $-0.15 \%$. They noted that the turbulence intensity profile was significantly lower than a reference turbulence intensity profile for fully developed flow provided by Laufer from a 1954 study. Therefore, Park et al. (1992) concluded that "the results in this research or previous results have not yet indicated what the effects of turbulence are on $\mathrm{C}_{\mathrm{d} .}$,

Lake and Reid (1992) tested several different flow conditioning devices to 
determine their optimum installation location upstream of an orifice meter. They noted that the relationship between the velocity profiles and the coefficient of discharge was not yet fully understood. They saw flatter velocity profiles than expected, yet the $\mathrm{C}_{\mathrm{d}}$ 's were close to the typical range.

Using air as the fluid, Karnik et al. (1994) explored the effect of good flow conditions (straight pipe) and a $90^{\circ}$ elbow with a flow straightener upstream of an orifice plate. They presented mean and turbulent velocity profiles at the location of measurement and pressure measurements upstream and downstream of the orifice plate. They asserted that overdeveloped or peaked profiles have higher local velocities, thereby reducing local pressures. Likewise, "in the case of the turbulent stresses, application of the momentum equation indicates that lower turbulent stresses result in high local pressures" and vice versa (Karnik et al. 1994). Therefore, they concluded that the pressure differences between fully developed flow profiles and underdeveloped — or overdeveloped—flow profiles cause the shift in $C_{d}$.

Although the above examples of the effect of turbulence and velocity profiles on orifice meter accuracy are not directly applicable to magnetic flow meters, the examples suggest other metering technology may also be influenced by local turbulence. Spearman et al. (1998) noted that the effect of velocity profiles on meter accuracy is better understood than the effects of local turbulence on meter accuracy. Similarly, it is not clear what effect local turbulence has on magnetic flow meters. The current study was undertaken to assess how increased local turbulence and velocity profiles influence magnetic flow meter accuracy. 


\section{CHAPTER III}

\section{PHYSICAL TEST SETUP AND PROCEDURE}

All tests for this study were conducted at the Utah Water Research Laboratory in Logan, Utah. The laboratory equipment used is traceable to the National Institute of Standards and Technology. The following sections provide details regarding the experimental setup and test procedure.

\section{Physical Test Setup}

A pump was used to supply water to a 12-inch supply line that reduced to a 10inch standard schedule carbon steel test line. The water that discharged from the test line was weighed using one of two gravimetric weight tanks. Each test meter was initially calibrated with 35D of 12-inch straight pipe that reduced to 23-25D of 10-inch (depending on the meter) straight pipe upstream of the meter and 8-10D (depending on the meter) of 10-inch straight pipe downstream of the meter.

Five meters from five different manufacturers were tested in this study. Table 1 displays the meter number, low flow cutoff, manufacturer accuracy specifications for each meter, and the manufacturer's recommended upstream pipe diameters between the disturbance and the meter.

Table 1. Meter Specifications

\begin{tabular}{|c|c|c|c|}
\hline $\begin{array}{c}\text { Meter } \\
\text { Number }\end{array}$ & $\begin{array}{c}\text { Low Flow Cutoff } \\
(\mathbf{f t} / \mathbf{s})\end{array}$ & $\begin{array}{c}\text { Accuracy } \\
\text { Specifications }\end{array}$ & $\begin{array}{c}\text { Manufacturer's Recommended } \\
\text { Upstream Pipe Diameters }\end{array}$ \\
\hline 1 & 0.16 & $\pm 1.00 \%$ & 2 \\
\hline 2 & 1.00 & $\pm 0.50 \%$ & 3 \\
\hline 3 & 0.80 & $\pm 0.40 \%$ & 5 \\
\hline 4 & 0.04 & $\pm 0.25 \%$ & 5 \\
\hline 5 & Varies & $\pm 0.20 \%$ & $\mathrm{NA}$ \\
\hline
\end{tabular}


The manufacturer's recommended upstream pipe diameters for meter number 5 was specific to the type of disturbance (e.g., elbow, valve, etc.). A recommendation for a flow conditioner was not found in the manufacturer's documentation.

The remaining four meter manufacturer's recommendations were independent of the upstream disturbance. Although the recommendations provided by the manufacturers are presented, the focus of the study is to explore the performance of the meters independent of the installation recommendation.

Following the initial straight pipe calibration, each meter was installed at distances of 1D, 3D, 5D, and 10.4D downstream of a CPA 65E liquid flow conditioner (Figure 4). Meter 5 was also tested at 18.4D downstream of the flow conditioner.

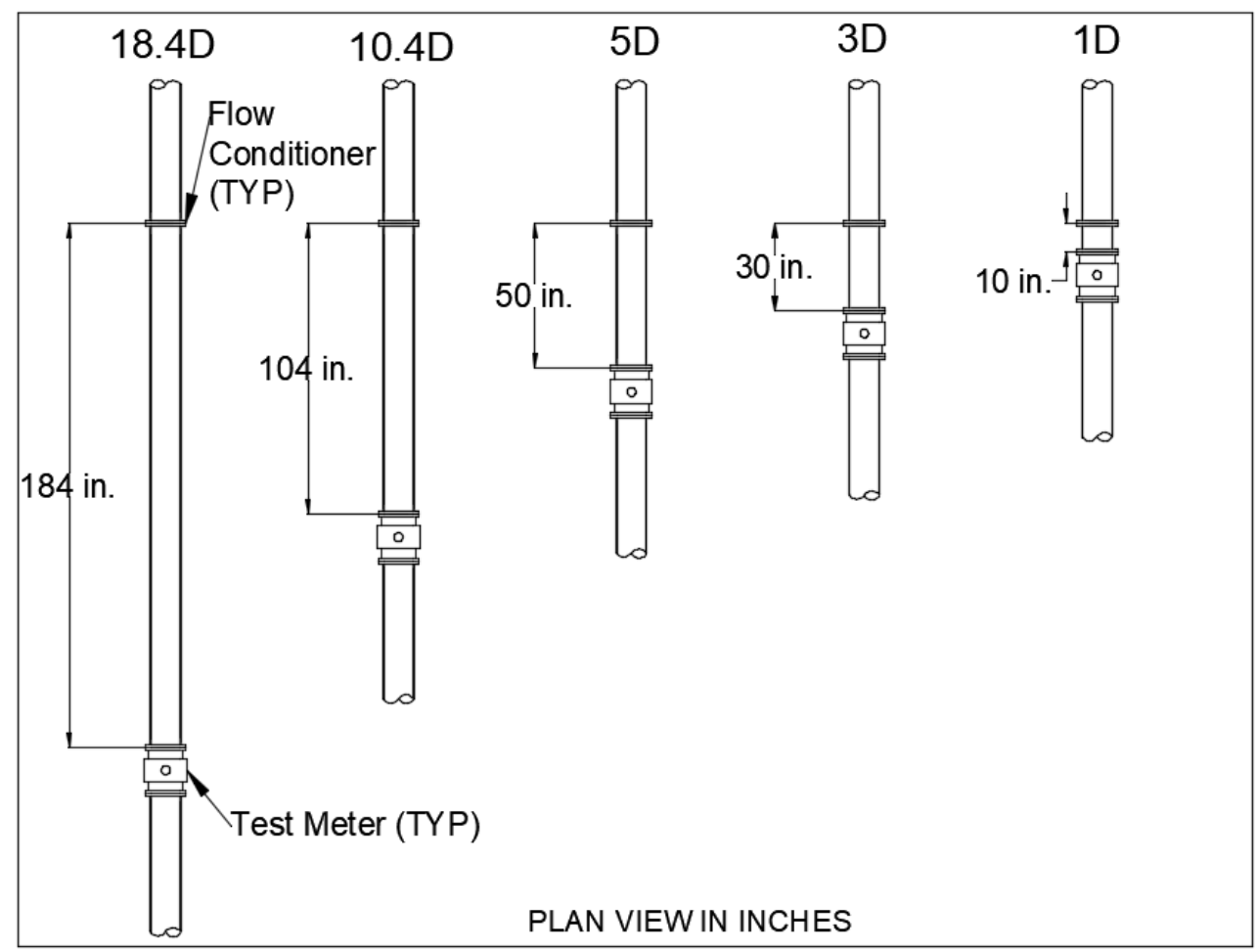

Figure 4. Test Setup Schematic 
The distance referenced represents the distance from the downstream flange of the conditioner to the upstream flange of the meter. The flow conditioner used in this study was donated by Canada Pipeline Accessories and was selected because of the local turbulence it creates and the nearly developed velocity profile that the design configuration produces as is demonstrated in the study (Figure 5). It is likely that other flow conditioners do not produce a profile as near fully developed in short distances as the CPA 65E.

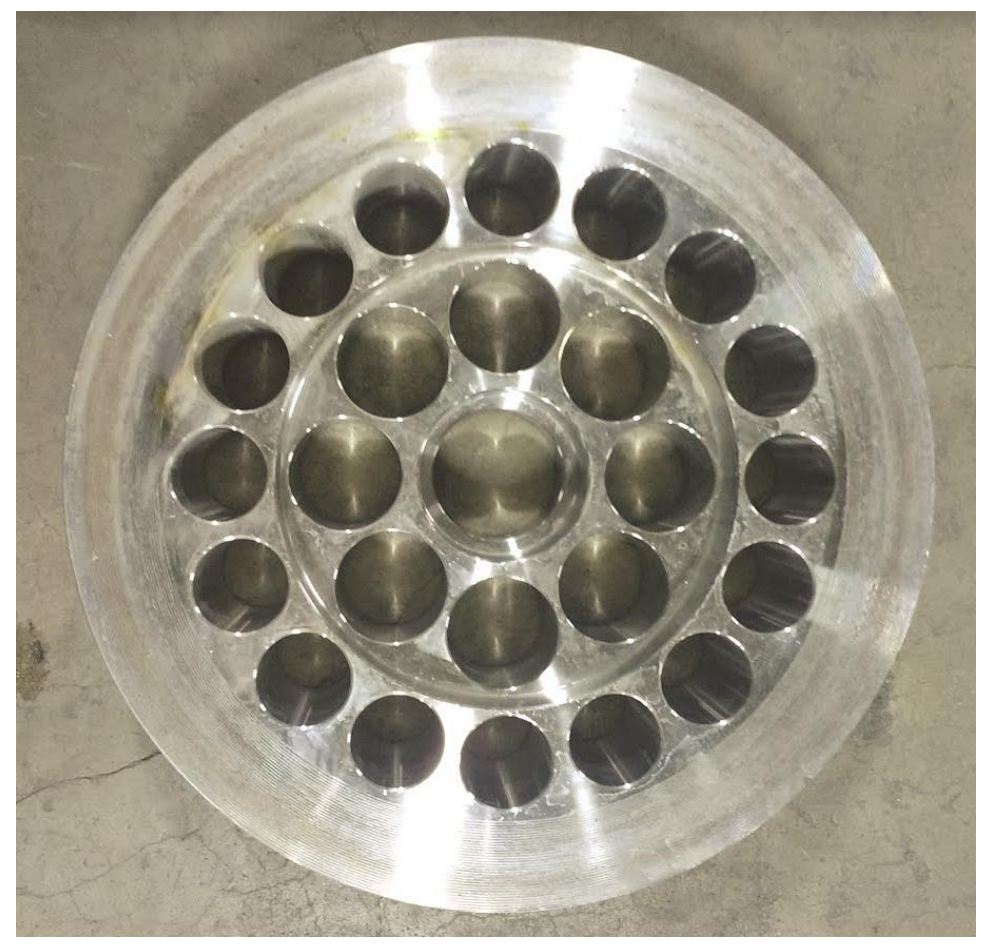

Figure 5. CPA 65E Flow Conditioner

\section{Physical Test Procedure}

Each meter was tested at six different flow rates. The corresponding pipe velocities for the tests were: $1,3,5,9,14$, and 18 feet per second (fps). The flow for each 
test was set with a downstream valve using a reference meter with a Fluke multimeter reading in $\mathrm{Hz}$. The actual flow rate for each test was calculated using weight tanks and a corresponding time. For the lowest flow rate, the 25,000-lb weight tank and a stop watch were used. For the remaining 5 flow rates, the 250,000-lb capacity weight tank with an automated timer were used. The duration of each test was at least 200 seconds to minimize random fluctuations in flow that may have occurred during the test.

The measured water temperature was used to determine the corresponding unit weight. This unit weight was then used to calculate the actual flow rate (Equation 3). $W_{\mathrm{H} 2 \mathrm{O}}$ is the weight of water collected in the weight tank (pounds) at the measured temperature during the test, $t$ is the duration of the test (seconds), and $Y_{H 20}$ is the unit weight of water (pounds per cubic foot).

$$
Q=W_{H 2 O} / t \gamma_{H 2 O}
$$

Equation 3. Calculated Flow Rate

The meter error was computed by subtracting the flow rate calculated using Equation 3 $\left(Q_{\text {actual }}\right)$ from the flow rate indicated by the meter $\left(Q_{\text {meter }}\right)$ (Equation 4$)$.

$$
\% \text { Error }=\frac{Q_{\text {meter }}-Q_{\text {actual }}}{Q_{\text {actual }}} \times 100
$$

Equation 4. Percent Deviation 


\section{CHAPTER IV}

\section{NUMERICAL MODELING}

Numerical modeling using computational fluid dynamics (CFD) provided additional insight and analysis for this study. All simulations presented herein were conducted using Star CCM+ version 12.04.011. A brief discussion of the parameters evaluated using CFD is included. This section also explains the numerical methods, boundary conditions, mesh generation, and uncertainties for the CFD analyses.

\section{CFD Parameters}

CFD was used to capture the turbulent kinetic energy (TKE) and turbulent dissipation rate (TDR) in the flow at select locations downstream of the flow conditioner. TKE is the mean kinetic energy per unit mass of fluid associated with the turbulent eddies. TDR is defined as the rate at which this kinetic energy is converted into thermal energy.

The flow conditioner used in this study created significant additional local turbulence due to the localized accelerations or eddies created by the multi-jet profile of the plate configuration. For this reason, the CFD analyses were employed to capture the relative differences of TKE and TDR with and without the flow conditioner at select locations in the pipeline, thereby providing insight regarding the effect of local turbulence on magnetic flow meter accuracy.

\section{Numerical Modeling}

The Reynolds-averaged Naiver Stokes (RANS) equations, k-epsilon (k- $\varepsilon$ ) turbulence model, and all wall y+ methods were used for the simulations. Finnemore and 
Franzini (1998) asserted that in the study of turbulent flow "conditions are so complex that rigid mathematical treatment is impossible."

Consequently, it is important to remember that CFD modeling is only an estimation and can be misinterpreted. For this reason, this study only compared the CFD results to other CFD results to make inferences about the general behavior of magnetic flow meters. This study was never intended to determine the magnitudes of specific parameters. Rather, the purpose of the modeling was to explore correlations between the TDR, TKE, velocity profiles, and magnetic flow meter performance.

It is a customary practice for CFD practitioners to determine a fully developed flow profile in a pipe using a periodic interface. This is done by assigning the solution of the outlet as the inputs for the inlet, thereby mathematically creating an infinite pipe. This process was employed to create fully developed profiles with pipe flow velocities of: 1,3 , $5,9,14$, and $18 \mathrm{fps}$. These fully developed profiles were used as the input for the respective simulations with and without a flow conditioner.

During this process, it was noted that the actual length of the pipe used in the simulation affected the results. Figure 6 is a plot of the TKE at the center line of the pipe from pipes of different lengths. This is a striking finding because the pipes are all mathematically infinite due to the periodic interface. Consequently, each of the simulations used a fully developed profile that was created with an actual pipe length of 48 inches or more.

It is also common for CFD practitioners to determine a volume mesh that captures the necessary resolution while optimizing the computational time. The American Society of Mechanical Engineers Journal of Fluids Engineering published a "Procedure 


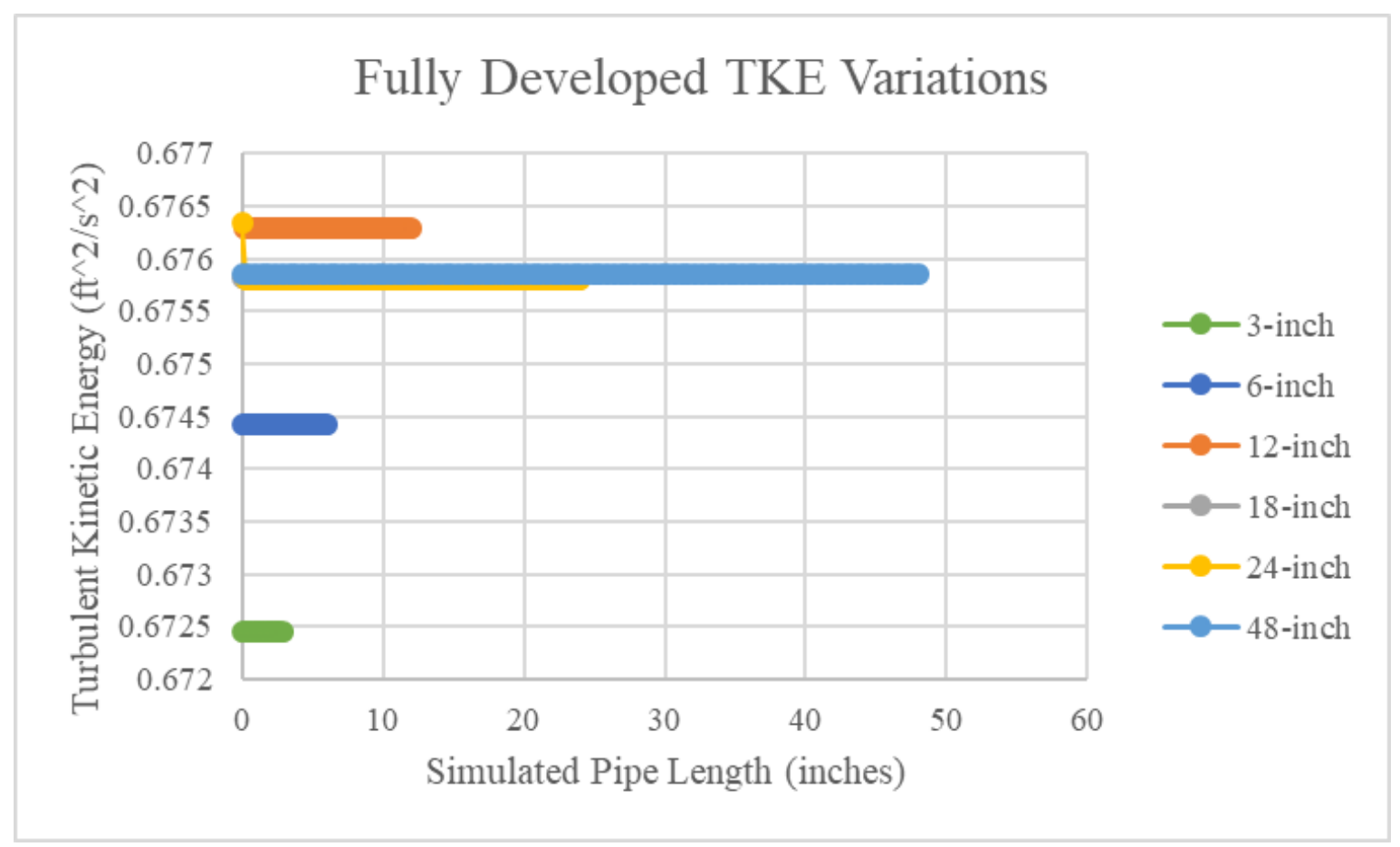

Figure 6. Fully Developed Flow TKE Variations with Simulated Pipe Length

for Estimation and Reporting of Uncertainty Due to Discretization in CFD Applications" (Celik et al. 2008).

This method was used to determine an uncertainty due to discretization for the highest and lowest flow rates. The 1-fps simulations had uncertainties due to discretization of $0.03 \%$ and $0.03 \%$ for TKE and TDR, respectively while the uncertainty for the 18 -fps model is $0.53 \%$ and $6.89 \%$ for TKE and TDR, respectively. The latter values may seem large for discretization error. However, it should be noted that the discretization error may be less than that associated with the $k-\varepsilon$ turbulence model.

\section{CFD Results Extraction}

Manufacturers' recommendations for the distance between an upstream 
disturbance and a meter are defined as the length of pipe between the downstream flange of the disturbance and the upstream flange of the meter. However, the meter electrodes are located at the centerline of the meter and not at the upstream flange of the meter. The meters tested in this study had an average length of approximately sixteen inches.

Consequently, all CFD data were extracted at the number of pipe diameters of interest plus eight inches (the distance from the upstream flange of the meter to the location of the meter electrodes) to capture the same flow profile that the electrodes of the meters would capture. Figure 7 presents how this was done using the test setup of a downstream distance of 3D as an example.

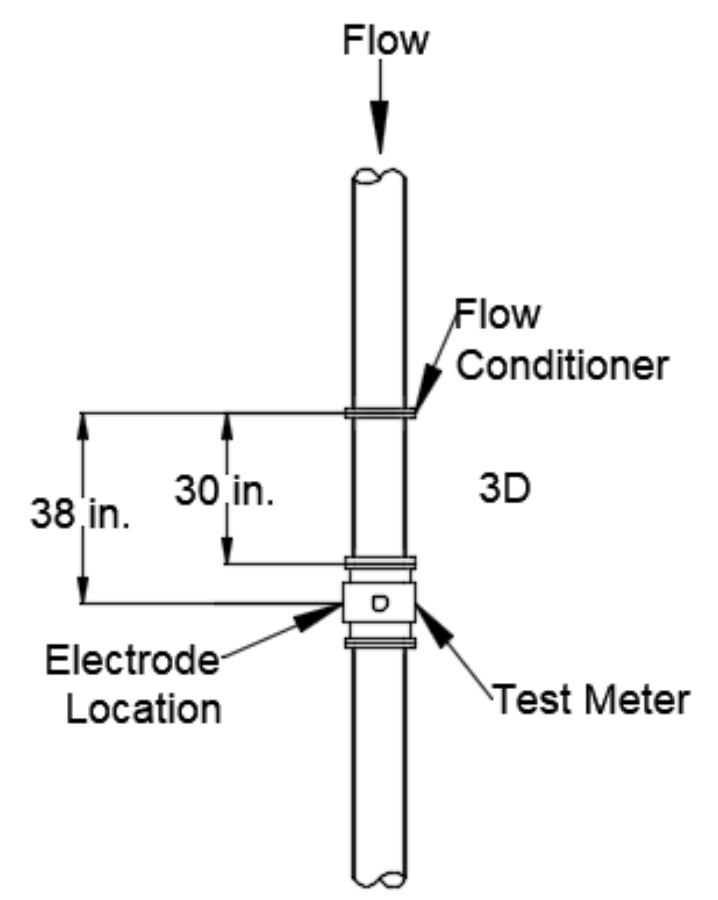

Figure 7. Electrode Location and Corresponding Distance for CFD Extraction

\section{Discussion of Fully Developed Flow}

Bates (1999) wrote, “developing turbulent pipe flow may require considerable 
distances in order to achieve fully developed structures of both the mean velocity and the associated turbulence profile." Klein (1981) stated, "some of the classical measurements of fully developed pipe flow were in fact conducted at conditions when the flow was still developing."

Several simulations were conducted using CFD to determine when the flow profile downstream of the conditioner returned to a fully developed state. A complete return of the flow profile to fully developed was not achieved even at a distance of 100D. Although the CFD showed that fully developed flow does not occur until beyond 100D, for practical purposes the remainder of the results will focus on common distances of magnetic meter installations.

With the finding summarized above, it can be asserted that in most applications there is insufficient space to allow the flow profile to completely develop prior to a magnetic flow meter installation. Even if sufficient space were available, the measuring resolution of current magnetic flow meters may not even detect the differences between, for example, the flow profile at 10D and the fully developed profile achieved at 100D+.

Consequently, more typical installations for magnetic flow meters downstream of disturbances were selected, as noted earlier in Chapter III. One test in this study that was conducted on meter 5 at 18.4D downstream of the flow conditioner demonstrated higher variations in accuracy than expected from that of straight pipe conditions. 


\section{CHAPTER V}

\section{RESULTS AND DISCUSSION}

This chapter presents the meter accuracy results obtained from laboratory testing and corresponding results from the numerical modeling. Laboratory results are displayed graphically, whereas the numerical modeling results are presented in tables and contour plots. The laboratory data has a $\pm 0.5 \%$ uncertainty with a $95 \%$ confidence interval. All of the test data was collected using the same instrumentation; therefore, the relative differences can be seen as real shifts and not as instrumentation uncertainty.

The laboratory data is presented in two separate sets of plots to emphasize different elements of the tests. The first set of plots includes all of the data, whereas the second set of plots omits the 1-fps data. The 1-fps data was omitted in the second analysis of the study because of the significantly greater metering errors at that lower velocity. Additionally, due to the substantial number of numerical simulation results, only the 18fps simulation results are included in this chapter (see Appendix for all numerical results). All of the numerical results show the same general trends, and only the magnitude of the trend varies from flow rate to flow rate.

\section{Laboratory Results}

Figures 8 through 12 present the laboratory results for meters 1 through 5, respectively. As noted earlier, the results are presented independent of the manufacturers' recommendation for upstream pipe to explore the effect of local turbulence on magnetic flow meter accuracy. The pipe velocity is plotted on the $\mathrm{x}$-axis and the percent deviation in meter accuracy is plotted on the y-axis. The blue bands represent the manufacturer's 
specified accuracy limits for each meter. For comparative purposes, the maximum and minimum limits of the percent deviation on the y-axis for each plot of meter results were $+4.00 \%$ and $-3.00 \%$, respectively.

The full set of straight pipe data for each meter were corrected by centering them on zero percent accuracy deviation, thereby mathematically removing any meter bias from the test data when it was installed in straight pipe. This mathematical correction was performed so that relative differences in the data with a flow conditioner installed upstream of the meter could be more easily compared to the meter accuracy results in straight pipe with no disturbance upstream.

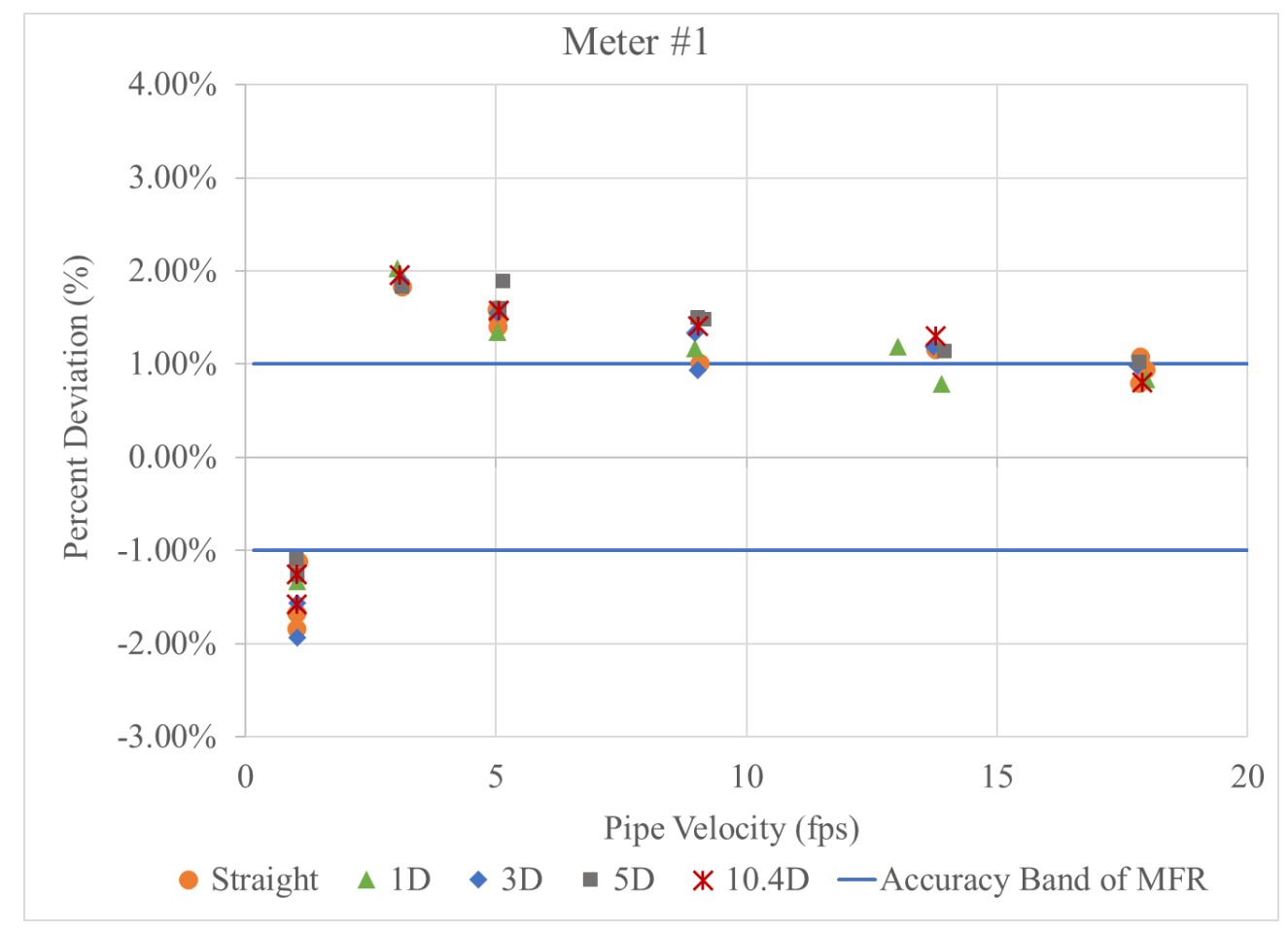

Figure 8. Meter \#1 Laboratory Test Results 1 ft/s Included 


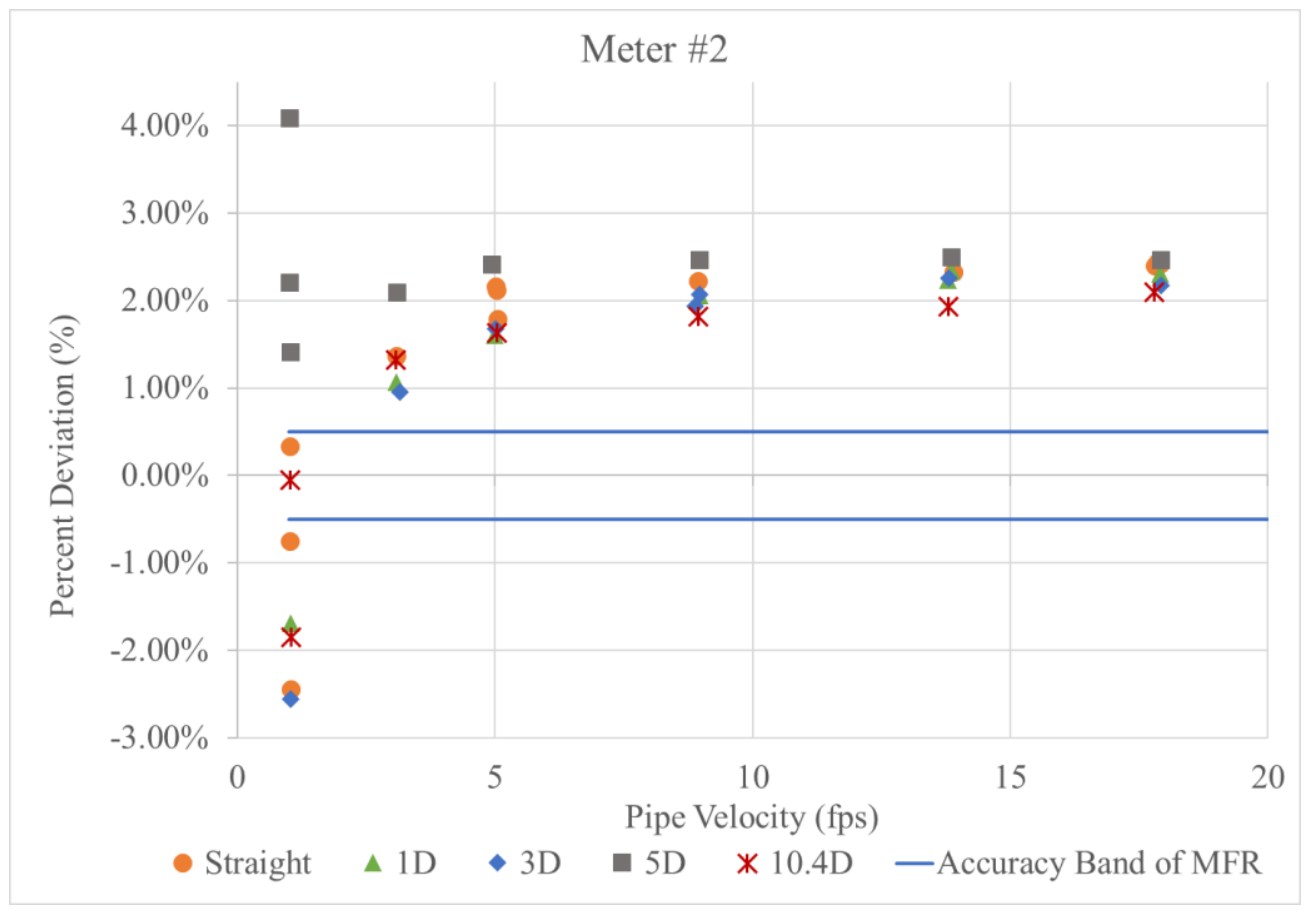

Figure 9. Meter \#2 Laboratory Test Results $1 \mathrm{ft} / \mathrm{s}$ Included

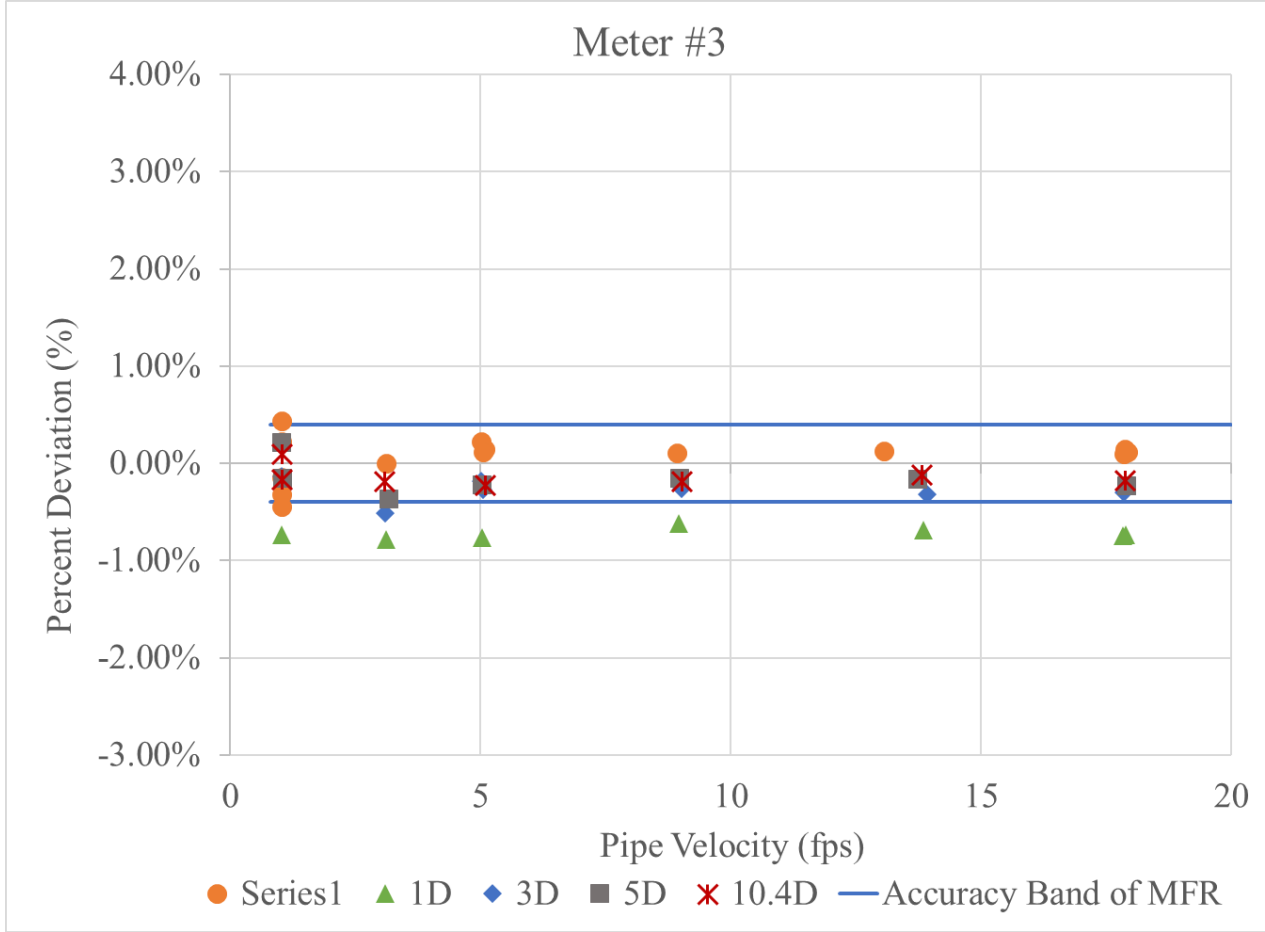

Figure 10. Meter \#3 Laboratory Test Results 1 ft/s Included 


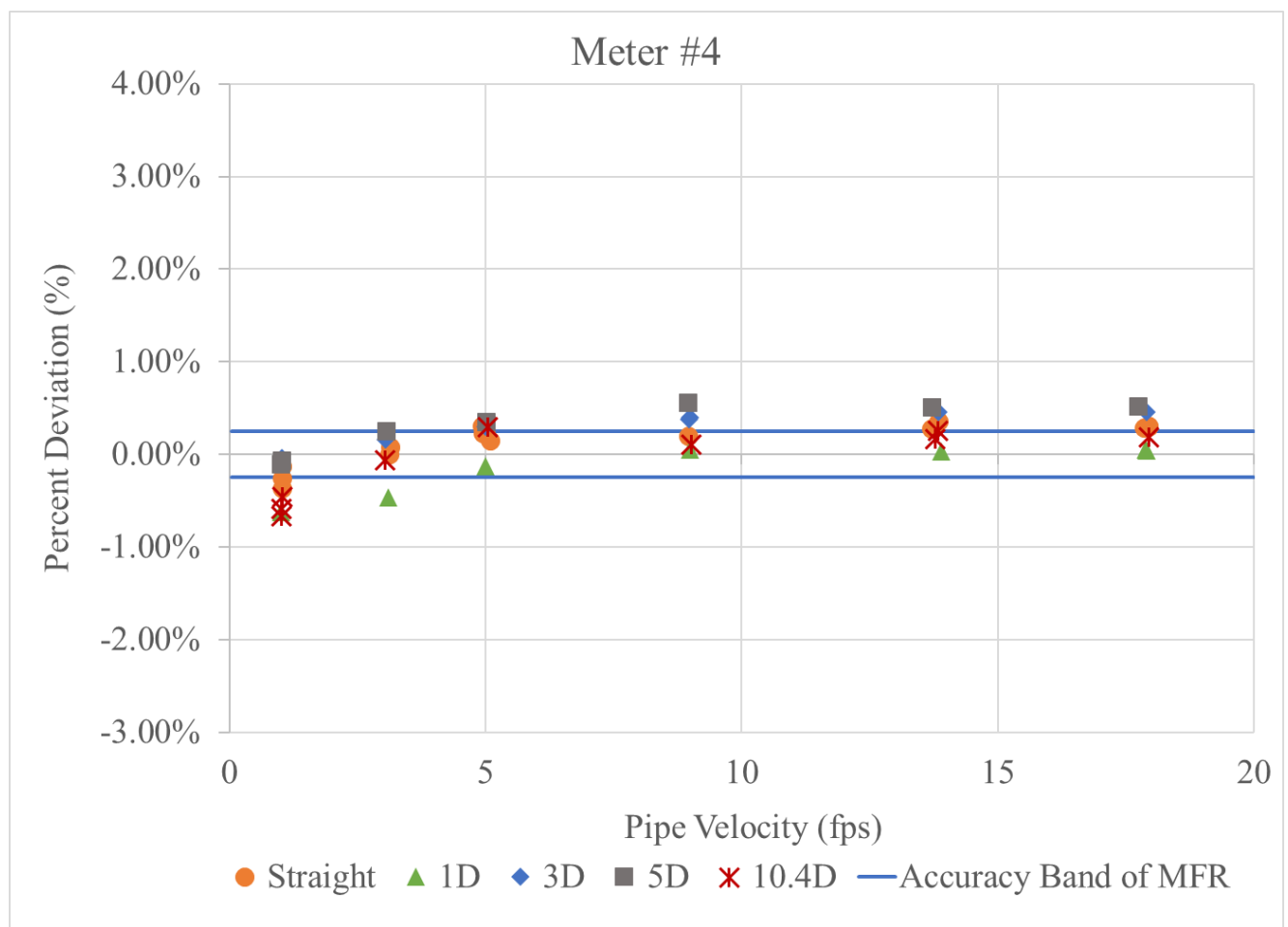

Figure 11. Meter \#4 Laboratory Test Results 1 ft/s Included

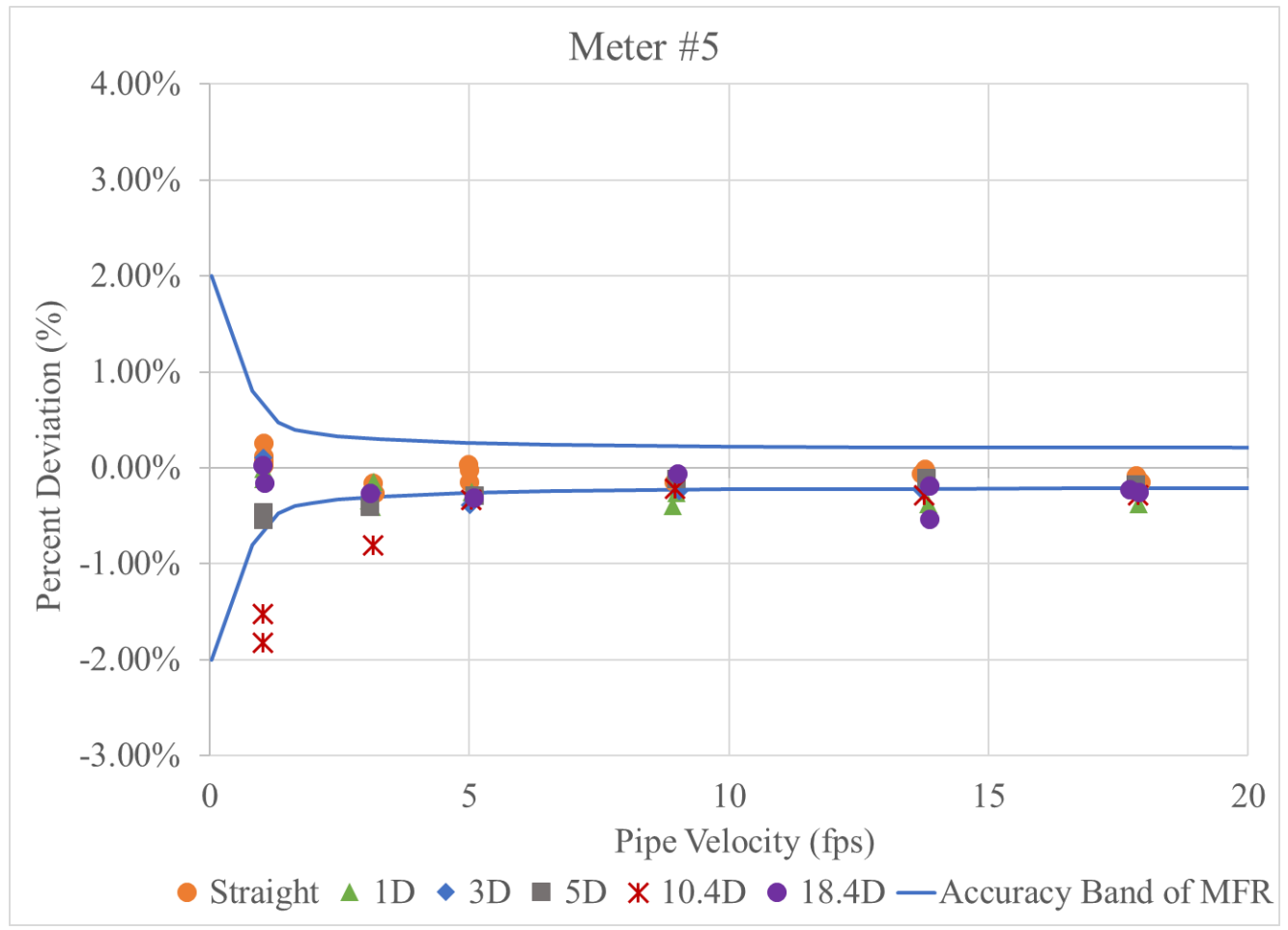

Figure 12. Meter \#5 Laboratory Test Results $1 \mathrm{ft} / \mathrm{s}$ Included 
When considering the full data set in Figures 8-12, it is interesting to note that each of the five meters was subjected to the same hydraulic disturbance, and some meters showed significantly greater errors than others at the lowest velocities and others did not. This implies that some meter manufacturers are capable of designing and programming the flow meter to accurately compute the flow rate at low velocities and others are not.

The Reynolds number increased from 50,000 to nearly 900,000 from the 1-fps to the 18-fps test, respectively. Interestingly, the straight pipe data for each of the flow meters tested indicates that meter performance did not decrease as the turbulence increased. Rather, it appears that for most meters, the accuracy of the meter remains constant or increases as the Reynolds number - or turbulence-increases. Furthermore, the lower Reynolds number - indicating lower turbulence - at the 1-fps test is not proportional to an increase in meter performance. Interestingly, for meters 1,2,3, and 5, meter performance decreases at the lower turbulence levels.

Figures 13 through 17 present the laboratory results with the 1-fps data removed for meters 1 through 5, respectively, and again, the pipe velocity is plotted on the $x$-axis and the percent deviation in meter accuracy is plotted on the y-axis. The blue bands represent the manufacturer's specified accuracy limits for each meter. To look closer at the higher flow rates, the maximum and minimum limits of the percent deviation on the $\mathrm{y}$-axis for each plot of meter results were $+2.50 \%$ and $-2.50 \%$, respectively. The full set of straight pipe data above $1 \mathrm{fps}$ for each meter were corrected by centering them on zero percent accuracy deviation, thereby mathematically removing any bias from the meter when it was installed in straight pipe. This mathematical correction was performed without the 1-fps data so that the decreased performance of the meters at 1-fps did not 
adversely affect the meter performance at the higher test velocities.

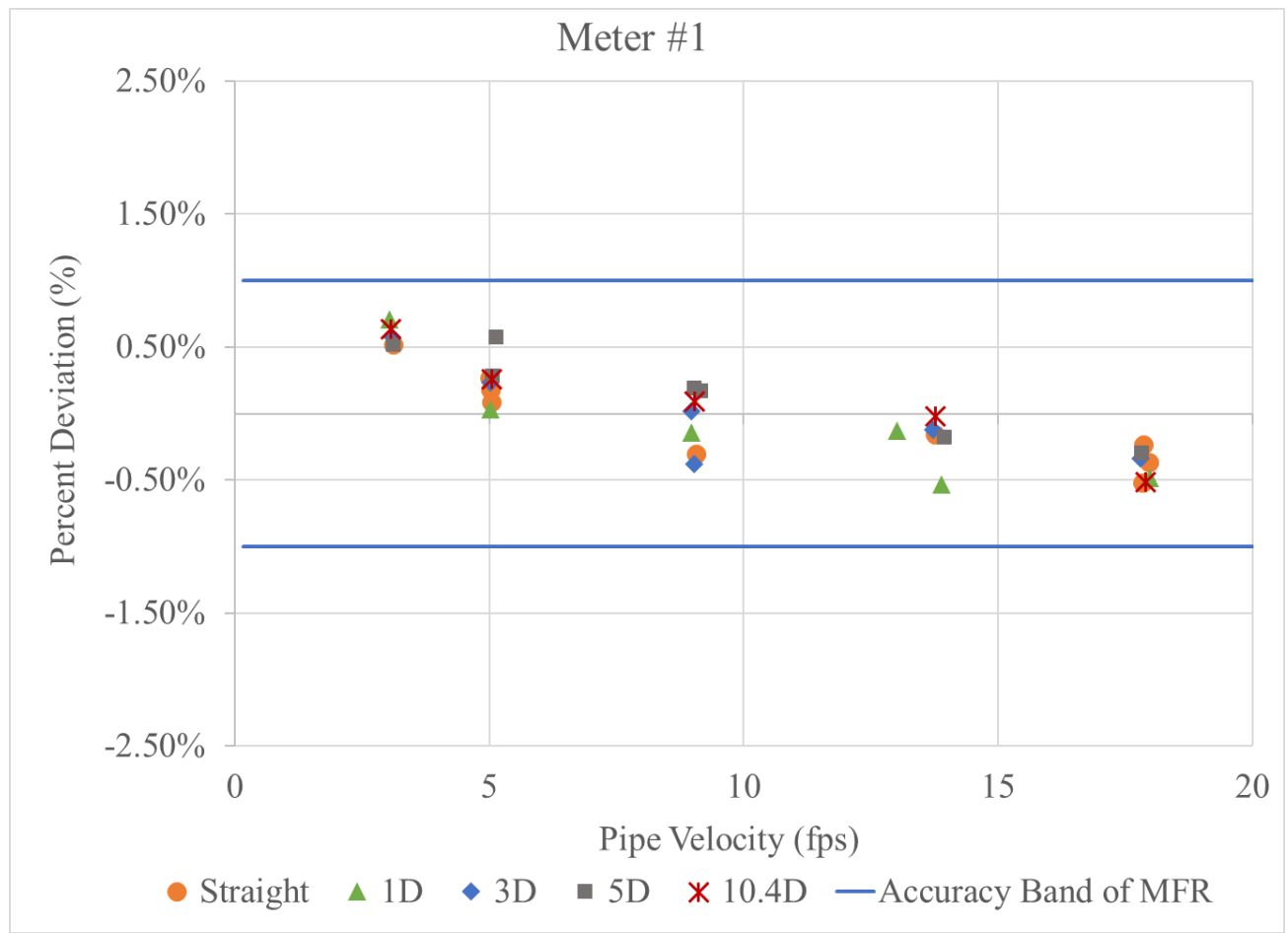

Figure 13. Meter \#1 Laboratory Test Results

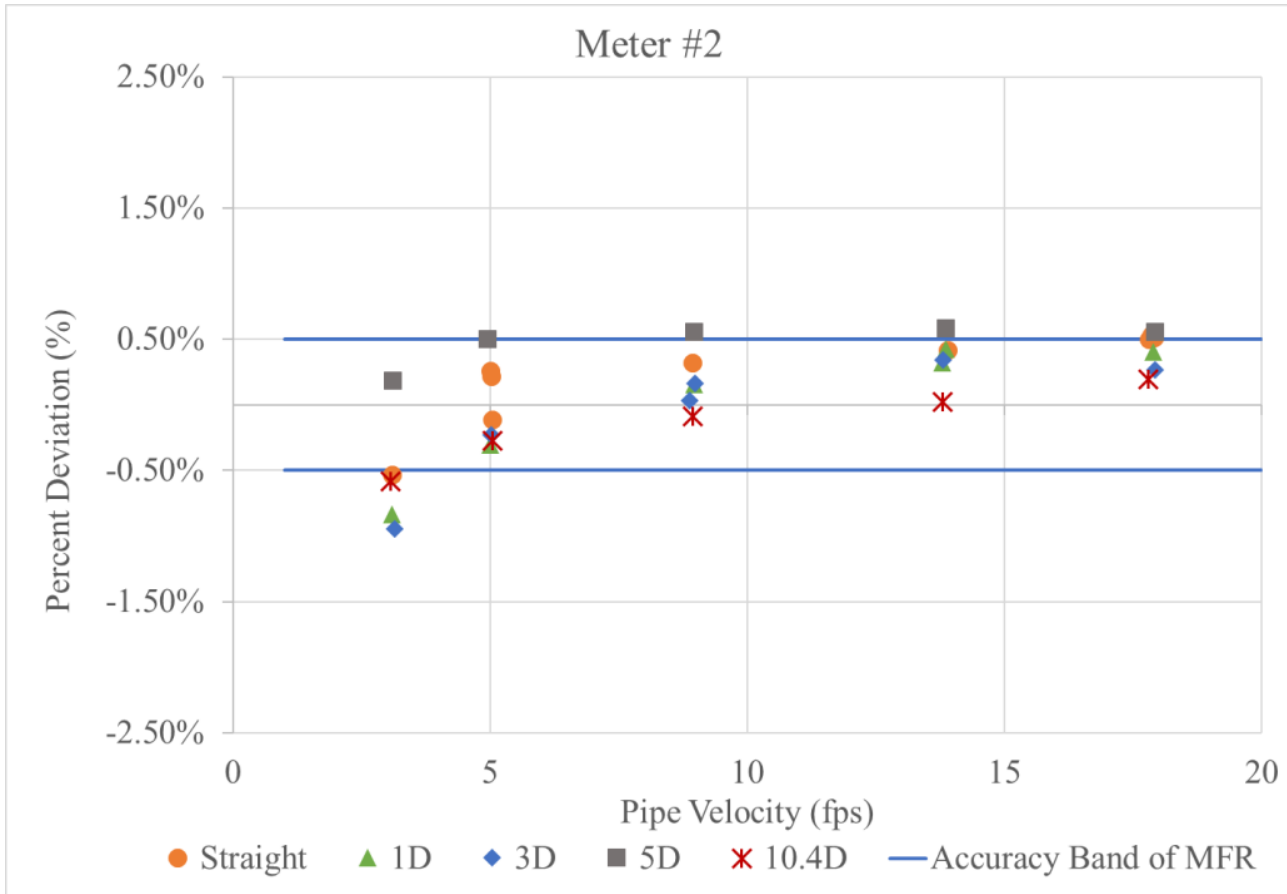

Figure 14. Meter \#2 Laboratory Test Results 


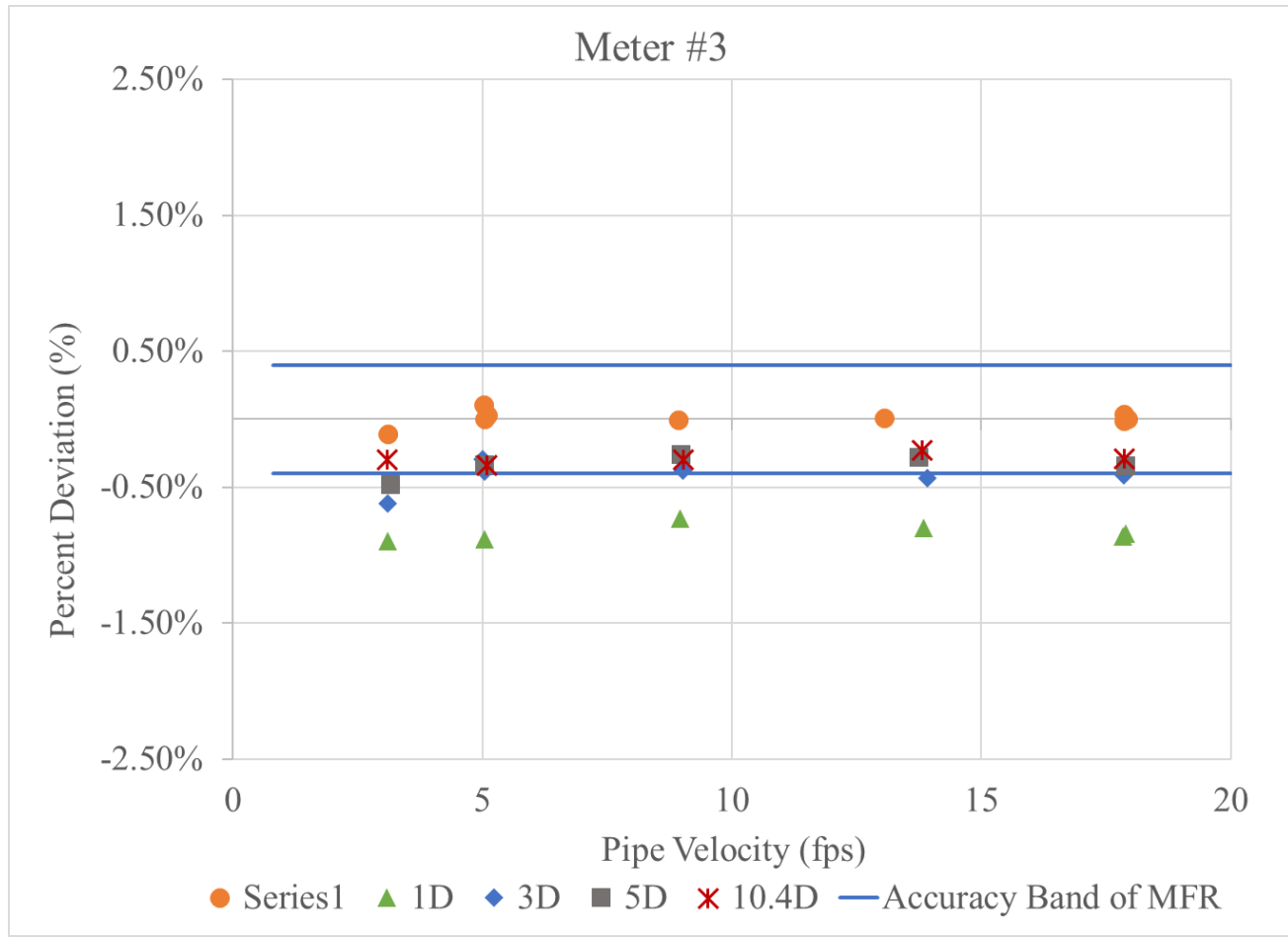

Figure 15. Meter \#3 Laboratory Test Results

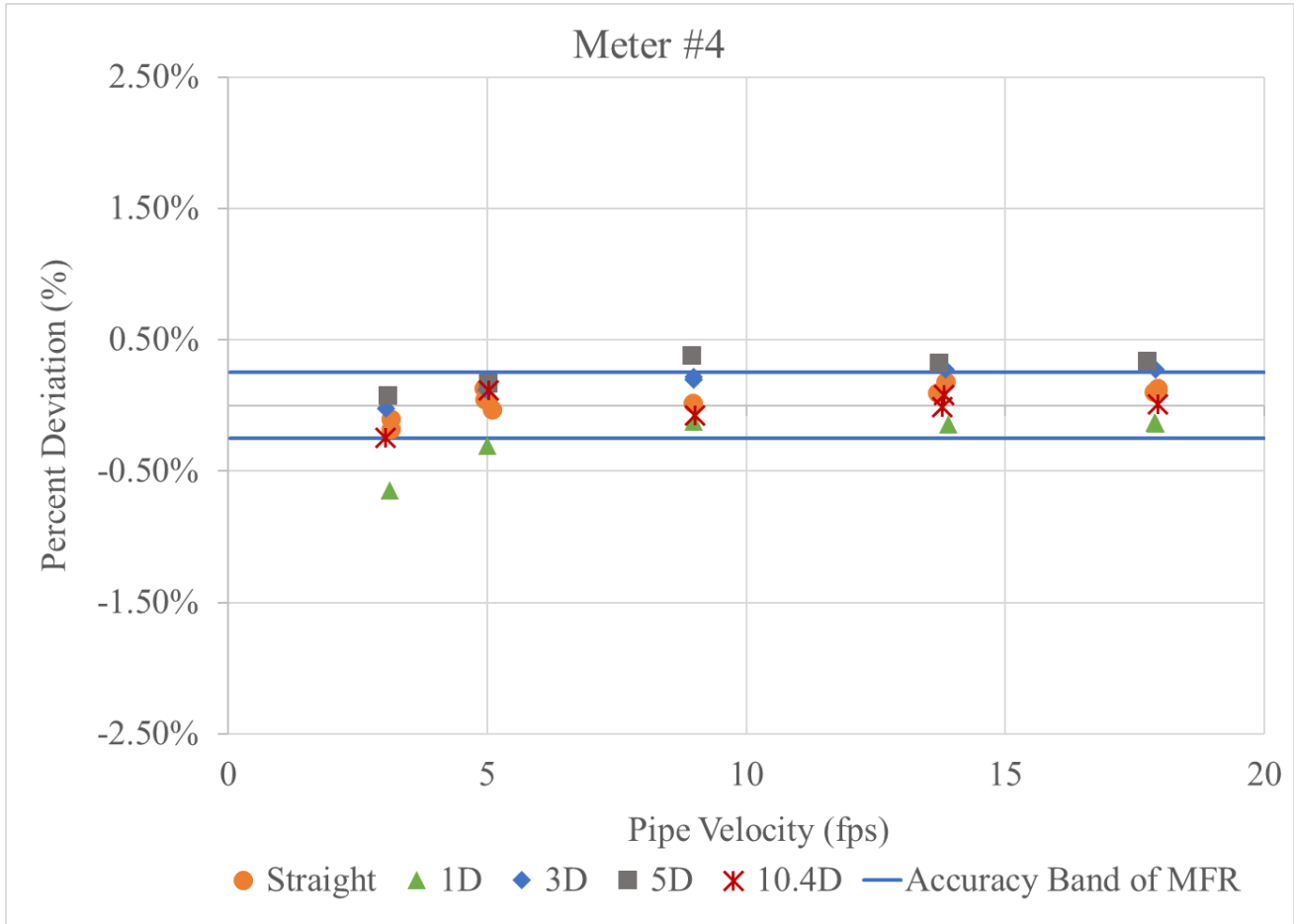

Figure 16. Meter \#4 Laboratory Test Results 


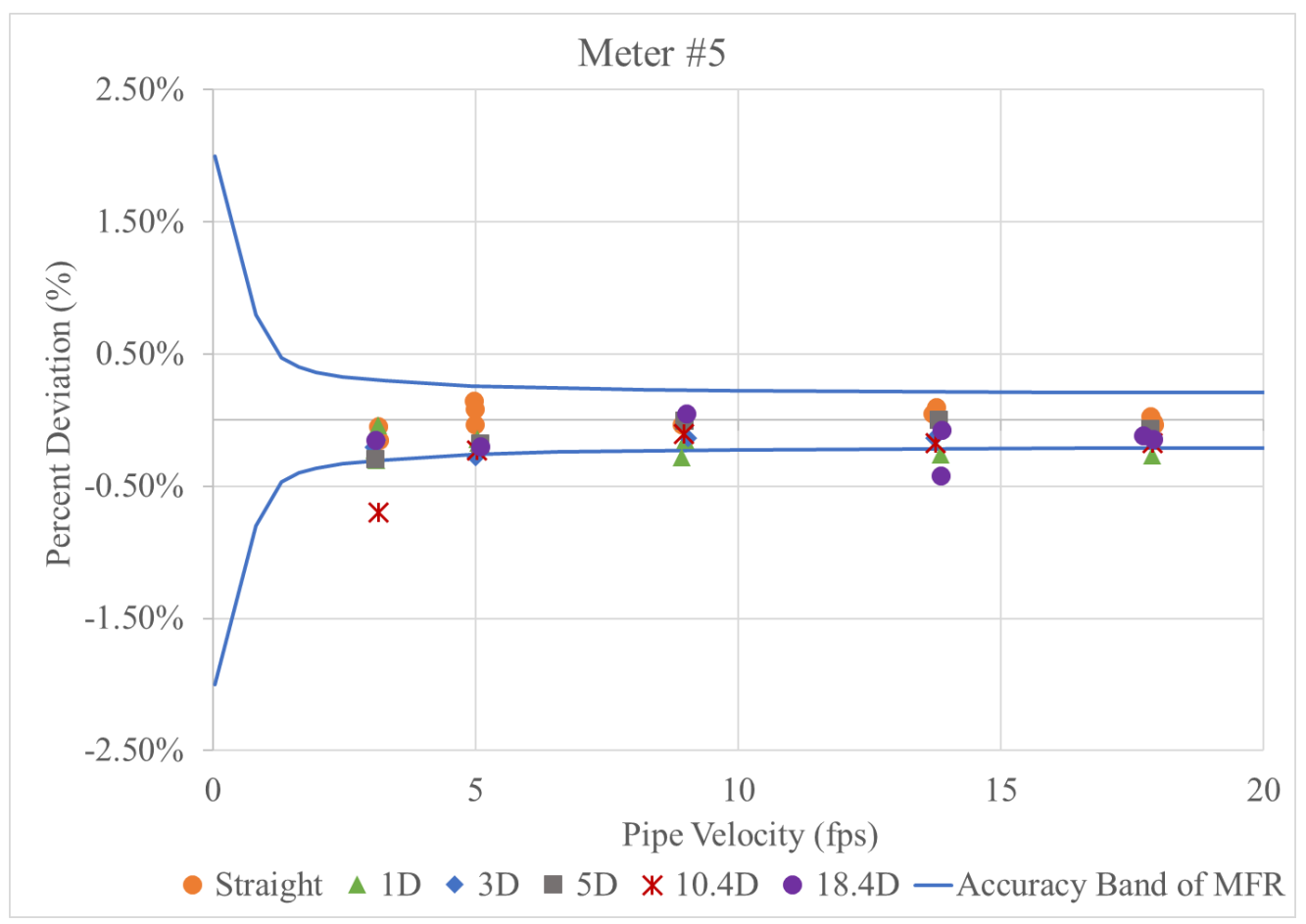

\section{Figure 17. Meter \#5 Laboratory Test Results}

Meter number 1 demonstrated outstanding repeatability at 3 and $18 \mathrm{fps}$. Overall, meter number 1 appeared to be relatively insensitive to the upstream disturbance of the flow conditioner. For example, the meter nearly produced straight pipe accuracy for the velocities of $3,5,9$, and 18 fps at $1 \mathrm{D}$ downstream of the flow conditioner.

Meter number 2 approached straight pipe performance at higher pipe velocities and appeared to be less sensitive to the location of the flow conditioner. Interestingly, meter number 2 had negative shifts in accuracy at 1D, 3D, and 10.4D, but demonstrated a positive shift in accuracy at 5D. The precision or repeatability of meter number 2 increases as the flow rate increases, but the previously mentioned shifts are still identifiable even at the highest flow rate.

In contrast, meter number 3 appeared to be highly sensitive to the distance 
between the disturbance and the meter. Meter number 3 approached straight pipe performance as the distance between the meter and the conditioner was increased, rather than improving performance as the pipe velocity increased like meter number 2.

Meter numbers 4 and 5 were the most precise or repeatable of the meters tested. Meter number 4 was the only meter that demonstrated a return to straight pipe performance at 10.4D downstream of the flow conditioner for each of the flow rates. Interestingly, meter number 5 performed worst at 3 fps and 10.4D but was still highly repeatable as compared to meter numbers 1,2 , and 3 .

\section{Numerical Results}

The numerical results are presented by comparing the simulated flow rate with the conditioner installed to an identical simulation that has no flow conditioner, thereby allowing a direct comparison of relative differences. Two tables are presented for the 18 fps simulations. Table 2 contains the extracted CFD values with a flow conditioner installed and Table 3 presents the extracted CFD values without a flow conditioner installed. Tables 2 and 3 present the average and maximum velocity, TKE, and TDR for the 18 fps simulations with and without a flow conditioner, respectively.

Table 2. CFD Results for $18 \mathrm{ft} / \mathrm{s}$ with Flow Conditioner

\begin{tabular}{|c|c|c|c|c|c|c|}
\hline \multicolumn{7}{|c|}{ With Flow Conditioner } \\
\hline $\begin{array}{c}\text { Distance } \\
\text { Between Flow } \\
\text { Conditioner } \\
\text { and Cross } \\
\text { Section }\end{array}$ & $\begin{array}{c}\text { Average } \\
\text { Velocity } \\
\text { (ft/s) }\end{array}$ & $\begin{array}{c}\text { Max } \\
\text { Velocity } \\
\text { (ft/s) }\end{array}$ & $\begin{array}{c}\text { Average } \\
\text { TKE } \\
\left(\mathrm{ft}^{\wedge} 2 / \mathrm{s}^{\wedge} 2\right)\end{array}$ & $\begin{array}{c}\operatorname{Max} \\
\text { TKE } \\
\left(\mathrm{ft}^{\wedge} 2 / \mathrm{s}^{\wedge} 2\right)\end{array}$ & $\begin{array}{c}\text { Average } \\
\text { TDR } \\
\left(\mathrm{ft}^{\wedge} 2 / \mathrm{s}^{\wedge} 3\right)\end{array}$ & $\begin{array}{c}\text { Max } \\
\text { TDR } \\
\left(\mathrm{ft}^{\wedge} 2 / \mathrm{s}^{\wedge} 3\right)\end{array}$ \\
\hline $1 \mathrm{D}$ & 18.02 & 27.06 & 5.97 & 8.93 & 227.53 & 5619.98 \\
\hline $3 \mathrm{D}$ & 18.02 & 22.24 & 2.05 & 4.17 & 62.11 & 2997.31 \\
\hline $5 \mathrm{D}$ & 18.02 & 21.78 & 1.46 & 4.06 & 48.29 & 2768.80 \\
\hline $10.4 \mathrm{D}$ & 18.02 & 21.52 & 1.32 & 4.13 & 46.96 & 2891.24 \\
\hline
\end{tabular}


Table 3. CFD Results at $18 \mathrm{ft} / \mathrm{s}$ without Flow Conditioner

\begin{tabular}{|c|c|c|c|c|c|c|}
\hline \multicolumn{7}{|c|}{ Without Flow Conditioner } \\
\hline $\begin{array}{c}\text { Distance } \\
\text { Between Flow } \\
\text { Conditioner } \\
\text { and Cross } \\
\text { Section }\end{array}$ & $\begin{array}{c}\text { Average } \\
\text { Velocity } \\
(\mathrm{ft} / \mathrm{s})\end{array}$ & $\begin{array}{c}\text { Max } \\
\text { Velocity } \\
\text { (ft/s) }\end{array}$ & $\begin{array}{c}\text { Average } \\
\text { TKE } \\
\left(\mathrm{ft}^{\wedge} 2 / \mathrm{s}^{\wedge} 2\right)\end{array}$ & $\begin{array}{c}\text { Max } \\
\text { TKE } \\
\left(\mathrm{ft}^{\wedge} 2 / \mathrm{s}^{\wedge} 2\right)\end{array}$ & $\begin{array}{c}\text { Average } \\
\text { TDR } \\
\left(\mathrm{ft}^{\wedge} 2 / \mathrm{s}^{\wedge} 3\right)\end{array}$ & $\begin{array}{c}\text { Max } \\
\text { TDR } \\
\left(\mathrm{ft}^{\wedge} 2 / \mathrm{s}^{\wedge} 3\right)\end{array}$ \\
\hline 1D & 17.96 & 20.82 & 1.40 & 4.19 & 48.74 & 2950.07 \\
\hline $3 \mathrm{D}$ & 17.96 & 20.77 & 1.37 & 4.19 & 48.42 & 2954.36 \\
\hline 5D & 17.96 & 20.73 & 1.34 & 4.18 & 48.14 & 2950.50 \\
\hline $10.4 \mathrm{D}$ & 17.96 & 20.62 & 1.28 & 4.18 & 47.60 & 2934.93 \\
\hline
\end{tabular}

Figures 18-29 present cross sections at 1D, 3D, 5D, and 10.4D of the velocity, TKE, and TDR for the CFD simulations at 18 fps with and without a flow conditioner, respectively.
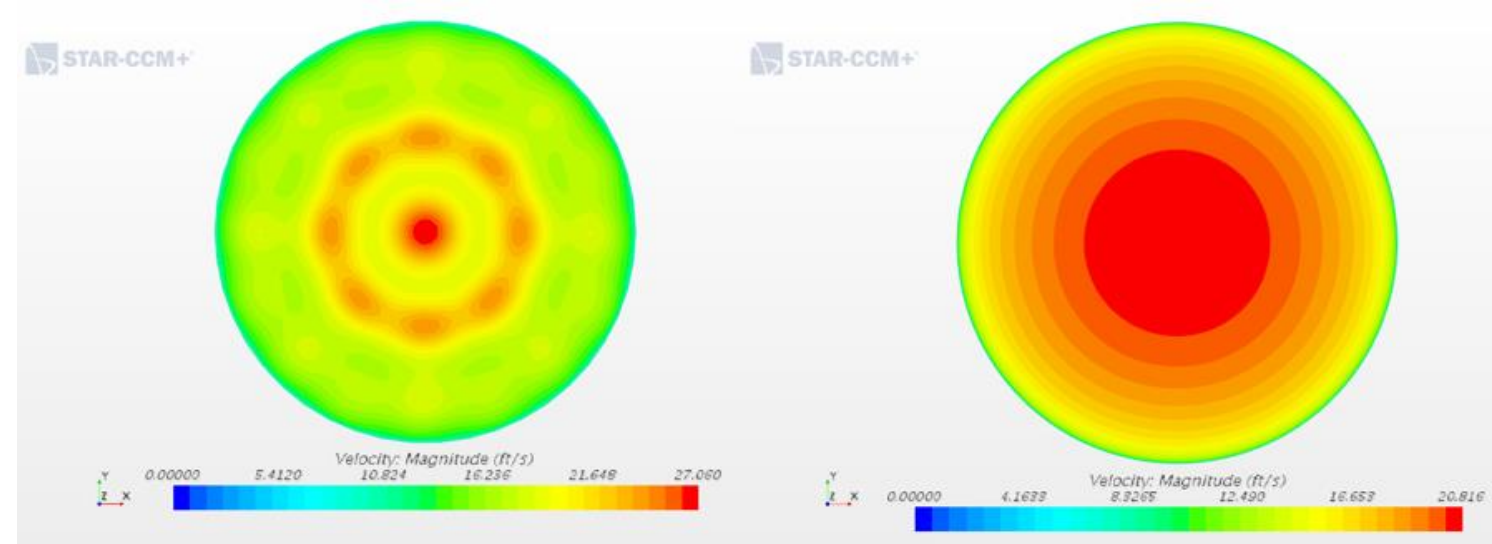

Figure 18. $18 \mathrm{ft} / \mathrm{s}$ Velocity at 1D with and without Flow Conditioner
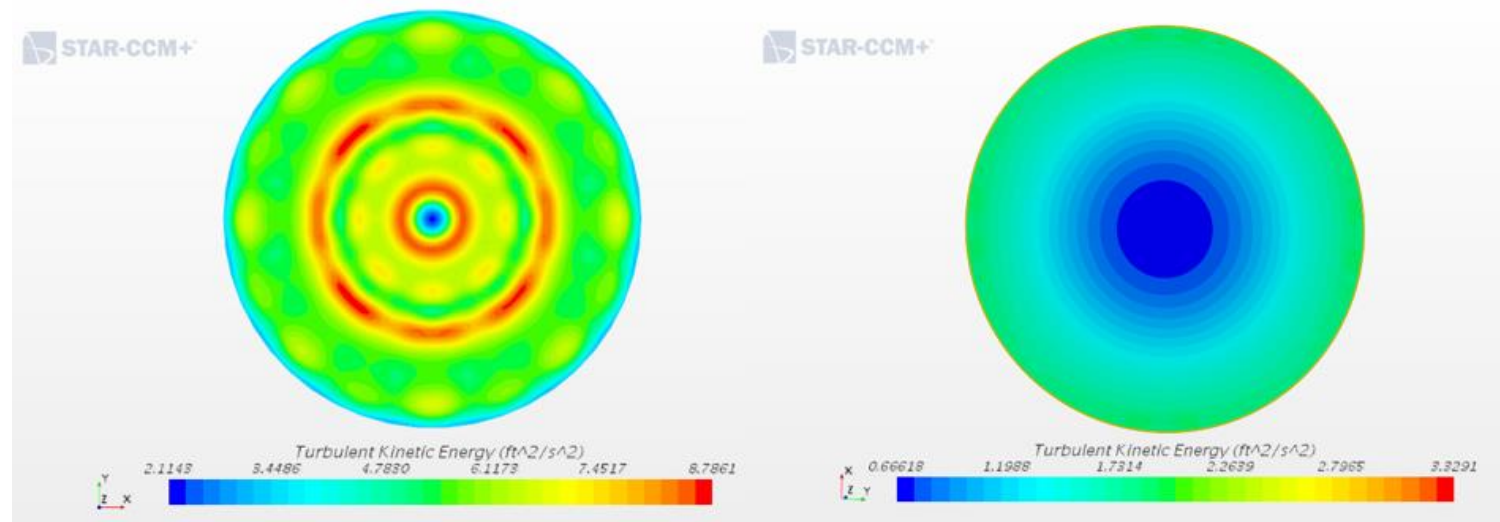

Figure 19. $18 \mathrm{ft} / \mathrm{s}$ TKE at 1D with and without Flow Conditioner 

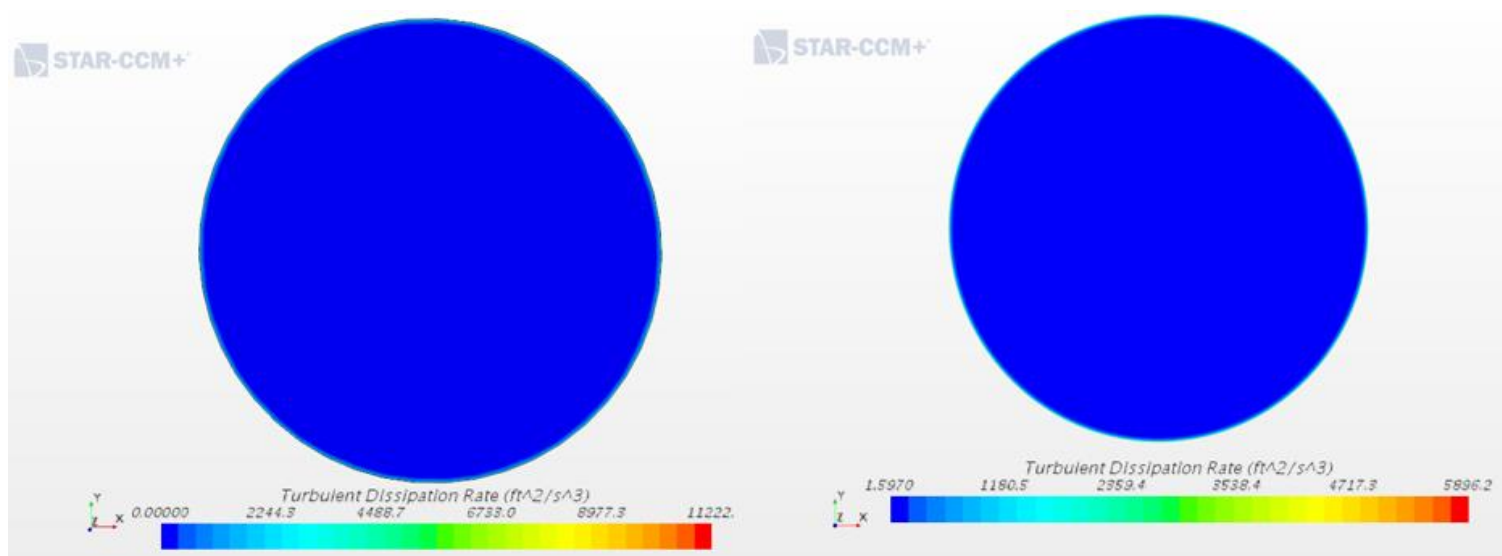

Figure 20. $18 \mathrm{ft} / \mathrm{s}$ TDR at $1 D$ with and without Flow Conditioner
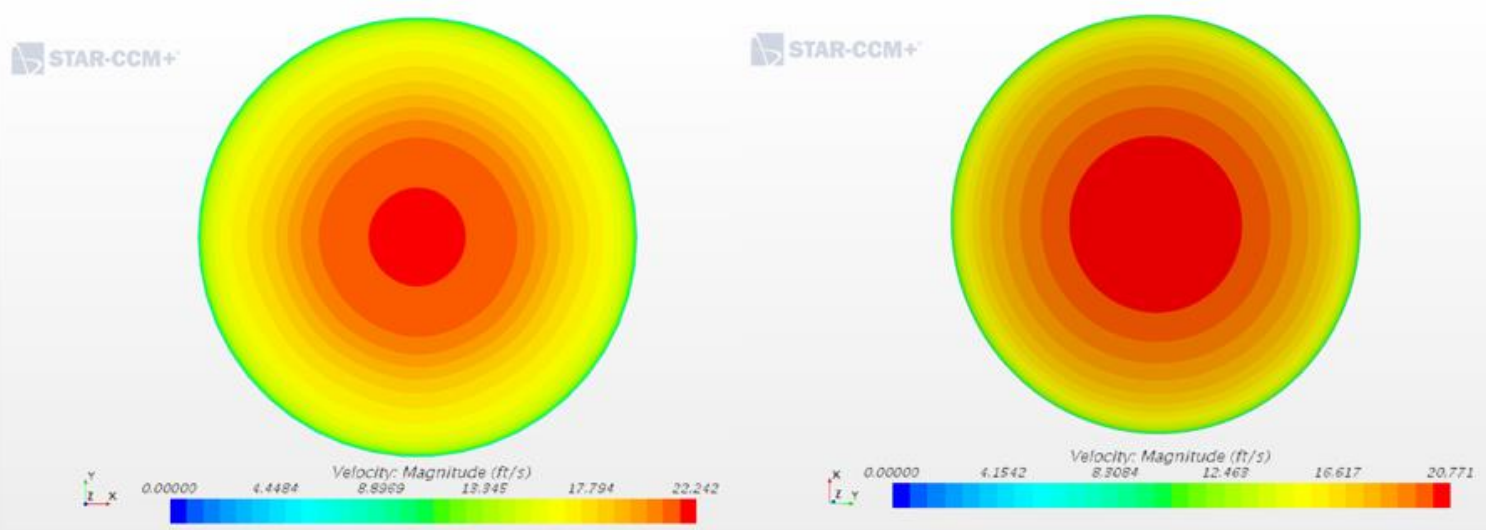

Figure 21. $18 \mathrm{ft} / \mathrm{s}$ Velocity at 3D with and without Flow Conditioner
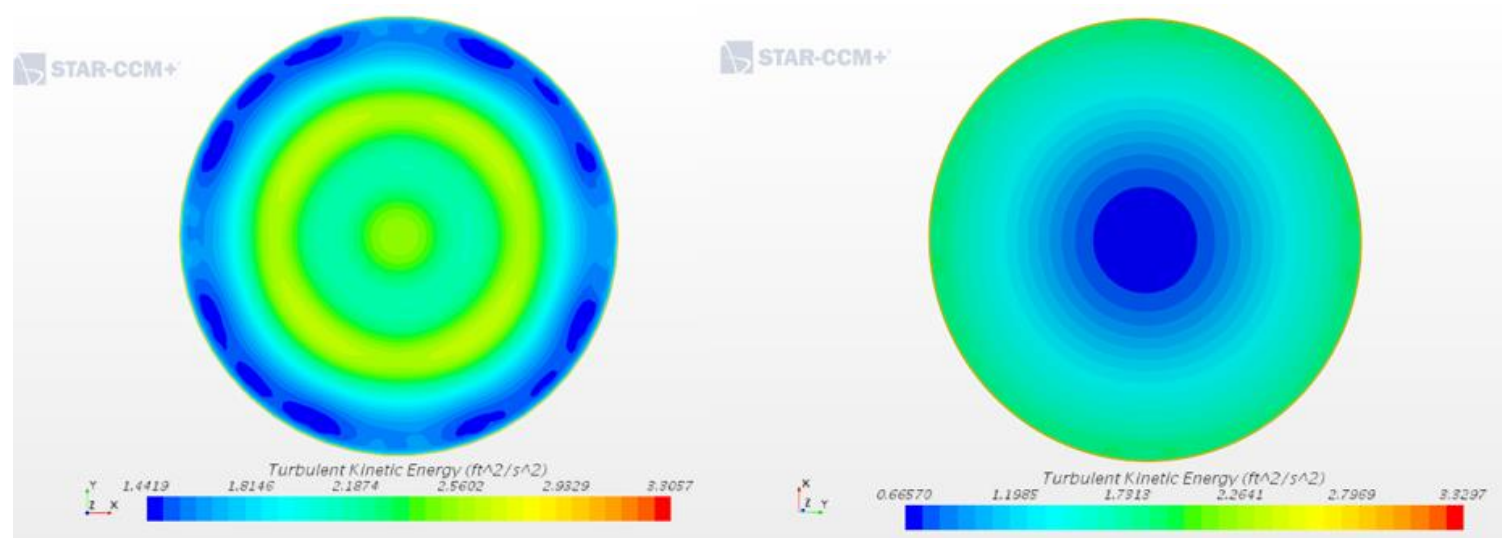

Figure 22. $18 \mathrm{ft} / \mathrm{s}$ TKE at 3D with and without Flow Conditioner 

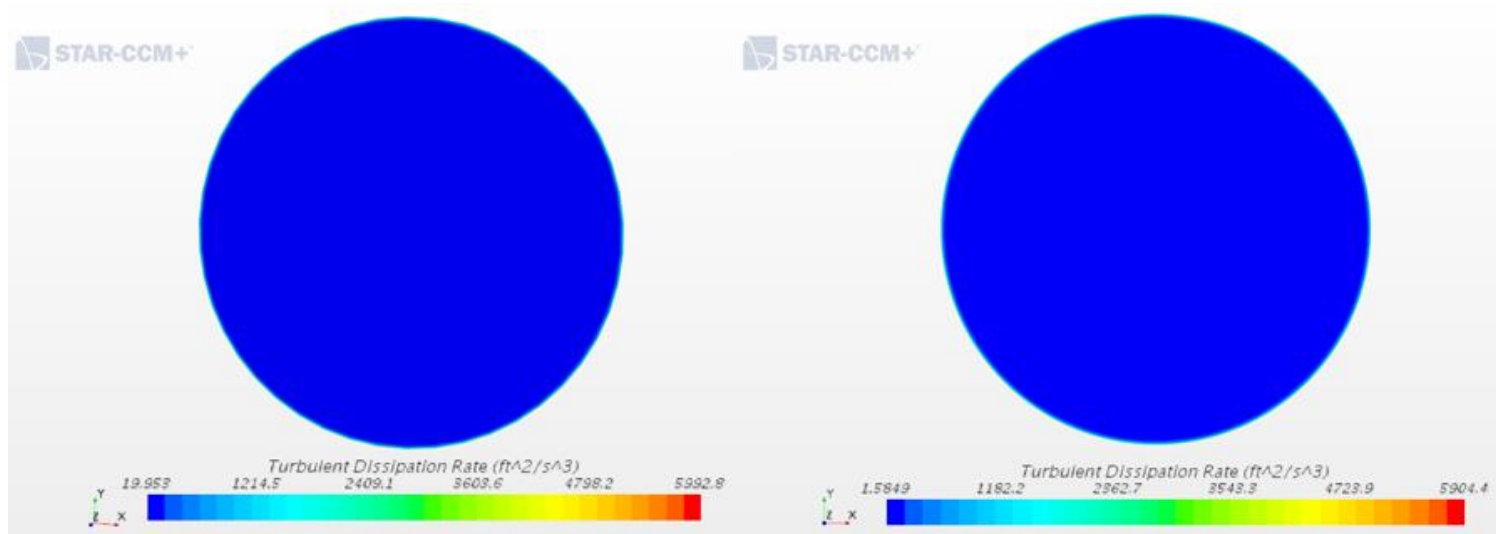

Figure 23. $18 \mathrm{ft} / \mathrm{s}$ TDR at 3D with and without Flow Conditioner
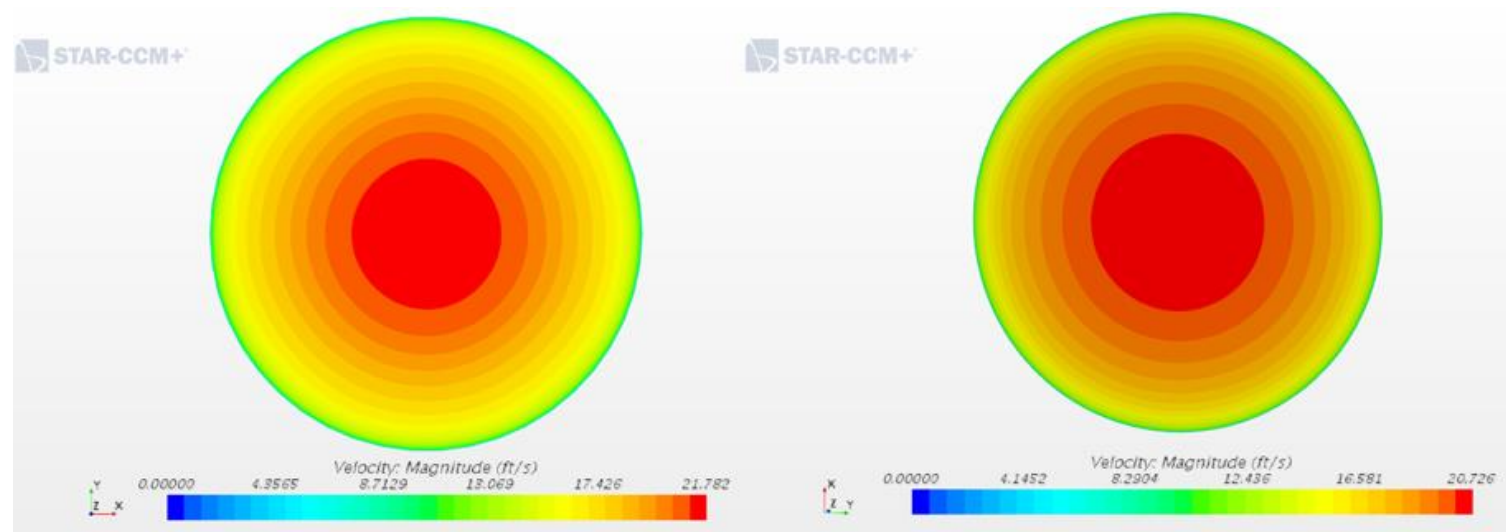

Figure 24. $18 \mathrm{ft} / \mathrm{s}$ Velocity at 5D with and without Flow Conditioner
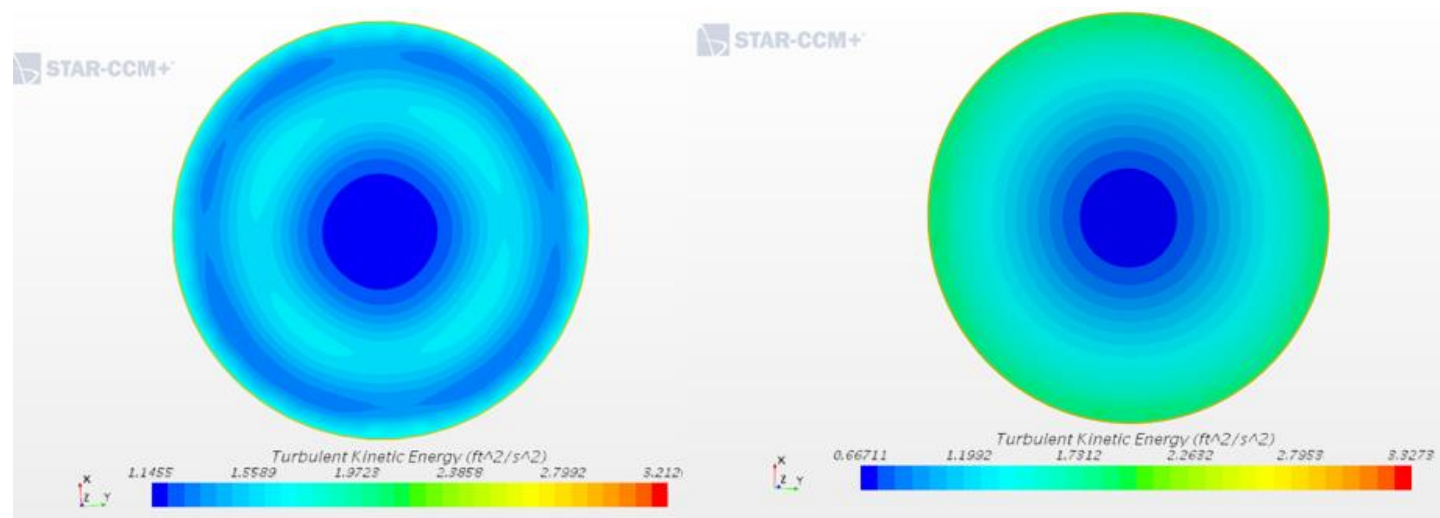

Figure 25. $18 \mathrm{ft} / \mathrm{s}$ TKE at 5D with and without Flow Conditioner 

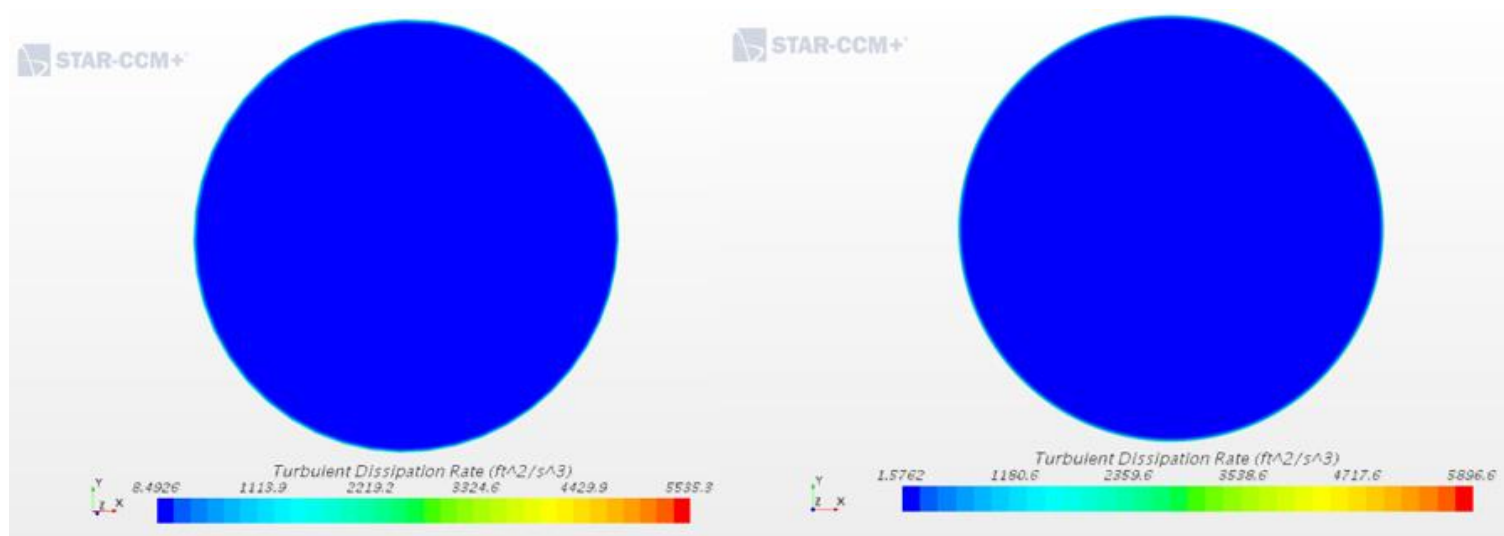

Figure 26. $18 \mathrm{ft} / \mathrm{s}$ TDR at 5D with and without Flow Conditioner
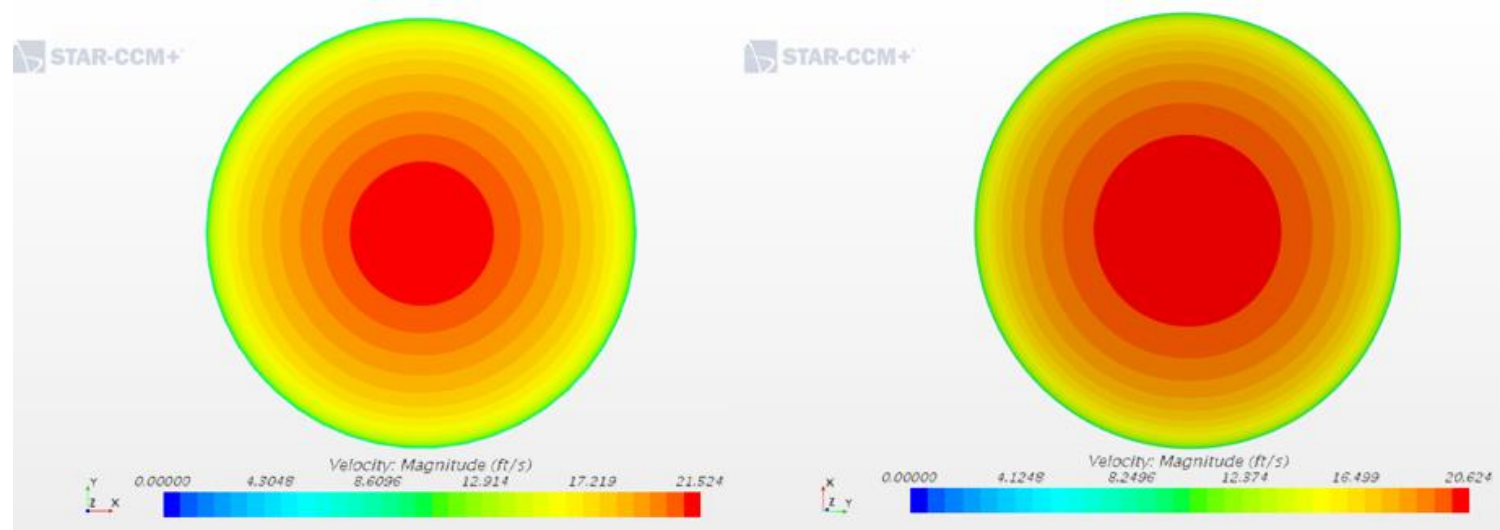

Figure 27. $18 \mathrm{ft} / \mathrm{s}$ Velocity at 10.4D with and without Flow Conditioner
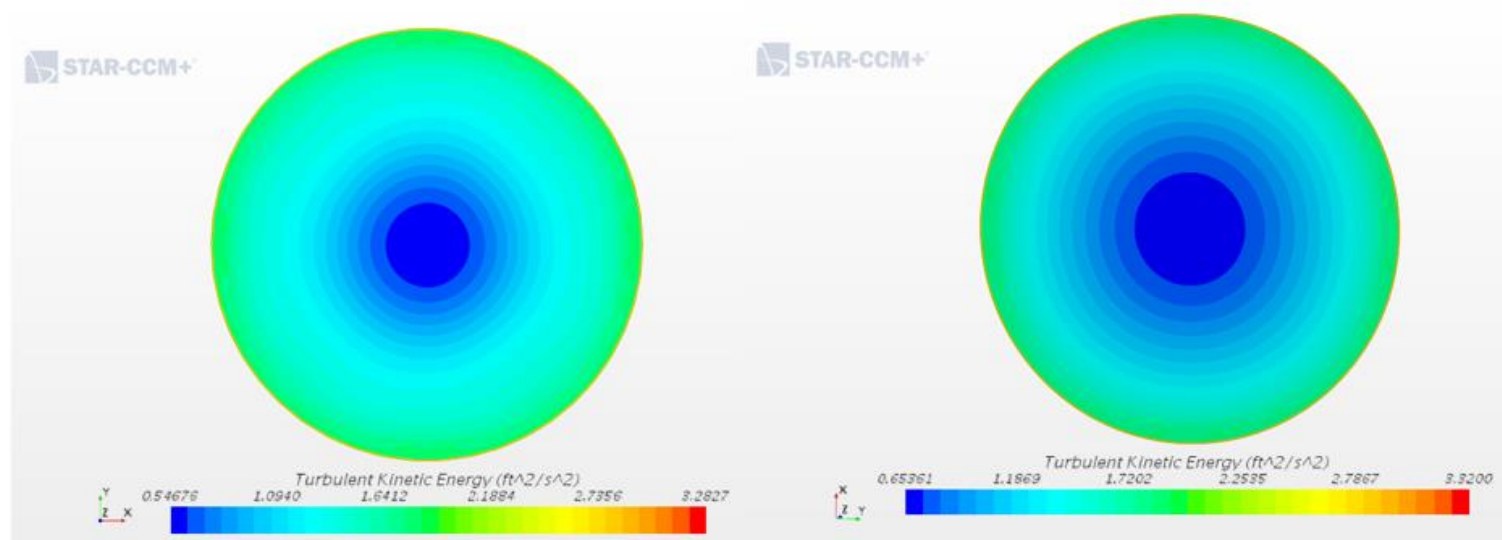

Figure 28. $18 \mathrm{ft} / \mathrm{s}$ TKE at 10.4D with and without Flow Conditioner 

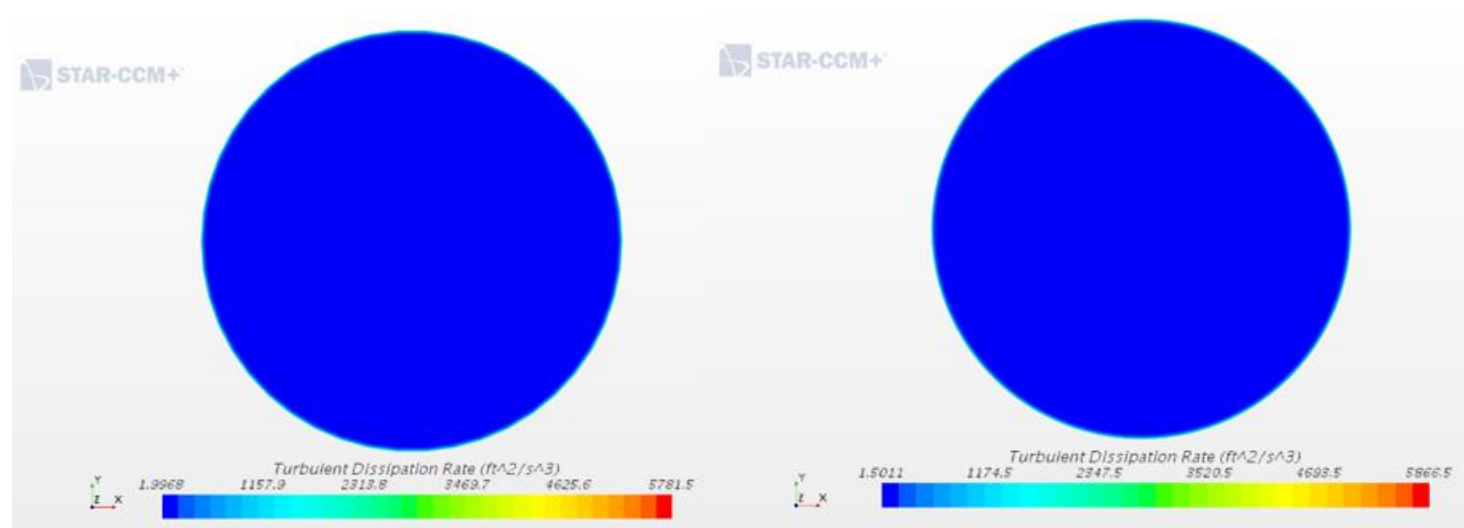

Figure 29. $18 \mathrm{ft} / \mathrm{s}$ TDR at 10.4D with and without Flow Conditioner

Figures 30 and 31 display the centerline velocity profiles for the 18 -fps tests with and without a flow conditioner, respectively.

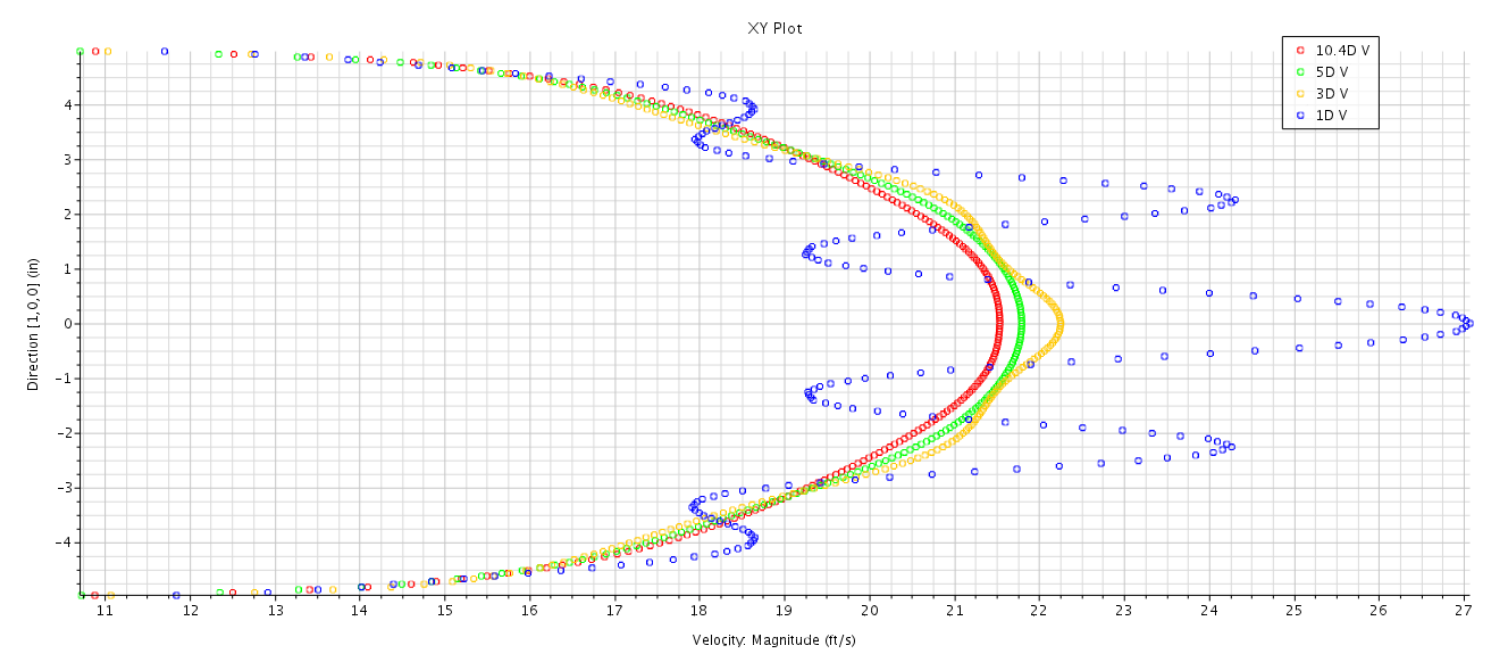

\section{Figure 30. $18 \mathrm{ft} / \mathrm{s}$ Velocity Profiles with Flow Conditioner}

The average TKE and TDR is over four times as great with the flow conditioner installed than without at 1D at the 18-fps velocities. As shown in Figures 30 and 31 the velocity profile at $1 \mathrm{D}$ is significantly distorted compared to the velocity profile at $1 \mathrm{D}$ without the flow conditioner. Whereas, at 3D, 5D, and $10.4 \mathrm{D}$ the velocity profile with the flow conditioner is much closer to the profiles at 3D, 5D, and $10.4 \mathrm{D}$ without the flow 
conditioner.

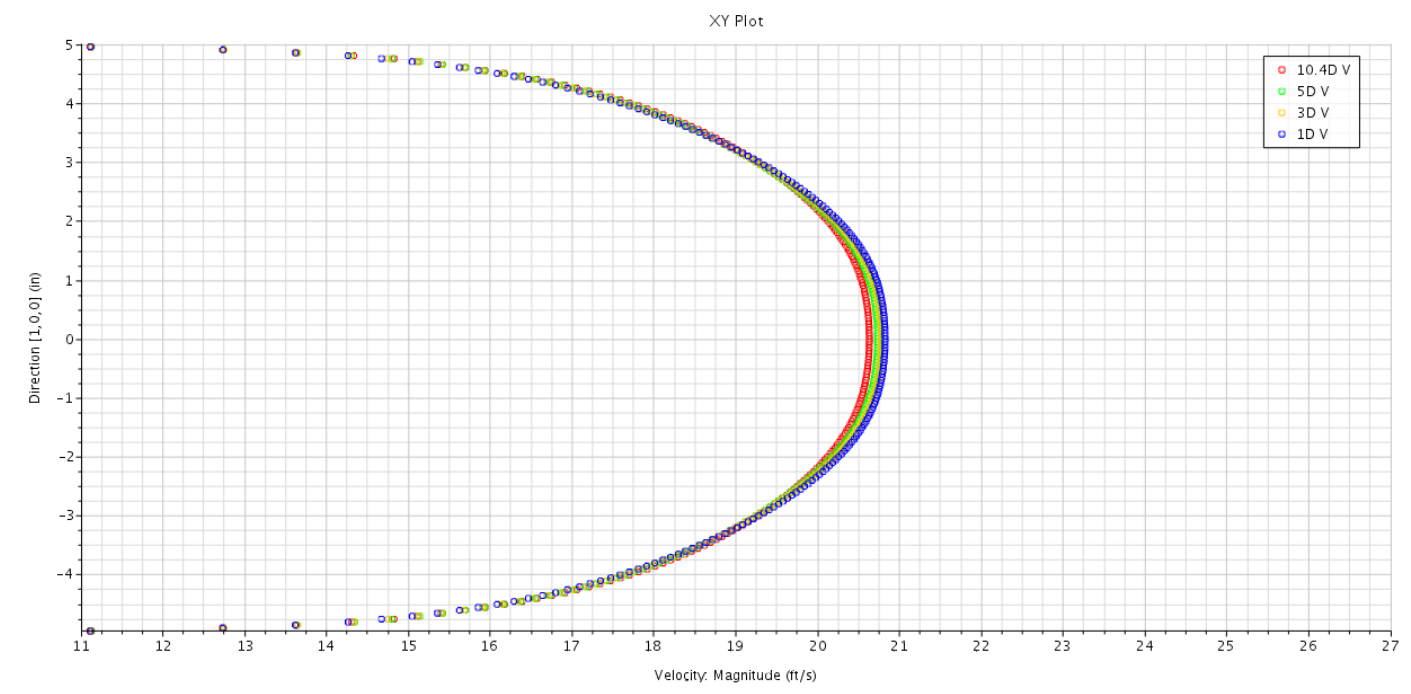

\section{Figure 31. $18 \mathrm{ft} / \mathrm{s}$ Velocity Profiles without Flow Conditioner}

Although the profile with the flow conditioner at 1D is significantly distorted,

Figure 32 presents a plot of the fully-developed (without conditioner) profile at 1D, distorted-profile (with conditioner) at 1D, and a polynomial-fitted trendline through the distorted profile.

This trendline is a representation of velocity profile that the weight function would use to calculate the flow rate. Considering the fitted trendline profile from Figure 27 and the TKE and TDR are four times as great with the flow conditioner than without, it appears that the performance of a magnetic flow meter is not significantly affected by the elevated levels of local turbulence.

Tables 4 and 5 present the percent deviation of each meter compared to straight pipe performance and the TKE with the flow conditioner divided by the TKE without the flow conditioner expressed as a percentage at 1D, 3D, 5D and 10.4D for 18-fps and 1-fps tests, respectively. Interestingly, the TKE at 1D for the 18 -fps simulation is $426 \%$ greater 


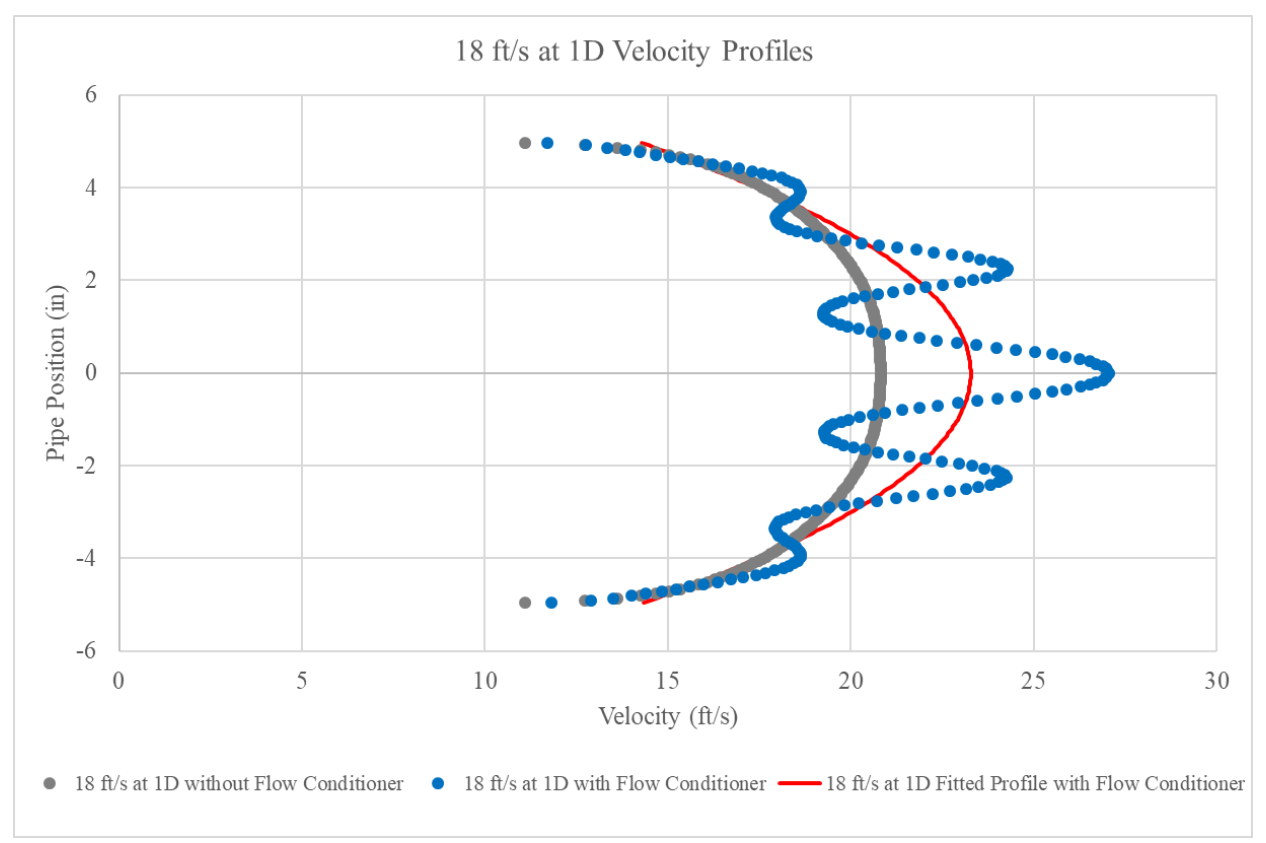

Figure 32. $18 \mathrm{ft} / \mathrm{s}$ at 1D Velocity Profiles

with the flow conditioner than without and the errors at 1D do not vary significantly from the errors at $10.4 \mathrm{D}$ for meters $1,2,4$, and 5 .

Table 4. TKE vs Percent Deviation from Straight Pipe Performance at $18 \mathrm{ft} / \mathrm{s}$

\begin{tabular}{|c|c|c|c|c|c|c|}
\hline \multicolumn{7}{|c|}{ TKE vs Percent Deviation from Straight at 18fps } \\
\hline $\begin{array}{c}\text { Distance } \\
\text { Between Flow } \\
\begin{array}{c}\text { Conditioner and } \\
\text { Cross Section }\end{array}\end{array} \begin{array}{c}\text { TKE with / } \\
\text { TKE without }\end{array}$ & Meter 1 & Meter 2 & Meter 3 & Meter 4 & Meter 5 \\
\hline 1D & $426 \%$ & $0.11 \%$ & $0.11 \%$ & $0.87 \%$ & $0.26 \%$ & $0.26 \%$ \\
\hline 3D & $150 \%$ & $0.04 \%$ & $0.25 \%$ & $0.42 \%$ & $0.16 \%$ & $0.13 \%$ \\
\hline 5D & $109 \%$ & $0.08 \%$ & $0.04 \%$ & $0.35 \%$ & $0.22 \%$ & $0.06 \%$ \\
\hline 10.4D & $103 \%$ & $0.14 \%$ & $0.32 \%$ & $0.30 \%$ & $0.11 \%$ & $0.17 \%$ \\
\hline
\end{tabular}

Table 5 shows that the TKE at 1D for the 1-fps simulation is only $295 \%$ greater with the flow conditioner than without. Interestingly, the magnitude of the errors is larger than the errors at $18 \mathrm{fps}$ with the higher TKE ratio for meters 1, 2, and 4. Furthermore, 
Table 5. TKE vs Percent Deviation from Straight Pipe Performance at $1 \mathrm{ft} / \mathrm{s}$

\begin{tabular}{|c|c|c|c|c|c|c|}
\hline \multicolumn{7}{|c|}{ TKE vs Percent Deviation from Straight at 1 fps } \\
\hline $\begin{array}{c}\text { Distance } \\
\text { Between Flow } \\
\begin{array}{c}\text { Conditioner and } \\
\text { Cross Section }\end{array}\end{array} \begin{array}{c}\text { TKE with / } \\
\text { TKE without }\end{array}$ & Meter 1 & Meter 2 & Meter 3 & Meter 4 & Meter 5 \\
\hline 1D & $295 \%$ & $0.21 \%$ & $0.74 \%$ & $0.81 \%$ & $0.37 \%$ & $0.20 \%$ \\
\hline 3D & $125 \%$ & $0.21 \%$ & $1.61 \%$ & $0.21 \%$ & $0.21 \%$ & $0.03 \%$ \\
\hline 5D & $98 \%$ & $0.36 \%$ & $2.35 \%$ & $0.04 \%$ & $0.16 \%$ & $0.64 \%$ \\
\hline 10.4D & $121 \%$ & $0.12 \%$ & $0.00 \%$ & $0.11 \%$ & $0.32 \%$ & $1.81 \%$ \\
\hline
\end{tabular}

Tables 4 and 5 also illustrate that the accuracy of the meter is not proportional to the relative magnitude of the TKE.

\section{Inferences from CFD}

This section discusses and analyzes the results obtained from the laboratory and numerical modeling. Several inferences are made about the general behavior of magnetic flow meters' response to increased local turbulence and velocity profiles. These statements are limited to the context of the meters tested and simulations produced in this study.

By comparing the general trends from the CFD simulations with and without a flow conditioner, several inferences can be made. First, the TKE and TDR at 1D are at least four times as large with the conditioner than without. These values when compared to the laboratory data shown in Figures 13 through 17 may indicate that increased local turbulence in a magnetic flow meter when installed 1D downstream of a flow conditioner does not significantly affect magnetic flow meter accuracy. Considering the extremely high-magnitude difference of the local turbulence between the simulations with a 
conditioner and without, the laboratory data showed relatively small deviations in accuracy.

When comparing the TKE and TDR levels, the laboratory data, and the CFD velocity profiles, it appears that the magnetic flow meters are only influenced by local turbulence to the degree that the upstream disturbance that distorts the velocity profile also increases local turbulence.

The 1-fps simulations showed that the TKE at 1D was not quite three times as large with the conditioner than without. Although the relative magnitude difference with the conditioner and without was less than the other simulations, the accuracy of the magnetic flow meters in this study showed greater errors at the 1 -fps test. The magnitude of the error of the meter was not proportional to the changes in the TKE and TDR in the simulations, thereby implying that the level of local turbulence is not the primary cause of metering error.

This study also illustrates that some meters can reproduce straight pipe performance at $1 \mathrm{D}$ downstream of a flow conditioner for some flow rates. This suggests that the variation in meter performance does not originate due to the electromagnetic metering technology. Rather, the variation in the meter performance is due to the application of the technology. All meters were subjected to the same hydraulic disturbance and some reproduced accurate and repeatable measurements, whereas others did not. This implies that some meter manufacturers are capable of programming the meter to compute a flow rate accurately even with four times the normal levels of local turbulence and distorted velocity profiles. Of course, it is also important to remember that the signal strength and sample rate of the meter are also important variables in this 
scenario. Consequently, magnetic flow meters remain an excellent choice for managing and metering water. 


\section{CHAPTER VI}

\section{CONCLUSION}

Magnetic flow meters are an excellent means of technology to measure and manage water. Significant research has focused on the sensitivity of magnetic flow meters to velocity profiles. The purpose of this research was to assess the effect of local turbulence and velocity profiles on magnetic flow meter accuracy.

Laboratory tests were conducted in Logan, Utah, on five magnetic flow meters at 1D, 3D, 5D, and 10.4D downstream of a CPA 65E flow conditioner at six different pipe flow velocities: 1, 3, 5, 9, 14, and 18 fps. Numerical modeling using Star CCM+ provided additional insight and indicated that local turbulence may not significantly influence magnetic flow meter accuracy. It appears that distorted velocity profiles are still the primary source of error for magnetic flow meters.

\section{Need for Further Research}

To isolate local turbulence from the velocity profile, an additional test might be conducted in laminar flow regime. A test in laminar flow would provide definitive data on the performance of magnetic flow meter accuracy without any turbulence.

Additionally, performing a test using a conductive fluid with an extremely high viscosity to produce a small $\mathrm{R}_{\mathrm{e}}$ could also provide a means of separating velocity profile and local turbulence. However, magnetic flow meters are most commonly installed in turbulent flow, which is why this test assessed the performance of magnetic flow meters in typical ranges of turbulent flows $\left(50,000<\mathrm{R}_{\mathrm{e}}<900,000\right)$.

To better understand the sensitivity of magnetic flow meters to local turbulence, 
the electromagnetic potential at the cross section of measurement could be computed using CFD. This method of analysis could provide insight by varying local turbulence levels and velocity profile distortions for different approach flows. This may provide additional understanding of the effects of local turbulence levels and distorted velocity profiles.

This study was limited by the capability of the CFD to accurately model and capture the physical phenomena that exist in the laboratory. Current CFD software may not be programmed to capture the phenomena that cause the errors detected in laboratory experiments. 


\section{REFERENCES}

AWWA. 2002. AWWA Standard: Cold-Water Meters-Displacement Type, Bronze, Main Case. AWWA, Denver.

Baker, R. C. 1982. Electromagnetic flowmeters Developments in Flow Measurement ( $1^{\text {st }}$ edition R. W. W. Scott). Applied Science, Ch 7.

Bates, C. J. 1999. Upstream installation and misalignment effects on the performance of a modified electromagnetic flowmeter. Flow Measurement and Instrumentation, 10: 7989.

Beck, K. J., Weller, R. P., Barfuss, S. L., Johnson, M. C. 2018. The Effect of a Short Radius Elbow on Electromagnetic Flow Meter Accuracy. Journal AWWA, DOI:10.1002/awwa.1055.

Bevir, M. K. 1970. The theory of induced voltage electromagnetic flowmeters. Journal of Fluid Mechanics, 43(3): 577-590.

Celik, I. B., Ghia, U., Roache, P. J., Freitas, C. J., Coleman, H., Raad, P. E. 2008. Procedure for Estimation and Reporting of Uncertainty Due to Discretization in CFD Applications. Journal of Fluids Engineering, 130(7): n.p.

Deacon, J. E. 1983. Proceedings of the $3^{\text {rd }}$ IMEKO Technical Committee on Flow measurement: Electromagnetic Flowmeter Installation Tests. Budapest, Hungary, 20-22 September 1983.

Finnemore, E. J., and Franzini, J. B. 2002. Fluid Mechanics with Engineering Applications (10 ${ }^{\text {th }}$ edition). New York, NY: McGraw-Hill Higher Education.

Flammer, G. H., Jeppson, R. W., and Keedy, H. F. 1983. Fundamental Principles and Applications of Fluid Mechanics. N. p.: n.p.

Flow Research. 2017. The World Market for Magnetic Flow Meters ( $6^{\text {th }}$ edition). Flow Research.com.

Halttunen, J. E. and Luntta, E. A. 1993. Proceedings of the $6^{\text {th }}$ International Conference on Flow Measurement: Modeling in the Analysis of Installation Effects on Flowmeters. Taejon, Korea.

Hemp, J. and Sanderson, M. L. 1981. Proceedings of the International Conference on Advances in Flow Measurement Techniques: Electromagnetic Flowmeters-A State of the Art Review. Warwick, England, 9-11 September 1981. 
Karnik, U., Jungowski, W. M., Botros, K. K. 1994. Effect of Turbulence on Orifice Meter Performance. Journal of Offshore Mechanics and Artic Engineering, 116(2): 77-85.

Keyence. 2018. Flow Meter Types and Principles. Flow Knowledge. Accessed 21 February 2018.

https://www.keyence.com/ss/products/process/flowknowledge/types/electromagnetic.jsp

Klein, A. 1981. Turbulent Developing Pipe Flow. Journal of Fluids Engineering, 103: 243-249.

Lake, W. T. and Reid, J. 1992. Proceedings of the North Sea Flow Measurement Workshop: Optimal Flow Conditioner. East Kilbride, Glasgow. 26-29 October 1992.

Luntta, E., Halttunen, J. 1989. The effect of velocity profile on electromagnetic flow measurement. Sensors and Actuators, 16: 335-344.

Morrow, T. B., Park, J. T., and McKee, R. J. 1991. Determination of Installation effect for a $100 \mathrm{~mm}$ orifice meter using a sliding vane technique. Flow Measurement Instrumentation 2: 14-20.

Park, J. T., Morrow, T. B., Yeh, T. T., and Mattingly, G. E. 1992. Proceedings of the International Gas Research Conference: Effect of Velocity Profile from Tee and Tube Bundle Flow Conditioner on Orifice Meters.

Perry, J. 2014. Installation Effects of an Electromagnetic Flow Meter. SeaMetrics. Accessed November 2017.

Shercliff, J. A. 1954. Relation between the Velocity Profile and the Sensitivity of Electromagnetic Flowmeters. Journal of Applied Physics 25: 817.

Shercliff, J. A. 1962. The Theory of Electromagnetic Flow-Measurement. Cambridge University Press.

Spearman, E. P., Sattary, J. A., Reader-Harris, M. J. 1996. Comparison of velocity and turbulence profiles downstream of perforated plate flow conditioners. Flow Measurement Instrumentation, 7: 181-199. 
APPENDIX 
The CFD results for the $1,3,5,9$, and 14 fps simulations are shown below.

\section{$1 \mathrm{ft} / \mathrm{s}$ CFD Simulation Results}

Table 6. CFD Results for $1 \mathrm{ft} / \mathrm{s}$ with Flow Conditioner

\begin{tabular}{|cccccc|c|}
\hline \multicolumn{7}{|c|}{ With Flow Conditioner } \\
\hline $\begin{array}{c}\text { Distance } \\
\text { Between Flow } \\
\text { Conditioner } \\
\text { and Cross } \\
\text { Section }\end{array}$ & $\begin{array}{c}\text { Average } \\
\text { Velocity } \\
(\mathrm{ft} / \mathrm{s})\end{array}$ & $\begin{array}{c}\text { Max } \\
\text { Velocity } \\
(\mathrm{ft} / \mathrm{s})\end{array}$ & $\begin{array}{c}\text { Average } \\
\text { TKE } \\
\left(\mathrm{ft}^{\wedge} 2 / \mathrm{s}^{\wedge} 2\right)\end{array}$ & $\begin{array}{c}\text { Max } \\
\mathrm{TKE} \\
\left(\mathrm{ft}^{\wedge} 2 / \mathrm{s}^{\wedge} 2\right)\end{array}$ & $\begin{array}{c}\text { Average } \\
\text { TDR } \\
\left(\mathrm{ft}^{\wedge} 2 / \mathrm{s}^{\wedge} 3\right)\end{array}$ & $\begin{array}{c}\text { Max } \\
\mathrm{TDR} \\
\left(\mathrm{ft}^{\wedge} 2 / \mathrm{s}^{\wedge} 3\right)\end{array}$ \\
\hline 1D & 1.000 & 1.590 & 0.017 & 0.037 & 0.039 & 0.159 \\
\hline 3D & 0.999 & 1.363 & 0.007 & 0.014 & 0.011 & 0.072 \\
\hline 5D & 0.999 & 1.288 & 0.006 & 0.013 & 0.008 & 0.059 \\
\hline $10.4 \mathrm{D}$ & 0.999 & 1.276 & 0.007 & 0.015 & 0.010 & 0.071 \\
\hline
\end{tabular}

Table 7. CFD Results for $1 \mathrm{ft} / \mathrm{s}$ without Flow Conditioner

\begin{tabular}{|c|c|c|c|c|c|c|}
\hline \multicolumn{7}{|c|}{ Without Flow Conditioner } \\
\hline $\begin{array}{c}\text { Distance } \\
\text { Between Flow } \\
\text { Conditioner } \\
\text { Location and } \\
\text { Cross Section }\end{array}$ & $\begin{array}{c}\text { Average } \\
\text { Velocity } \\
(\mathrm{ft} / \mathrm{s})\end{array}$ & $\begin{array}{c}\text { Max } \\
\text { Velocity } \\
(\mathrm{ft} / \mathrm{s})\end{array}$ & $\begin{array}{c}\text { Average } \\
\text { TKE } \\
\left(\mathrm{ft}^{\wedge} 2 / \mathrm{s}^{\wedge} 2\right)\end{array}$ & $\begin{array}{c}\operatorname{Max} \\
\text { TKE } \\
\left(\mathrm{ft}^{\wedge} 2 / \mathrm{s}^{\wedge} 2\right)\end{array}$ & $\begin{array}{c}\text { Average } \\
\text { TDR } \\
\left(\mathrm{ft}^{\wedge} 2 / \mathrm{s}^{\wedge} 3\right)\end{array}$ & $\begin{array}{c}\operatorname{Max} \\
\mathrm{TDR} \\
\left(\mathrm{ft}^{\wedge} 2 / \mathrm{s}^{\wedge} 3\right)\end{array}$ \\
\hline $1 \mathrm{D}$ & 0.997 & 1.184 & 0.006 & 0.015 & 0.009 & 0.070 \\
\hline $3 \mathrm{D}$ & 0.997 & 1.187 & 0.006 & 0.015 & 0.009 & 0.070 \\
\hline $5 \mathrm{D}$ & 0.997 & 1.189 & 0.006 & 0.015 & 0.009 & 0.070 \\
\hline $10.4 \mathrm{D}$ & 0.997 & 1.196 & 0.006 & 0.015 & 0.009 & 0.070 \\
\hline
\end{tabular}



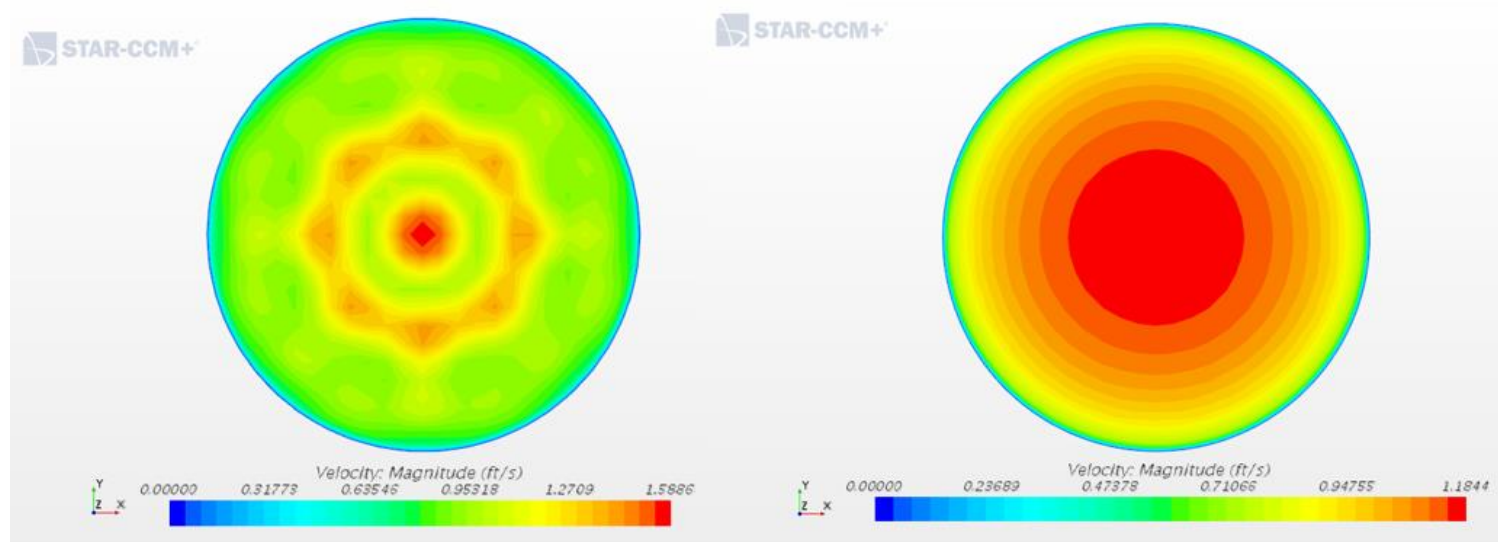

Figure 33. $1 \mathrm{ft} / \mathrm{s}$ Velocity at $1 \mathrm{D}$ with and without Flow Conditioner
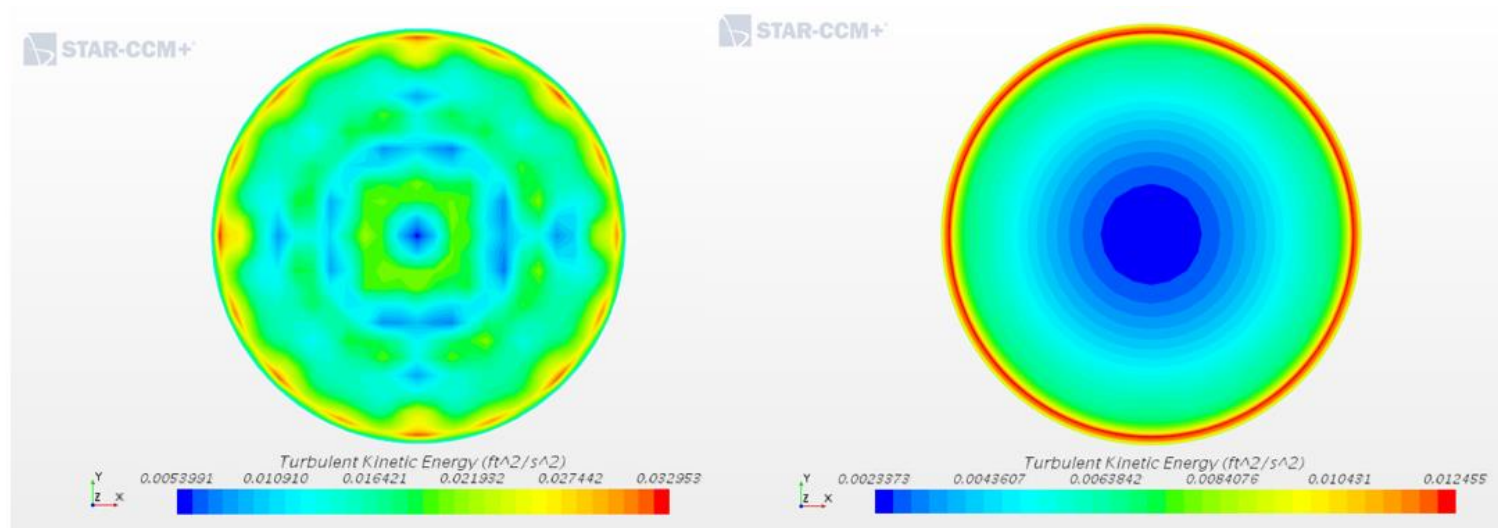

Figure 34. $1 \mathrm{ft} / \mathrm{s}$ TKE at 1D with and without Flow Conditioner

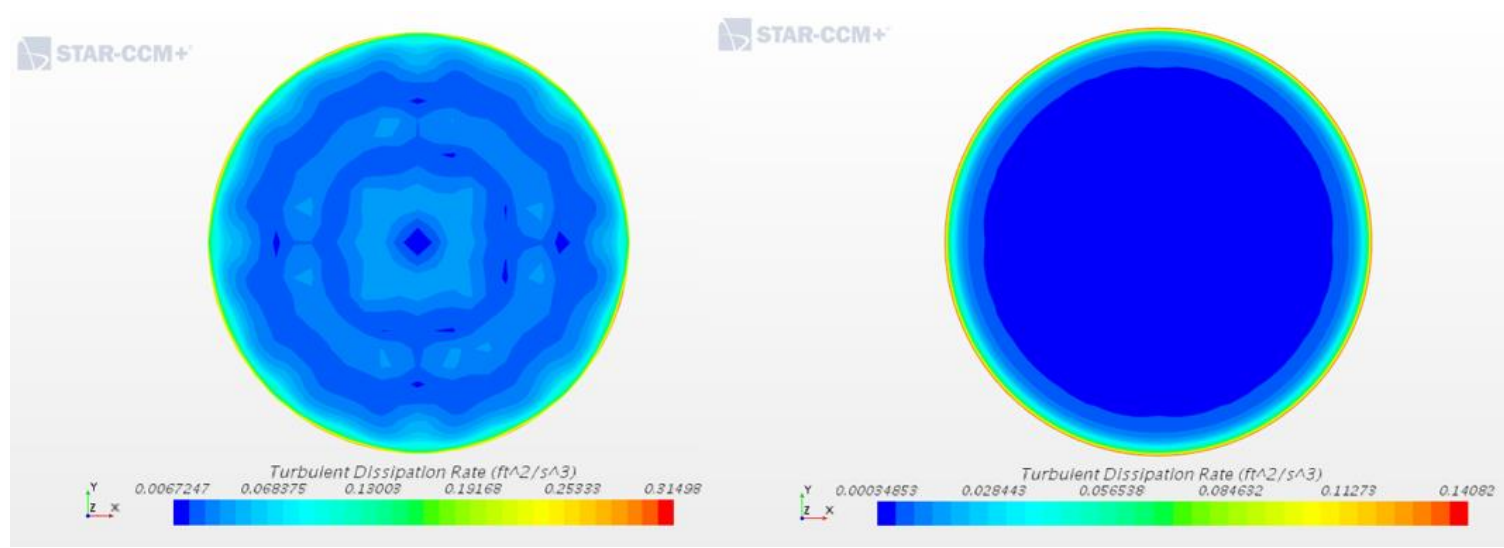

Figure 35. $1 \mathrm{ft} / \mathrm{s}$ TDR at 1D with and without Flow Conditioner 

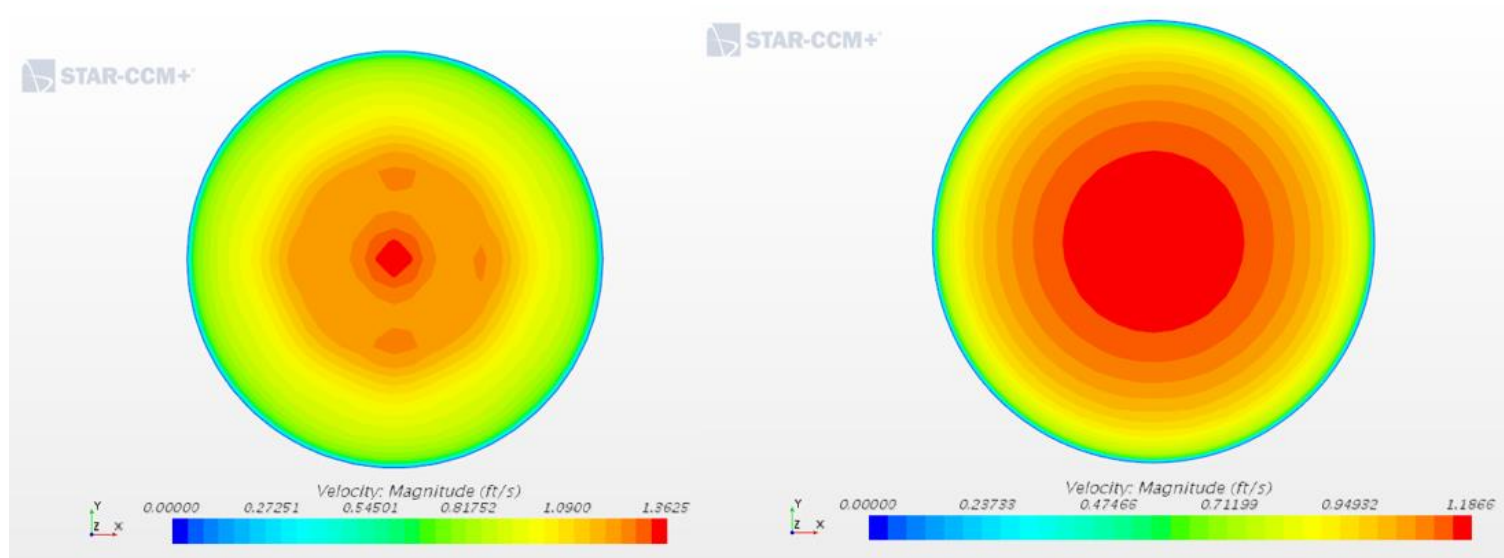

Figure 36. $1 \mathrm{ft} / \mathrm{s}$ Velocity at 3D with and without Flow Conditioner
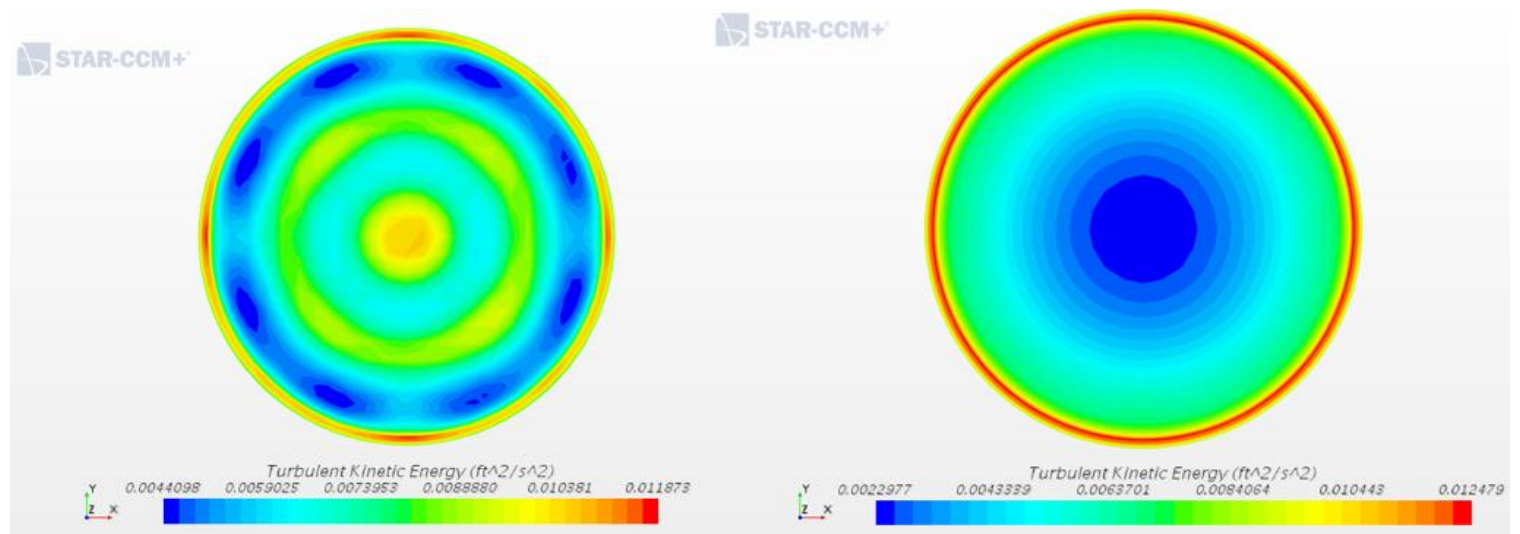

Figure 37. $1 \mathrm{ft} / \mathrm{s}$ TKE at 3D with and without Flow Conditioner
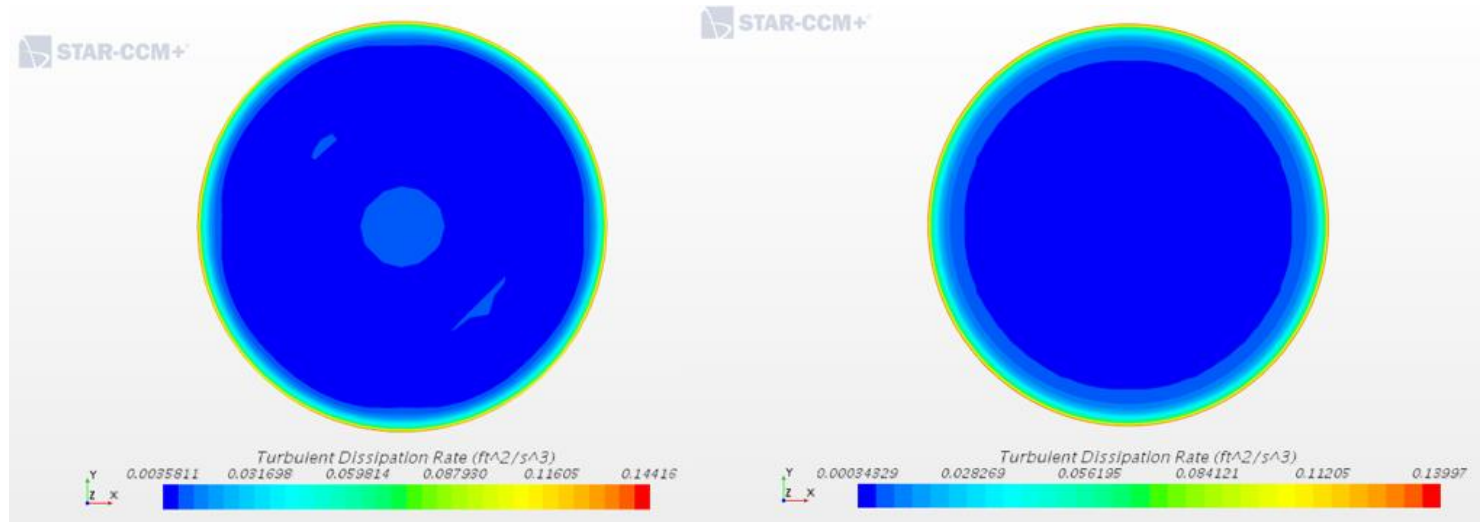

Figure 38. $1 \mathrm{ft} / \mathrm{s}$ TDR at 3D with and without Flow Conditioner 

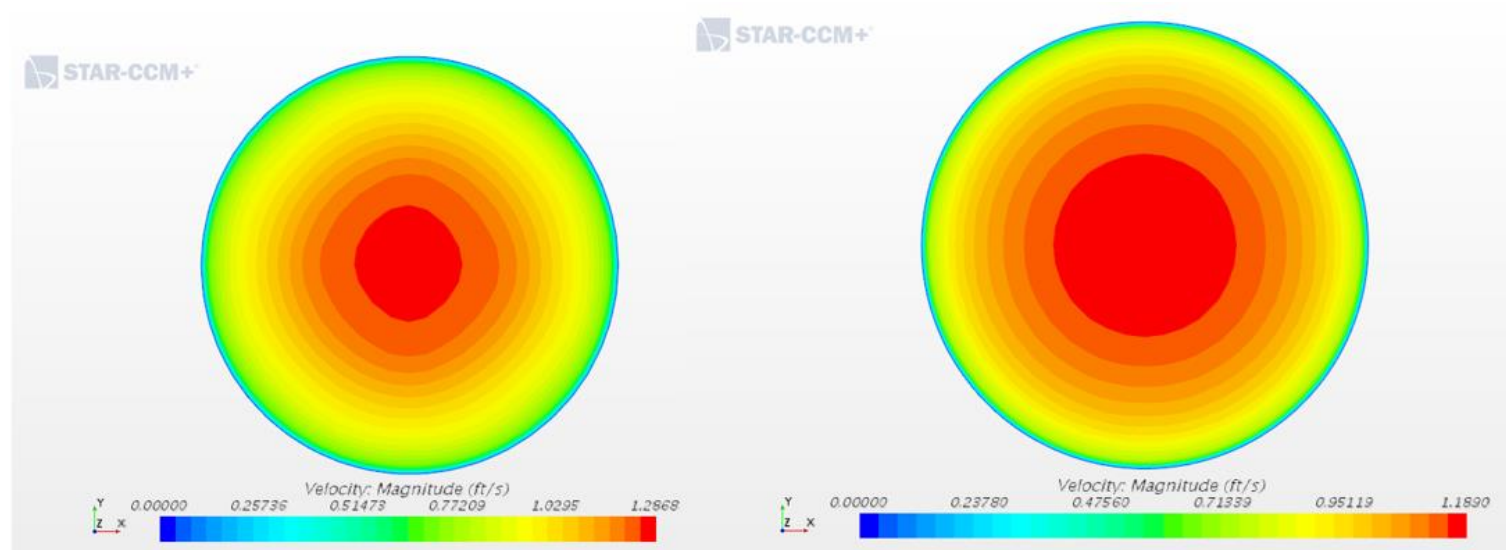

Figure 39. $1 \mathrm{ft} / \mathrm{s}$ Velocity at 5D with and without Flow Conditioner
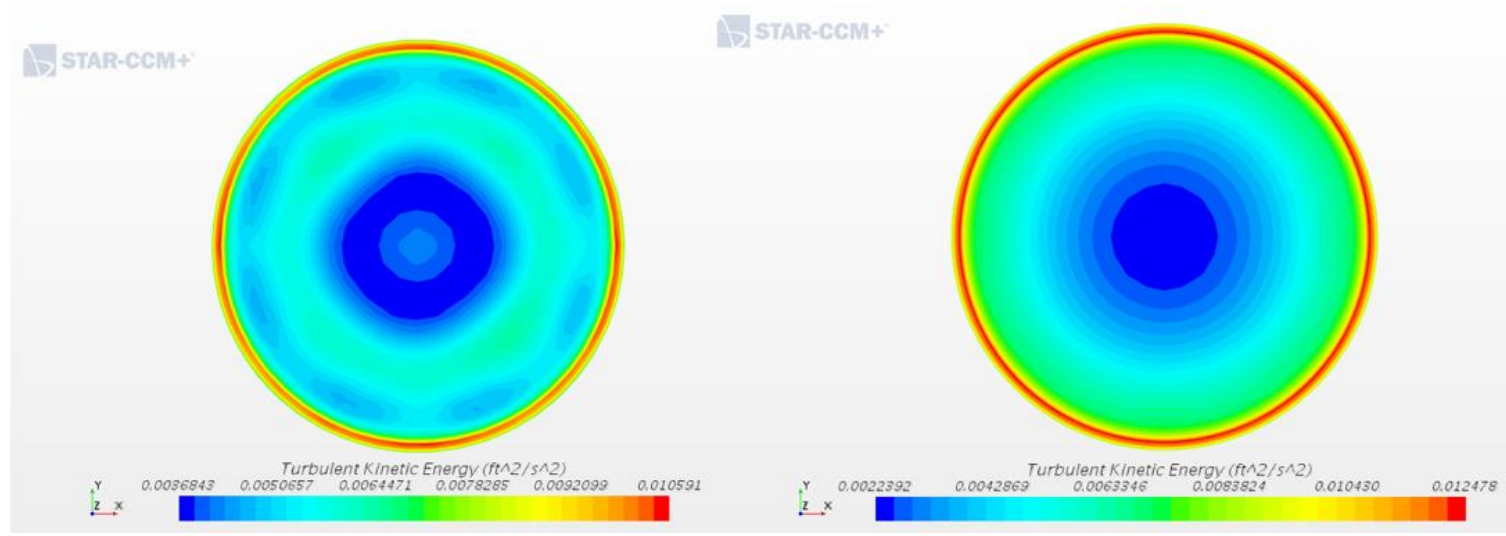

Figure 40. $1 \mathrm{ft} / \mathrm{s}$ TKE at 5D with and without Flow Conditioner
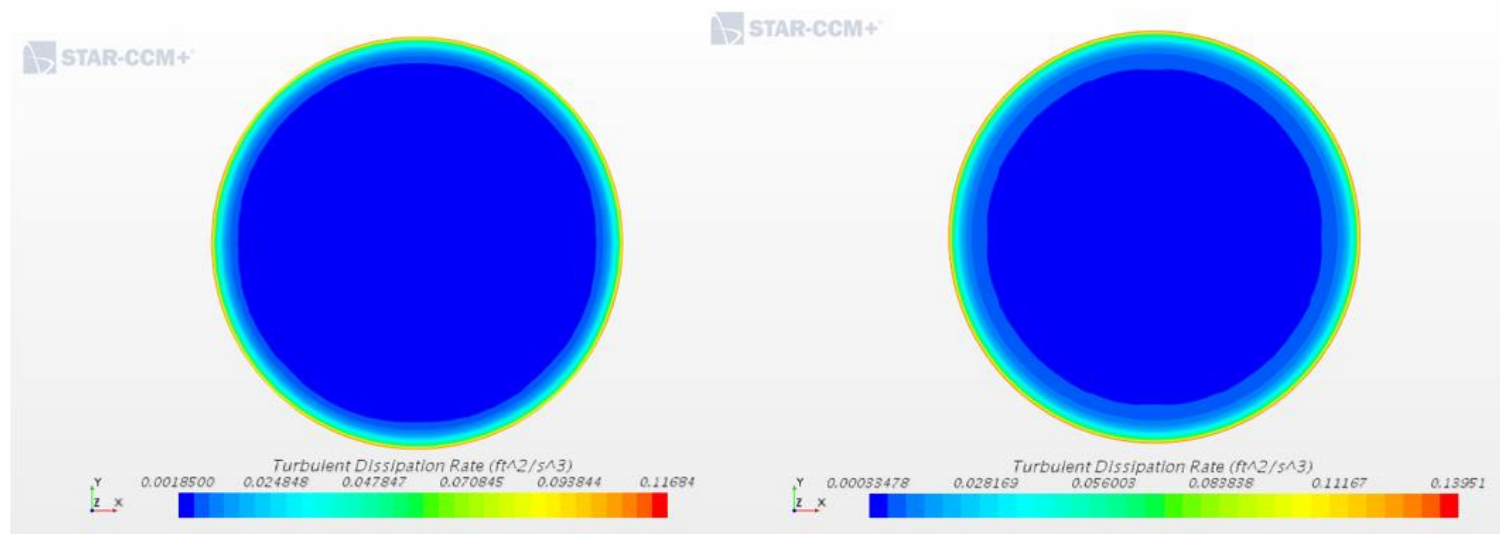

Figure 41. $1 \mathrm{ft} / \mathrm{s}$ TDR at 5D with and without Flow Conditioner 


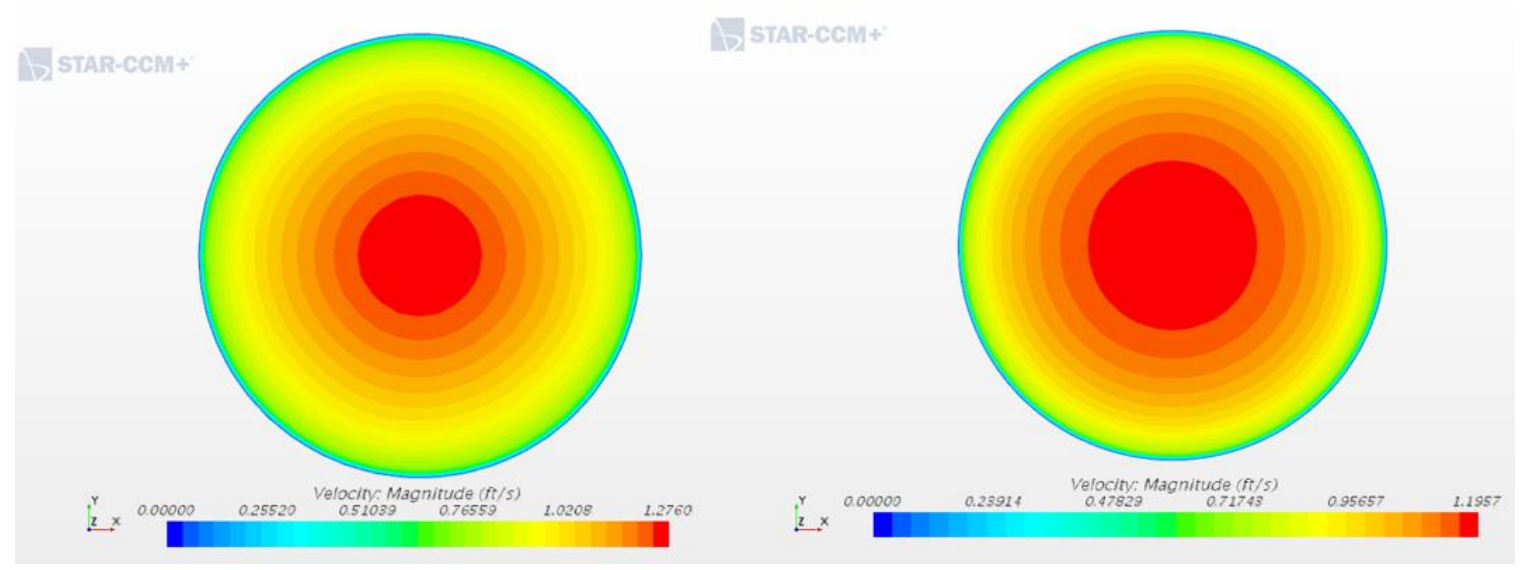

Figure 42. $1 \mathrm{ft} / \mathrm{s}$ Velocity at 10.4D with and without Flow Conditioner
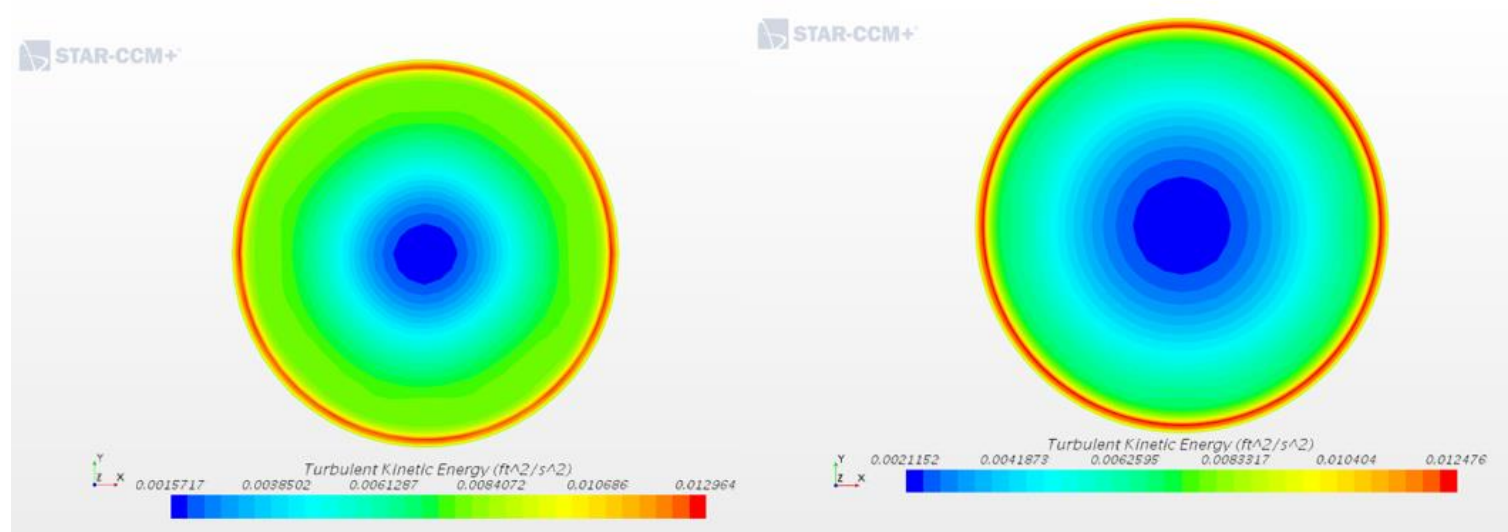

Figure 43. $1 \mathrm{ft} / \mathrm{s}$ TKE at 10.4D with and without Flow Conditioner
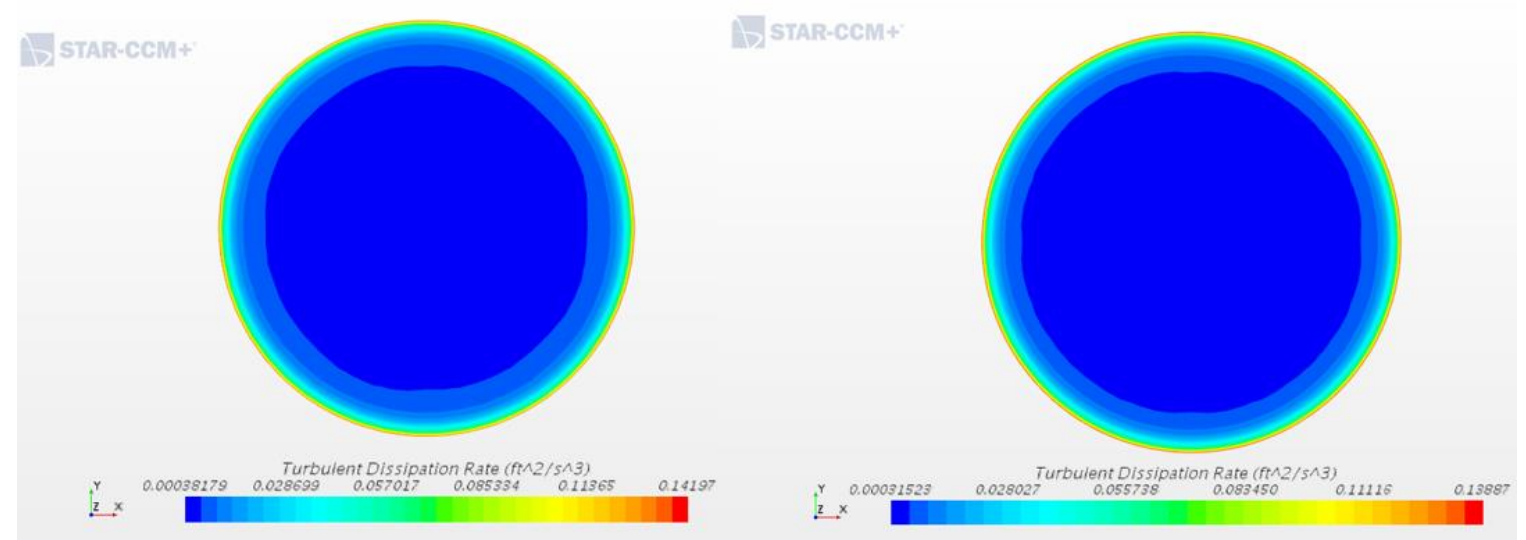

Figure 44. $1 \mathrm{ft} / \mathrm{s}$ TDR at 10.4D with and without Flow Conditioner 


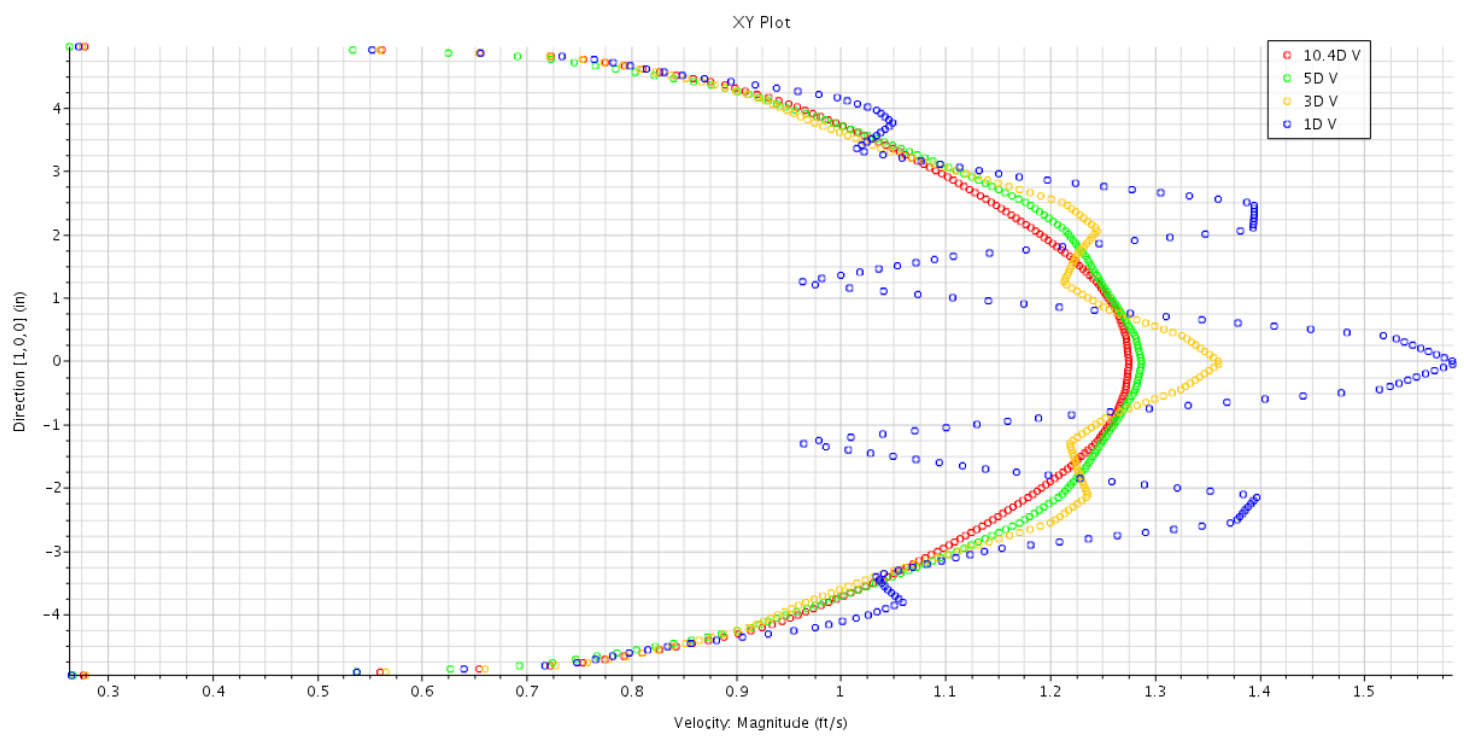

Figure 45. $1 \mathrm{ft} / \mathrm{s}$ Velocity Profiles with Flow Conditioner

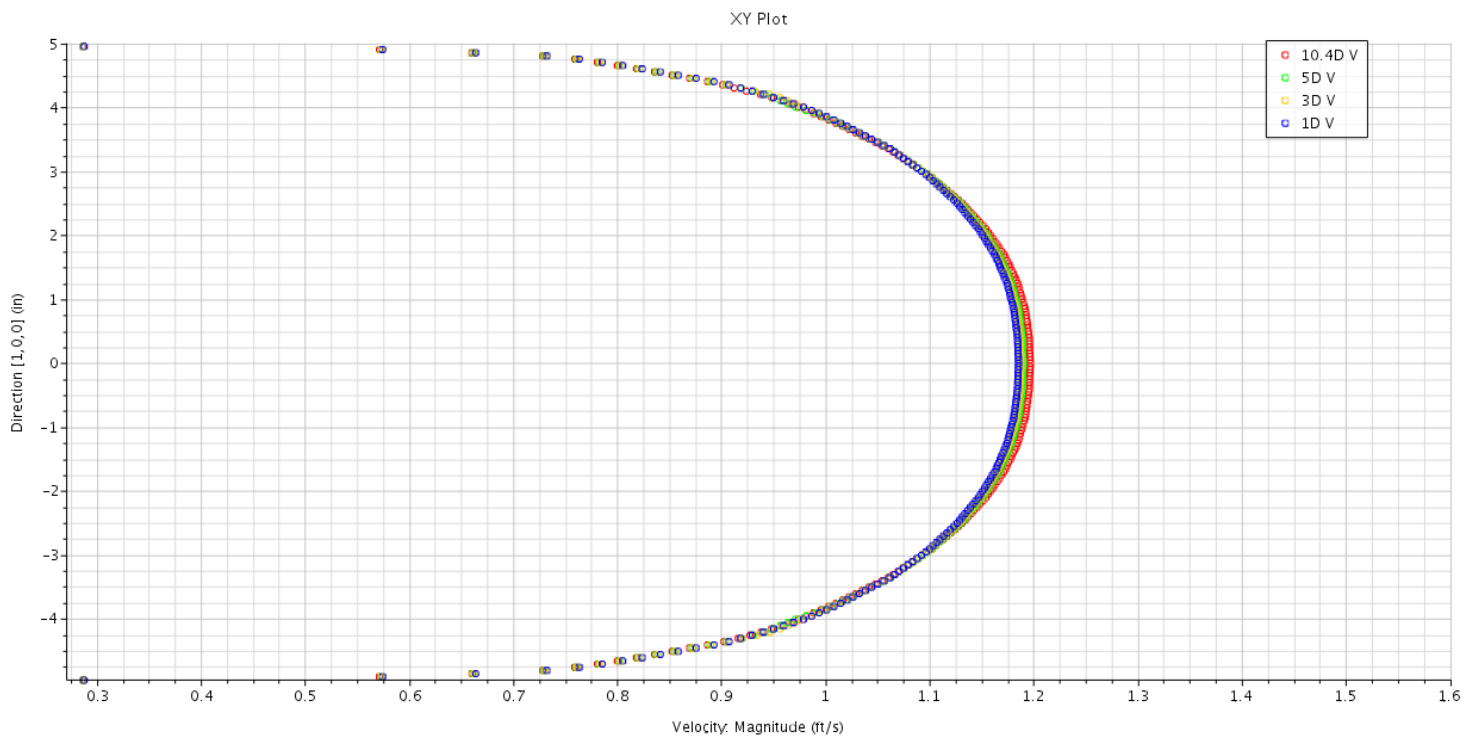

Figure 46. $1 \mathrm{ft} / \mathrm{s}$ Velocity Profiles without Flow Conditioner 


\section{3 ft/s CFD Simulation Results}

Table 8. CFD Results for $3 \mathrm{ft} / \mathrm{s}$ with Flow Conditioner

\begin{tabular}{|c|c|c|c|c|c|c|}
\hline \multicolumn{7}{|c|}{ With Flow Conditioner } \\
\hline $\begin{array}{c}\text { Distance } \\
\text { Between } \\
\text { Flow } \\
\text { Conditioner } \\
\text { and Cross } \\
\text { Section } \\
\end{array}$ & $\begin{array}{c}\text { Average } \\
\text { Velocity } \\
\text { (ft/s) }\end{array}$ & $\begin{array}{c}\text { Max } \\
\text { Velocity } \\
(\mathrm{ft} / \mathrm{s})\end{array}$ & $\begin{array}{c}\text { Average } \\
\text { TKE } \\
\left(\mathrm{ft}^{\wedge} 2 / \mathrm{s}^{\wedge} 2\right)\end{array}$ & $\begin{array}{c}\text { Max } \\
\text { TKE } \\
\left(\mathrm{ft}^{\wedge} 2 / \mathrm{s}^{\wedge} 2\right)\end{array}$ & $\begin{array}{c}\text { Average } \\
\text { TDR } \\
\left(\mathrm{ft}^{\wedge} 2 / \mathrm{s}^{\wedge} 3\right)\end{array}$ & $\begin{array}{c}\mathrm{Max} \\
\mathrm{TDR} \\
\left(\mathrm{ft}^{\wedge} 2 / \mathrm{s}^{\wedge} 3\right)\end{array}$ \\
\hline $1 \mathrm{D}$ & 3.01 & 4.62 & 0.16 & 0.28 & 0.95 & 4.57 \\
\hline $3 \mathrm{D}$ & 3.01 & 3.81 & 0.06 & 0.08 & 0.22 & 2.34 \\
\hline $5 \mathrm{D}$ & 3.01 & 3.71 & 0.04 & 0.09 & 0.17 & 2.13 \\
\hline $10.4 \mathrm{D}$ & 3.01 & 3.69 & 0.04 & 0.09 & 0.17 & 2.28 \\
\hline
\end{tabular}

Table 9. CFD Results for $3 \mathrm{ft} / \mathrm{s}$ without Flow Conditioner

\begin{tabular}{|c|c|c|c|c|c|c|}
\hline \multicolumn{7}{|c|}{ Without Flow Conditioner } \\
\hline $\begin{array}{l}\text { Distance } \\
\text { Between } \\
\text { Flow } \\
\text { Conditioner } \\
\text { and Cross } \\
\text { Section } \\
\end{array}$ & $\begin{array}{c}\text { Average } \\
\text { Velocity } \\
(\mathrm{ft} / \mathrm{s})\end{array}$ & $\begin{array}{c}\text { Max } \\
\text { Velocity } \\
\text { (ft/s) }\end{array}$ & $\begin{array}{c}\text { Average } \\
\text { TKE } \\
\left(\mathrm{ft}^{\wedge} 2 / \mathrm{s}^{\wedge} 2\right)\end{array}$ & $\begin{array}{c}\text { Max } \\
\text { TKE } \\
\left(\mathrm{ft}^{\wedge} 2 / \mathrm{s}^{\wedge} 2\right)\end{array}$ & $\begin{array}{c}\text { Average } \\
\text { TDR } \\
\left(\mathrm{ft}^{\wedge} 2 / \mathrm{s}^{\wedge} 3\right)\end{array}$ & $\begin{array}{c}\operatorname{Max} \\
\text { TDR } \\
\left(\mathrm{ft}^{\wedge} 2 / \mathrm{s}^{\wedge} 3\right)\end{array}$ \\
\hline 1D & 3.00 & 3.47 & 0.04 & 0.08 & 0.16 & 2.25 \\
\hline $3 \mathrm{D}$ & 3.00 & 3.47 & 0.04 & 0.08 & 0.16 & 2.23 \\
\hline $5 \mathrm{D}$ & 3.00 & 3.48 & 0.04 & 0.08 & 0.16 & 2.23 \\
\hline $10.4 \mathrm{D}$ & 3.00 & 3.49 & 0.04 & 0.08 & 0.16 & 2.23 \\
\hline
\end{tabular}



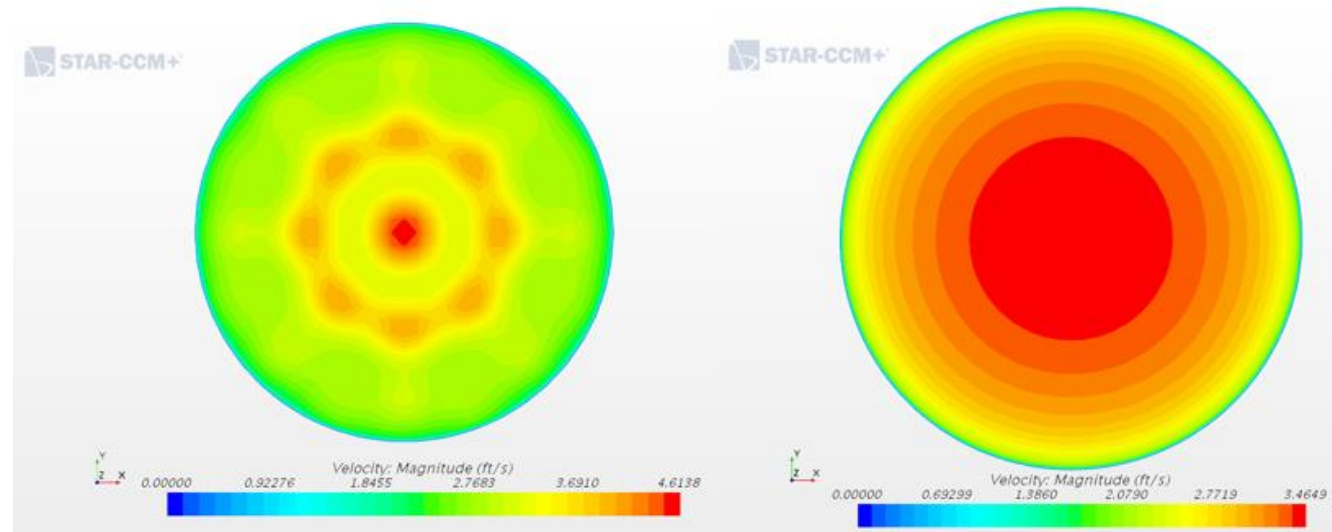

Figure 47. $3 \mathrm{ft} / \mathrm{s}$ Velocity at 1D With and Without Flow Conditioner
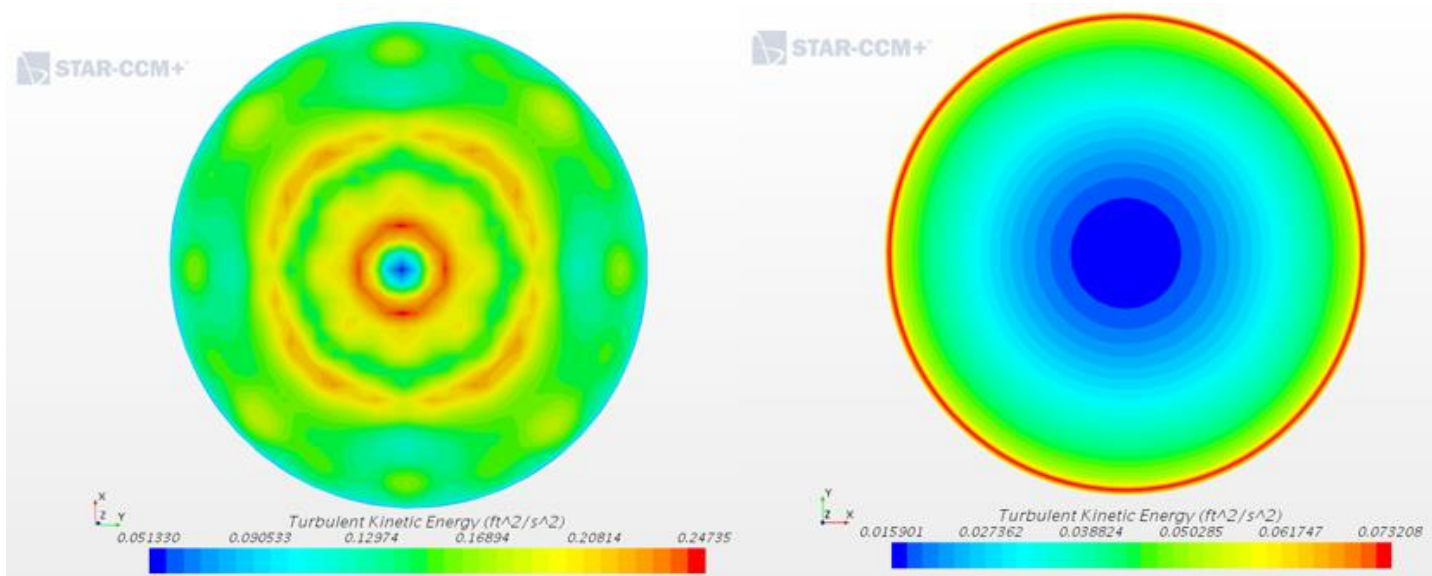

Figure 48. $3 \mathrm{ft} / \mathrm{s}$ TKE at 1D With and Without Flow Conditioner
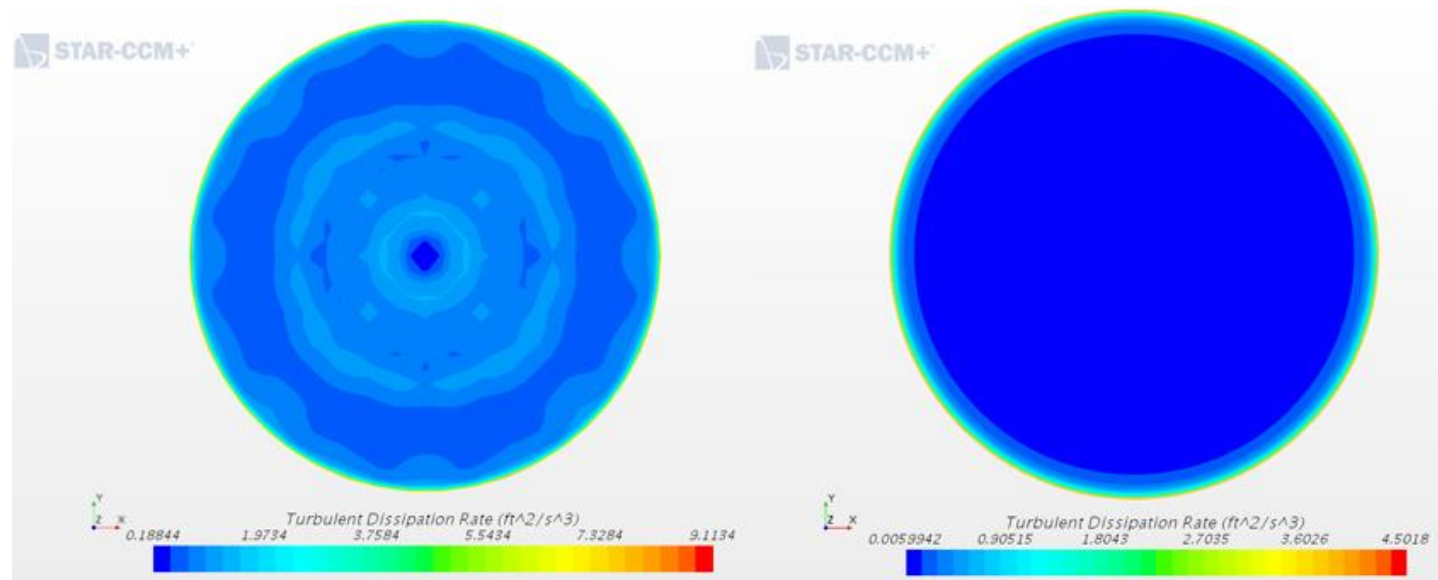

Figure 49. $3 \mathrm{ft} / \mathrm{s}$ TDR at 1D With and Without Flow Conditioner 

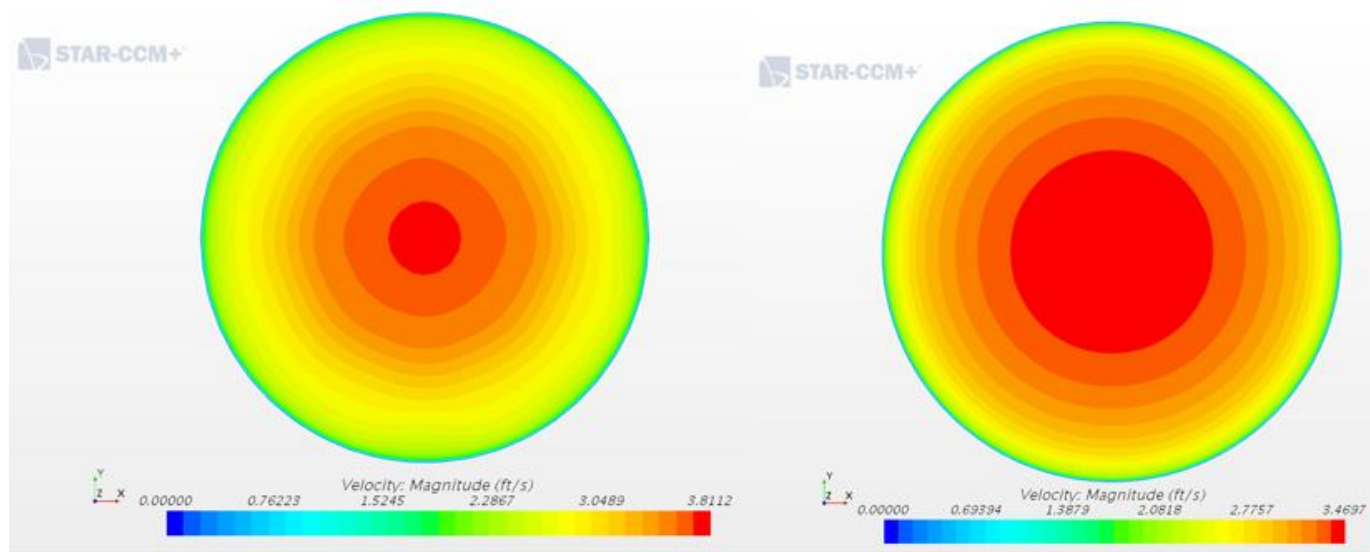

Figure 50. $3 \mathrm{ft} / \mathrm{s}$ Velocity at 3D With and Without Flow Conditioner
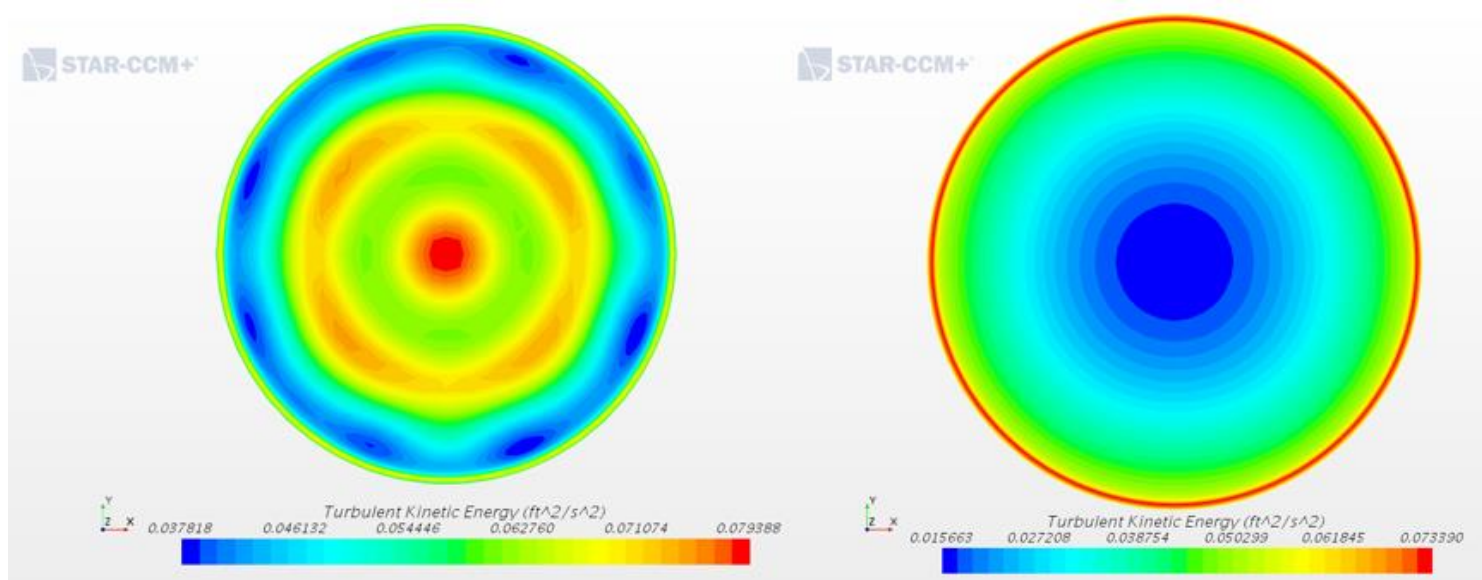

Figure 51. $3 \mathrm{ft} / \mathrm{s}$ TKE at 3D With and Without Flow Conditioner
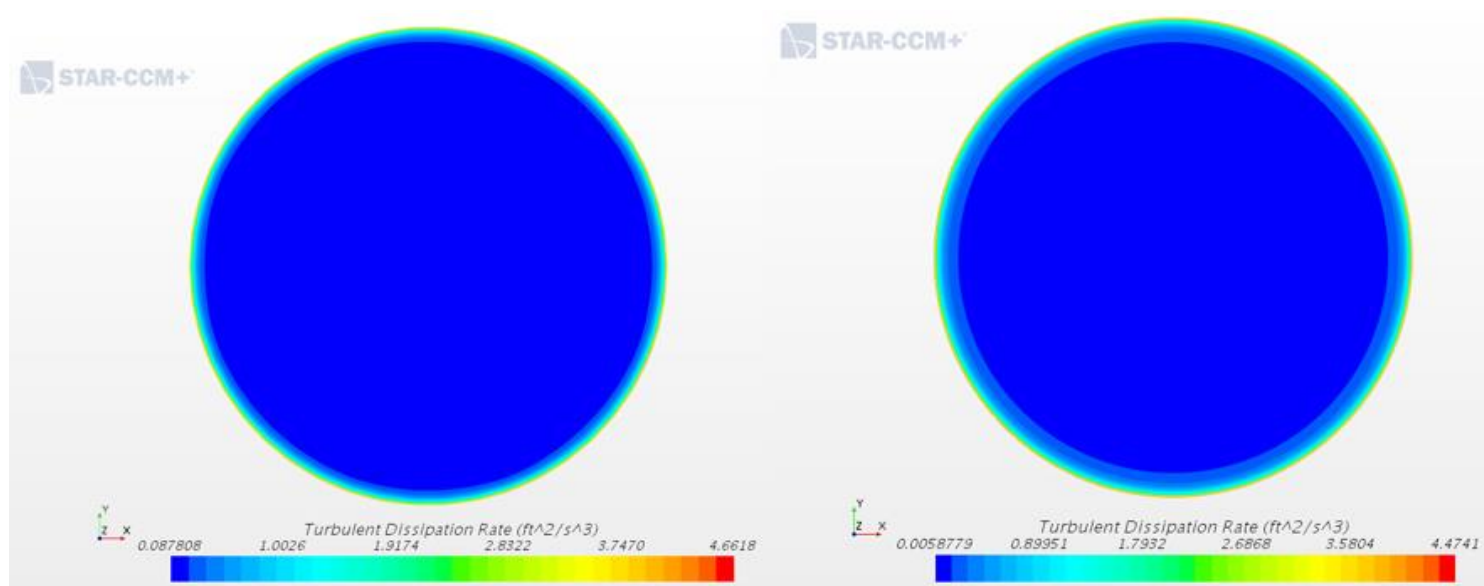

Figure 52. $3 \mathrm{ft} / \mathrm{s}$ TDR at 3D With and Without Flow Conditioner 

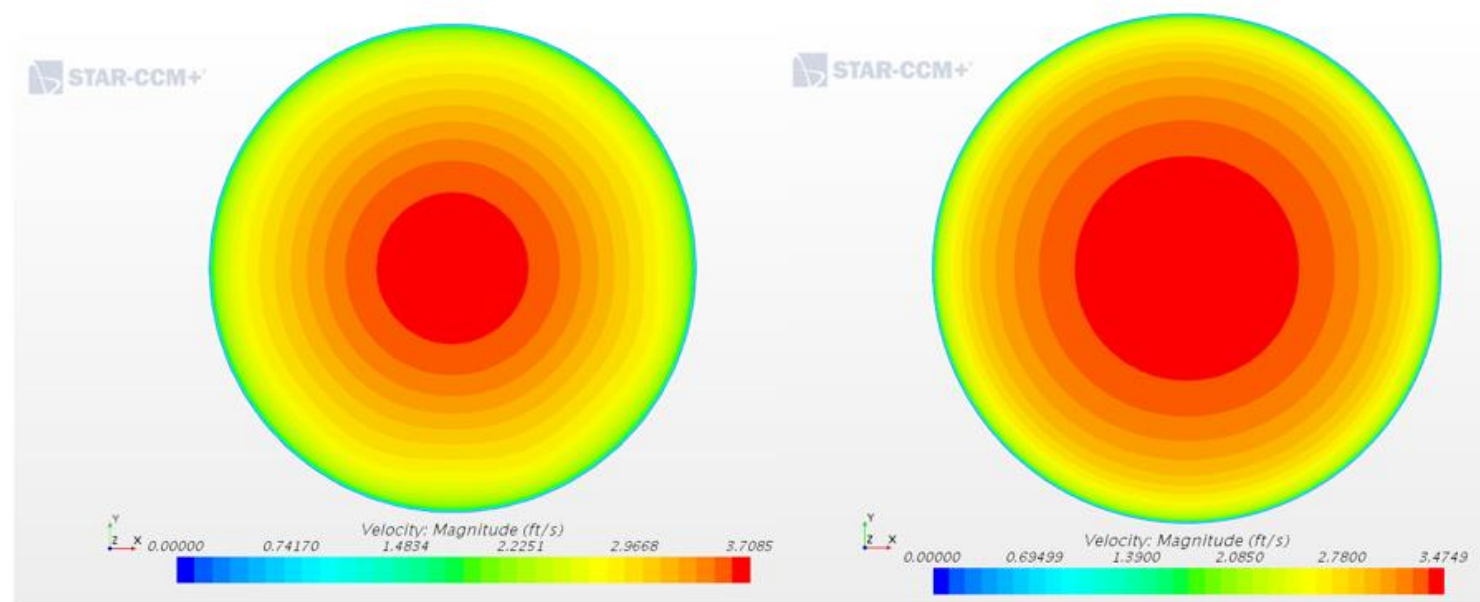

Figure 53. $3 \mathrm{ft} / \mathrm{s}$ Velocity at 5D With and Without Flow Conditioner
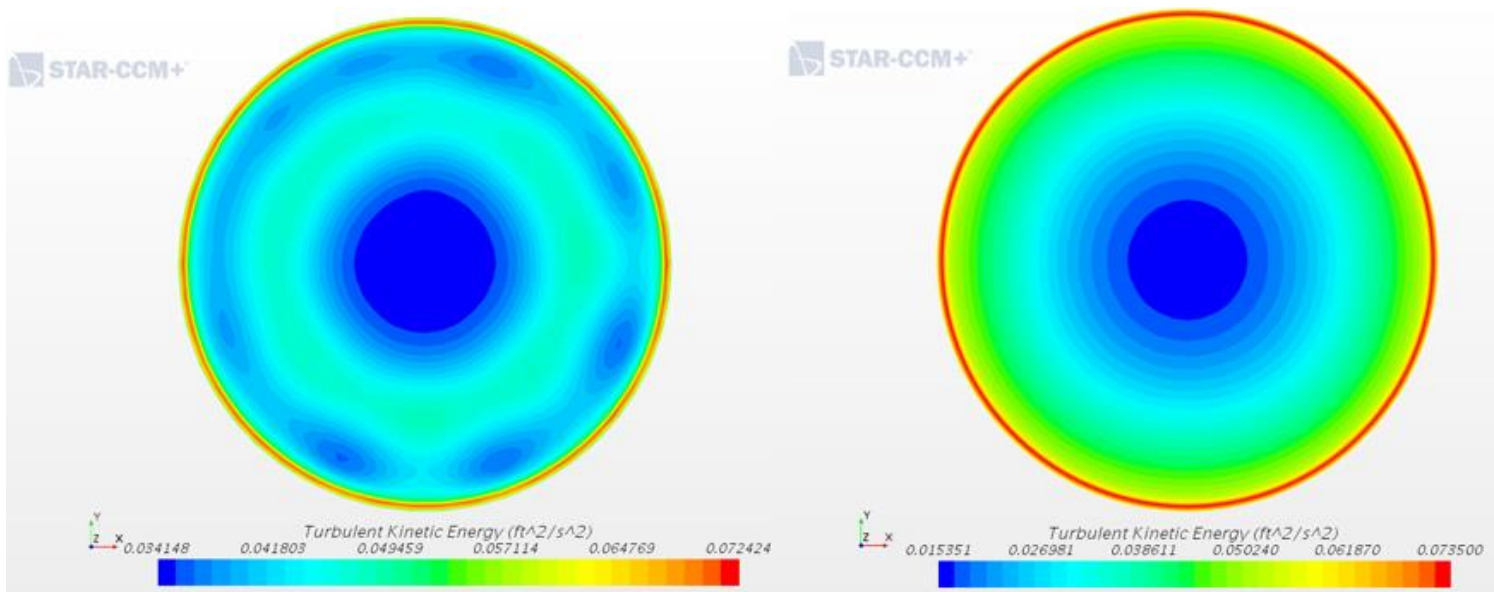

Figure 54. $3 \mathrm{ft} / \mathrm{s}$ TKE at 5D With and Without Flow Conditioner
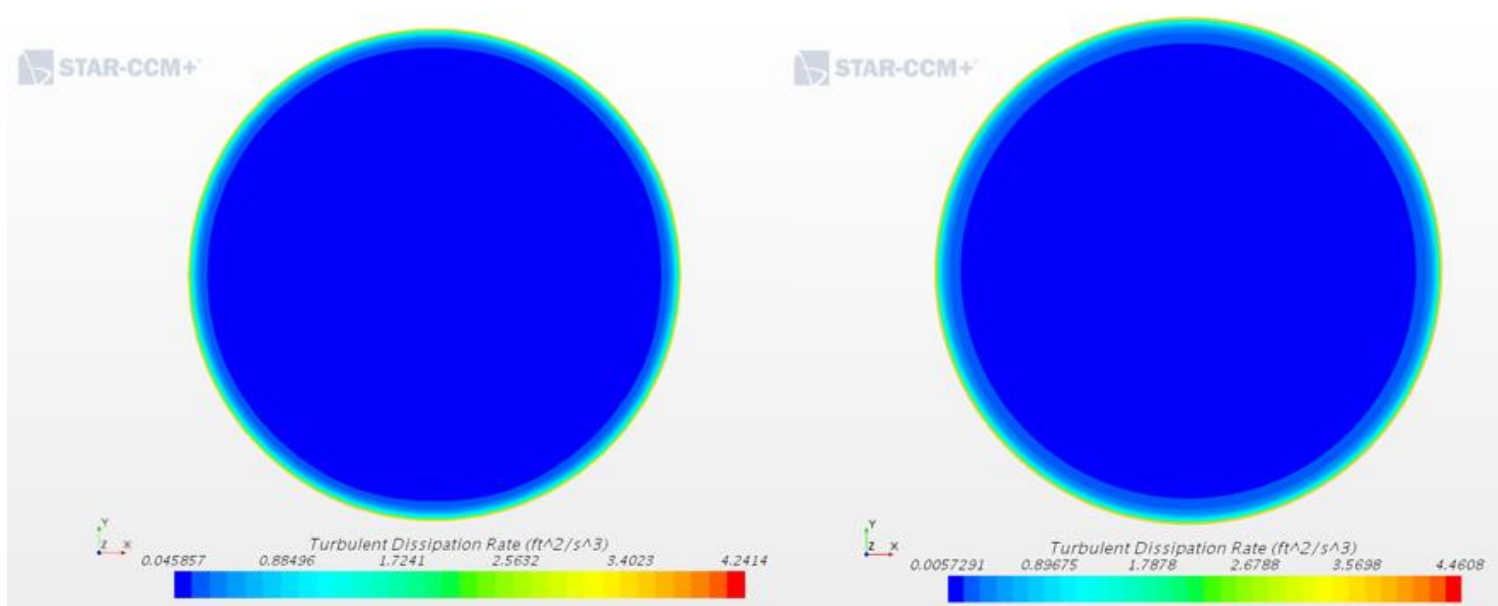

Figure 55. $3 \mathrm{ft} / \mathrm{s}$ TDR at 5D With and Without Flow Conditioner 

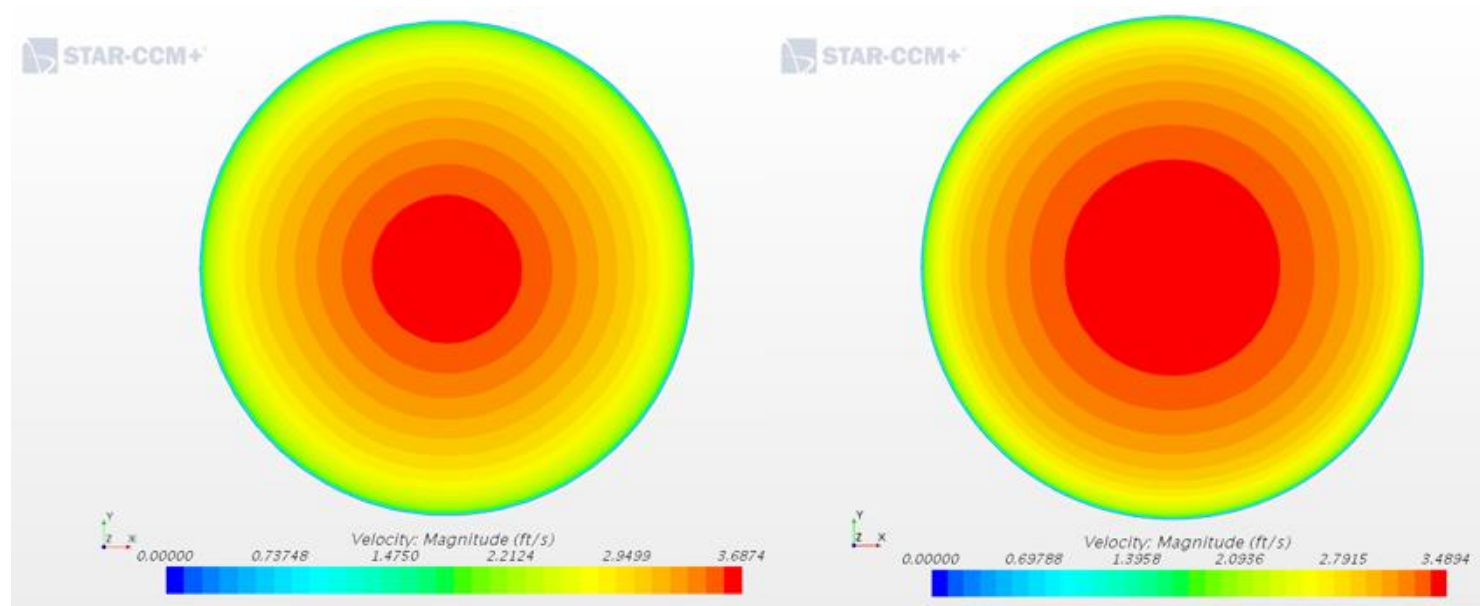

Figure 56. $3 \mathrm{ft} / \mathrm{s}$ Velocity at 10.4D With and Without Flow Conditioner
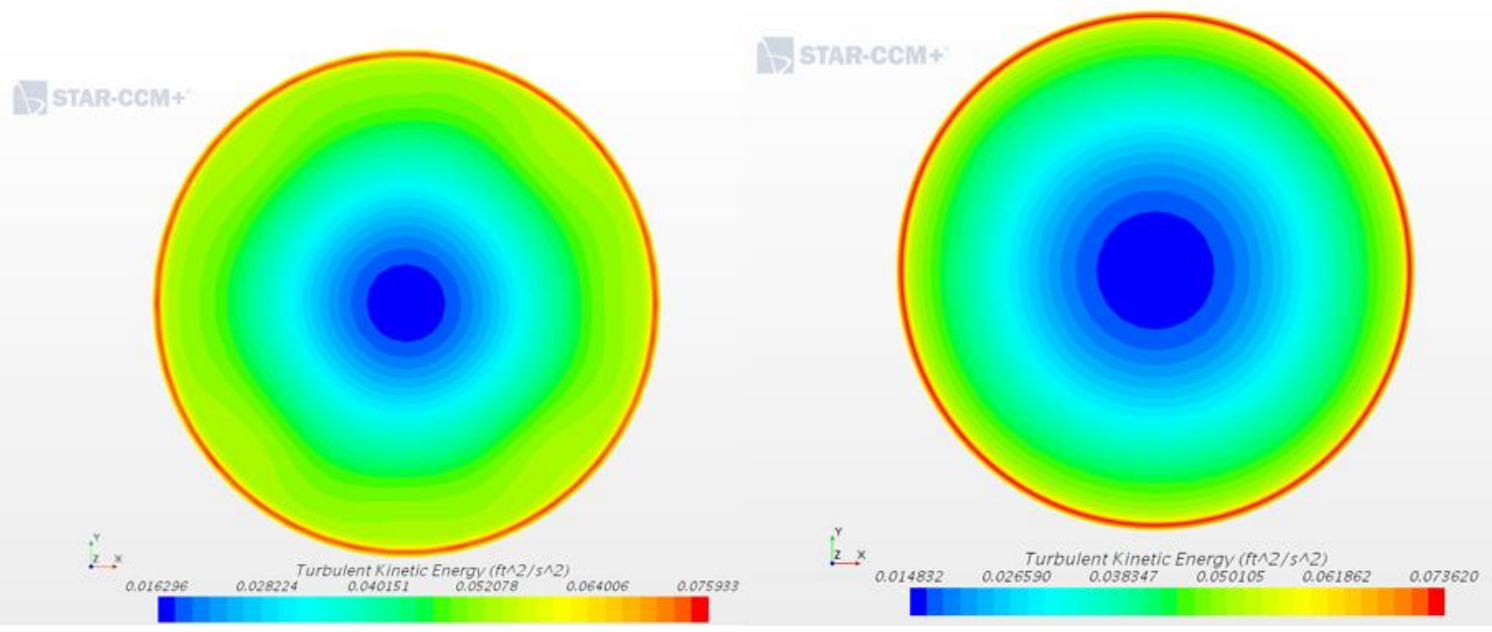

Figure 57. $3 \mathrm{ft} / \mathrm{s}$ TKE at 10.4D With and Without Flow Conditioner
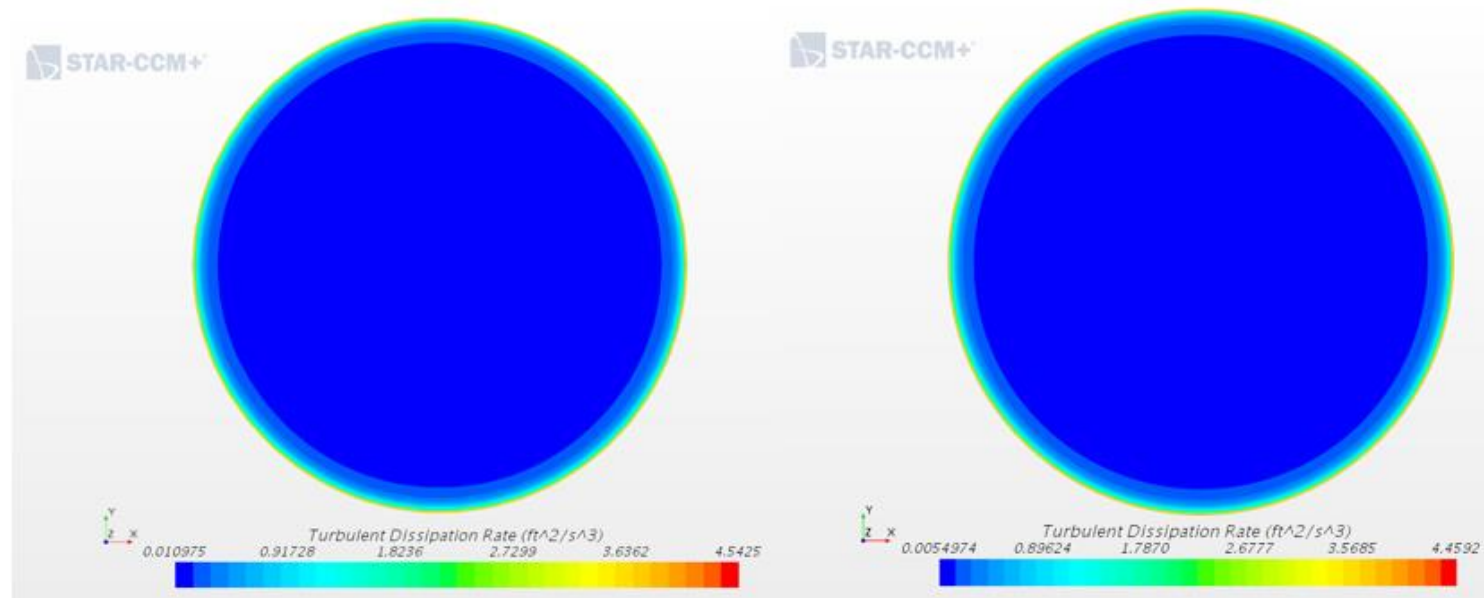

Figure 58. $3 \mathrm{ft} / \mathrm{s}$ TDR at 10.4D With and Without Flow Conditioner 


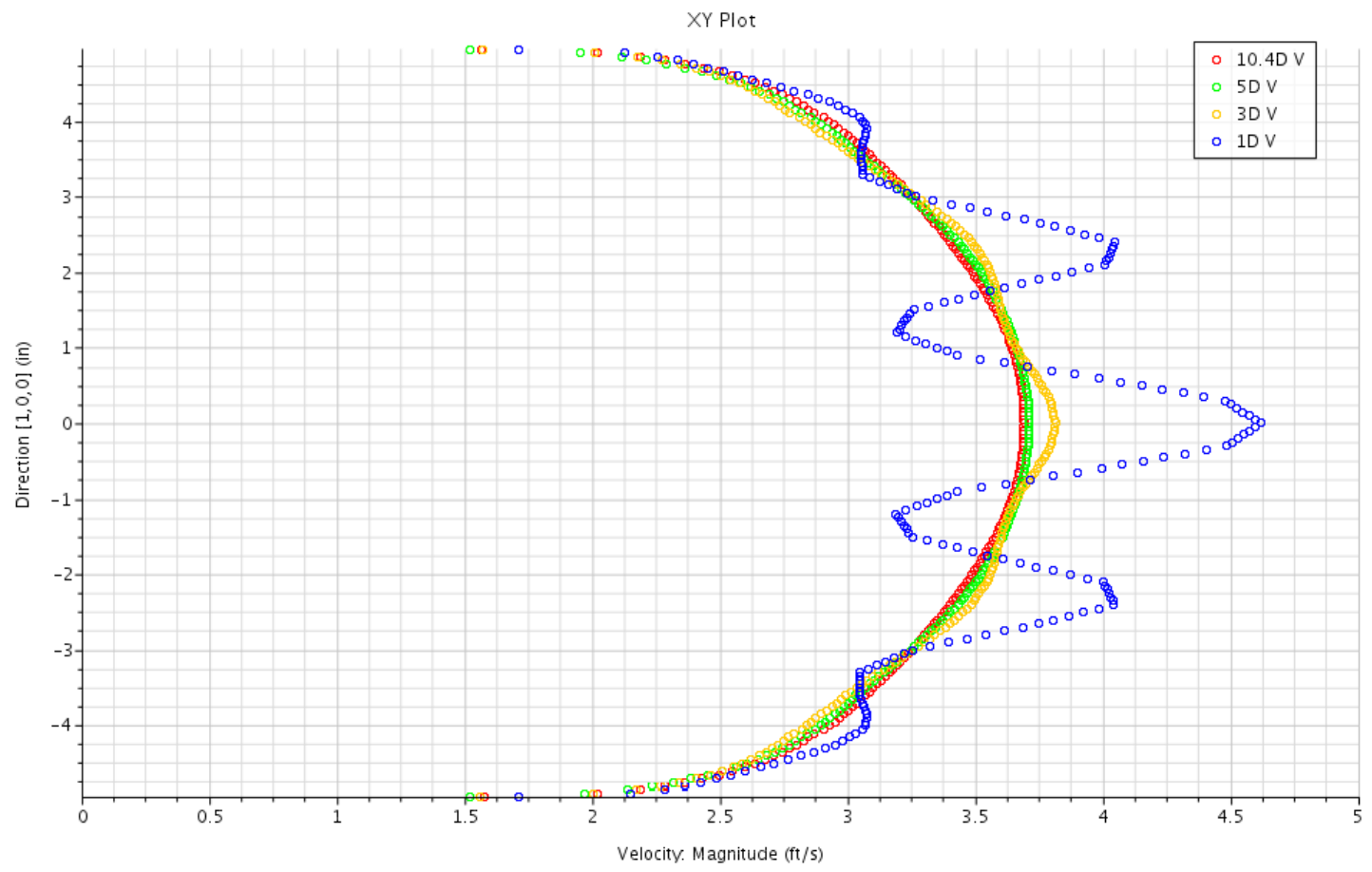

Figure 59. $3 \mathrm{ft} / \mathrm{s}$ Velocity Profiles with Flow Conditioner

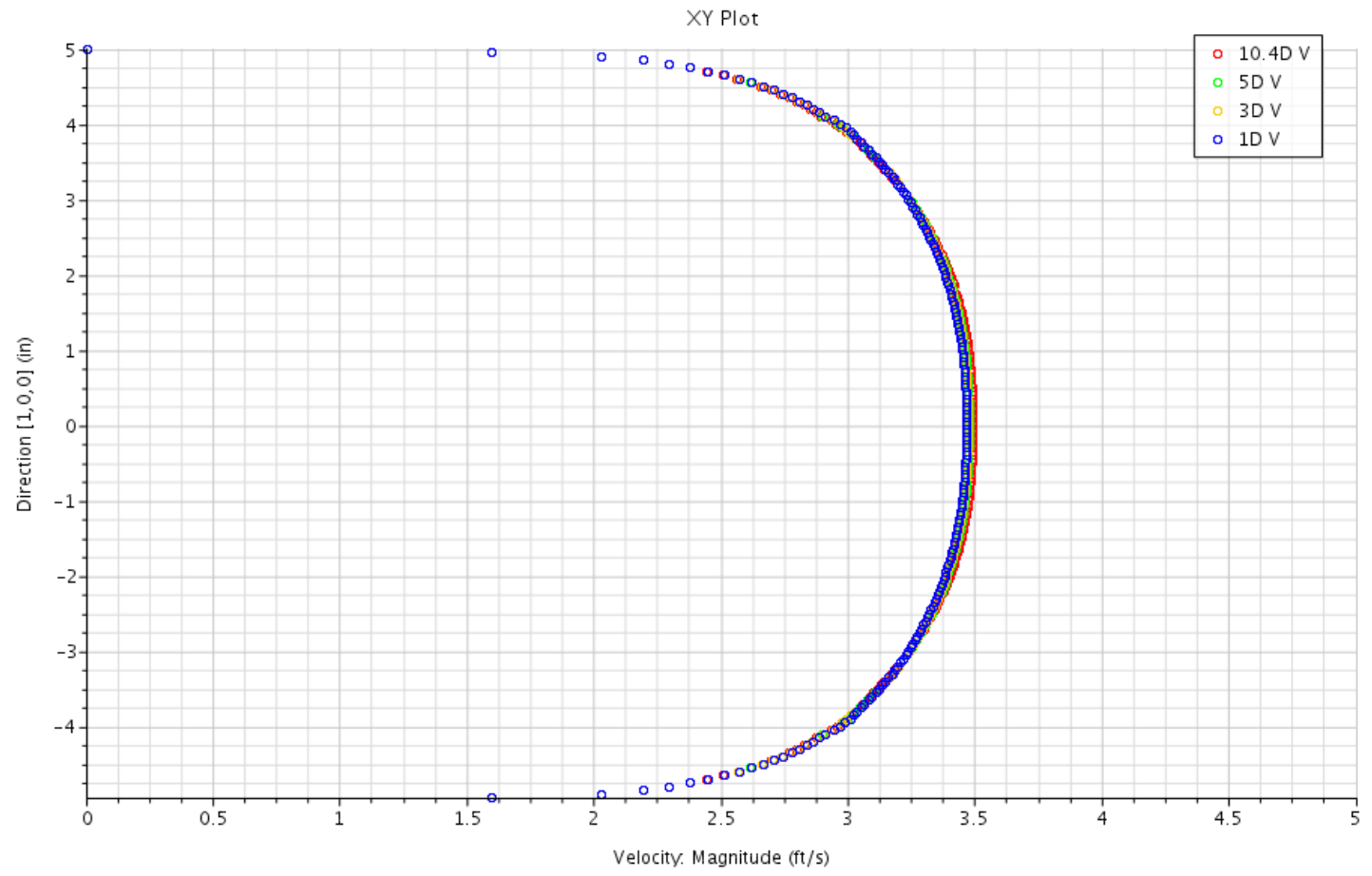

Figure 60. $3 \mathrm{ft} / \mathrm{s}$ Velocity Profiles without Flow Conditioner 
$5 \mathrm{ft} / \mathrm{s}$ CFD Simulation Results

Table 10. CFD Results for $5 \mathrm{ft} / \mathrm{s}$ with Flow Conditioner

\begin{tabular}{|c|c|c|c|c|c|c|}
\hline \multicolumn{7}{|c|}{ With Flow Conditioner } \\
\hline $\begin{array}{c}\text { Distance } \\
\text { Between Flow } \\
\text { Conditioner } \\
\text { and Cross } \\
\text { Section }\end{array}$ & $\begin{array}{c}\text { Average } \\
\text { Velocity } \\
(\mathrm{ft} / \mathrm{s})\end{array}$ & $\begin{array}{c}\text { Max } \\
\text { Velocity } \\
(\mathrm{ft} / \mathrm{s})\end{array}$ & $\begin{array}{c}\text { Average } \\
\text { TKE } \\
\left(\mathrm{ft}^{\wedge} 2 / \mathrm{s}^{\wedge} 2\right)\end{array}$ & $\begin{array}{c}\text { Max } \\
\text { TKE } \\
\left(\mathrm{ft}^{\wedge} 2 / \mathrm{s}^{\wedge} 2\right)\end{array}$ & $\begin{array}{c}\text { Average } \\
\text { TDR } \\
\left(\mathrm{ft}^{\wedge} 2 / \mathrm{s}^{\wedge} 3\right)\end{array}$ & $\begin{array}{c}\text { Max } \\
\text { TDR } \\
\left(\mathrm{ft}^{\wedge} 2 / \mathrm{s}^{\wedge} 3\right)\end{array}$ \\
\hline $1 \mathrm{D}$ & 5.01 & 7.65 & 0.44 & 0.72 & 4.16 & 20.33 \\
\hline $3 \mathrm{D}$ & 5.01 & 6.34 & 0.16 & 0.21 & 1.00 & 10.87 \\
\hline $5 \mathrm{D}$ & 5.01 & 6.18 & 0.12 & 0.18 & 0.76 & 10.21 \\
\hline $10.4 \mathrm{D}$ & 5.01 & 6.13 & 0.14 & 0.24 & 0.86 & 11.11 \\
\hline
\end{tabular}

Table 11. CFD Results for $5 \mathrm{ft} / \mathrm{s}$ without Flow Conditioner

\begin{tabular}{|cccccccc|}
\hline \multicolumn{7}{|c|}{ Without Flow Conditioner } \\
\hline $\begin{array}{c}\text { Distance } \\
\text { Between Flow } \\
\text { Conditioner } \\
\text { and Cross } \\
\text { Section }\end{array}$ & $\begin{array}{c}\text { Average } \\
\text { Velocity } \\
(\mathrm{ft} / \mathrm{s})\end{array}$ & $\begin{array}{c}\text { Max } \\
\text { Velocity } \\
(\mathrm{ft} / \mathrm{s})\end{array}$ & $\begin{array}{c}\text { Average } \\
\mathrm{TKE} \\
\left(\mathrm{ft} \wedge 2 / \mathrm{s}^{\wedge} 2\right)\end{array}$ & $\begin{array}{c}\text { Max } \\
\mathrm{TKE} \\
\left(\mathrm{ft} \wedge 2 / \mathrm{s}^{\wedge} 2\right)\end{array}$ & $\begin{array}{c}\text { Average } \\
\text { TDR } \\
\left(\mathrm{ft} \wedge 2 / \mathrm{s}^{\wedge} 3\right)\end{array}$ & $\begin{array}{c}\text { Max } \\
\text { TDR } \\
\left(\mathrm{ft} \wedge 2 / \mathrm{s}^{\wedge} 3\right)\end{array}$ \\
\hline 1D & 4.99 & 5.77 & 0.11 & 0.17 & 0.64 & 10.64 \\
\hline 3D & 4.99 & 5.77 & 0.10 & 0.17 & 0.63 & 10.59 \\
\hline 5D & 4.99 & 5.75 & 0.10 & 0.16 & 0.62 & 10.56 \\
\hline 10.4D & 4.99 & 5.73 & 0.10 & 0.16 & 0.61 & 10.67 \\
\hline
\end{tabular}



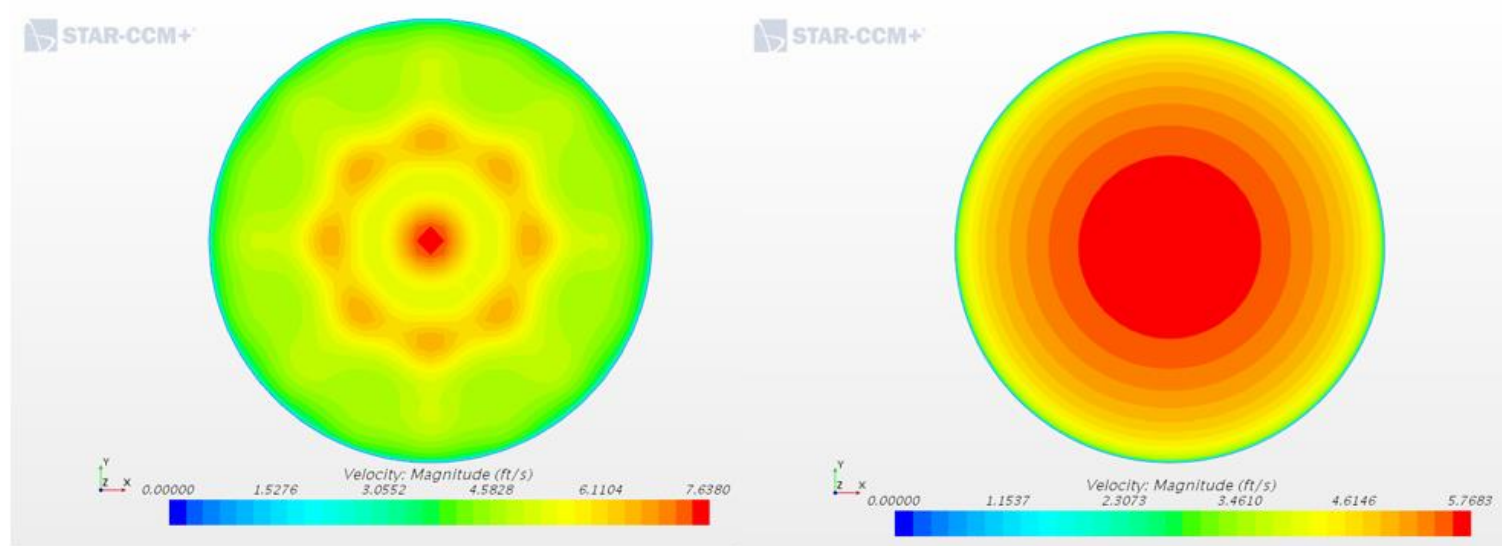

Figure $61.5 \mathrm{ft} / \mathrm{s}$ Velocity at $1 \mathrm{D}$ with and without Flow Conditioner
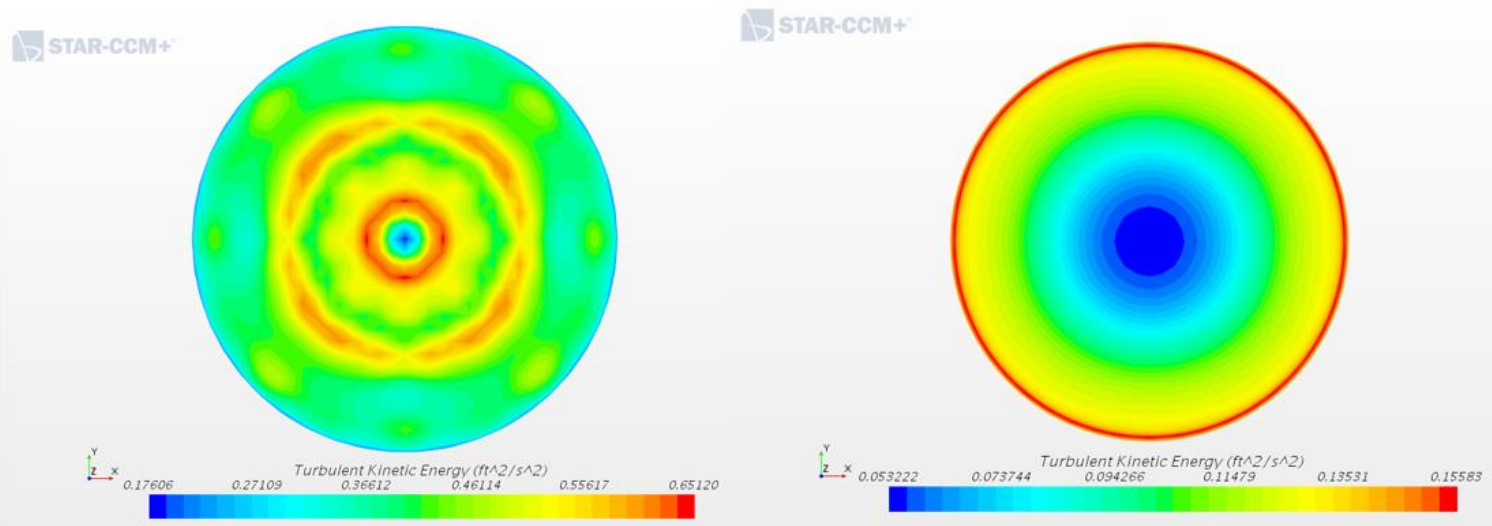

Figure 62. $5 \mathrm{ft} / \mathrm{s}$ TKE at 1D with and without Flow Conditioner
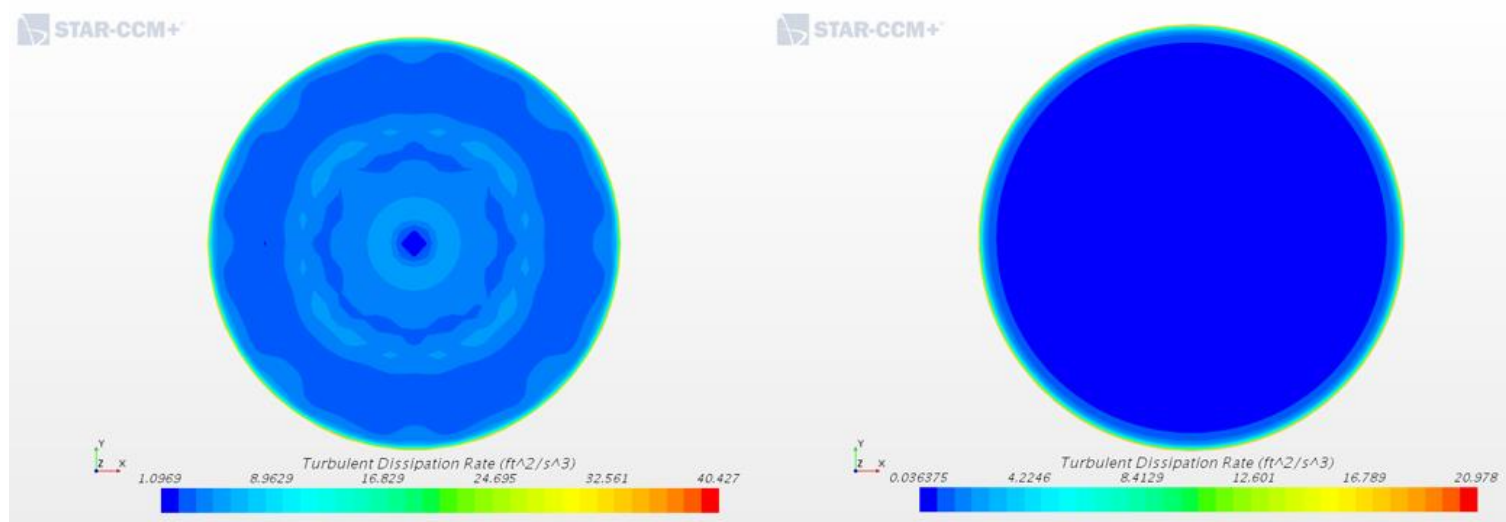

Figure 63. $5 \mathrm{ft} / \mathrm{s}$ TDR at 1D with and without Flow Conditioner 

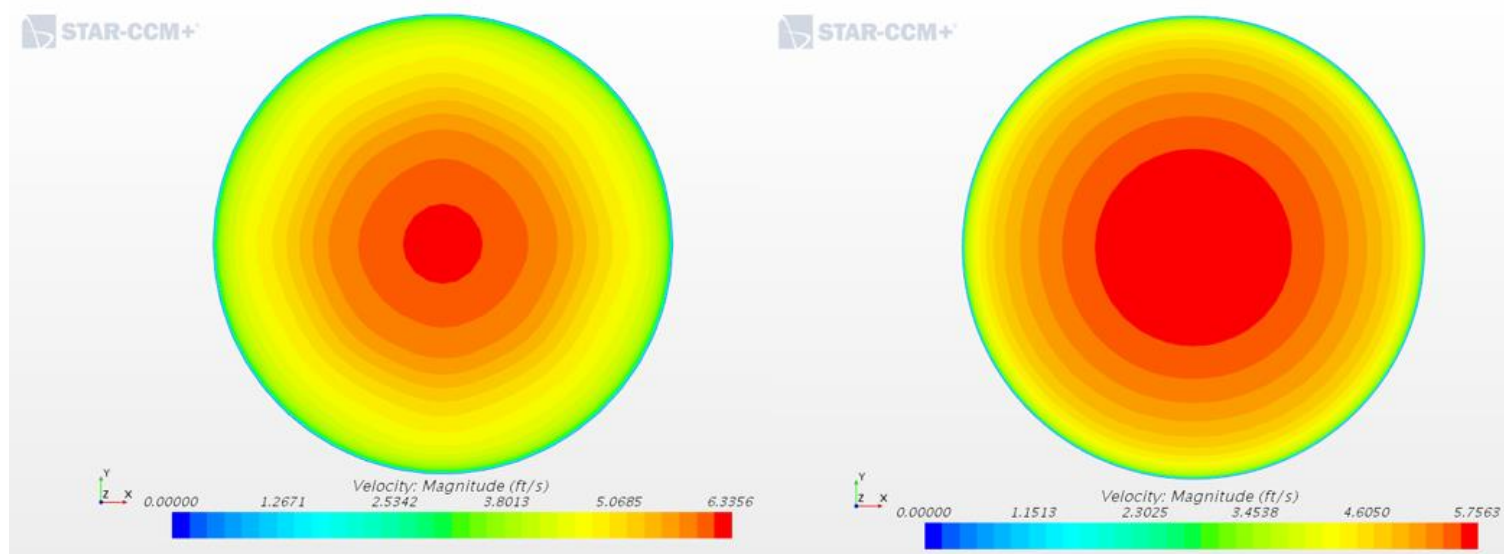

Figure 64. $5 \mathrm{ft} / \mathrm{s}$ Velocity at 3D with and without Flow Conditioner

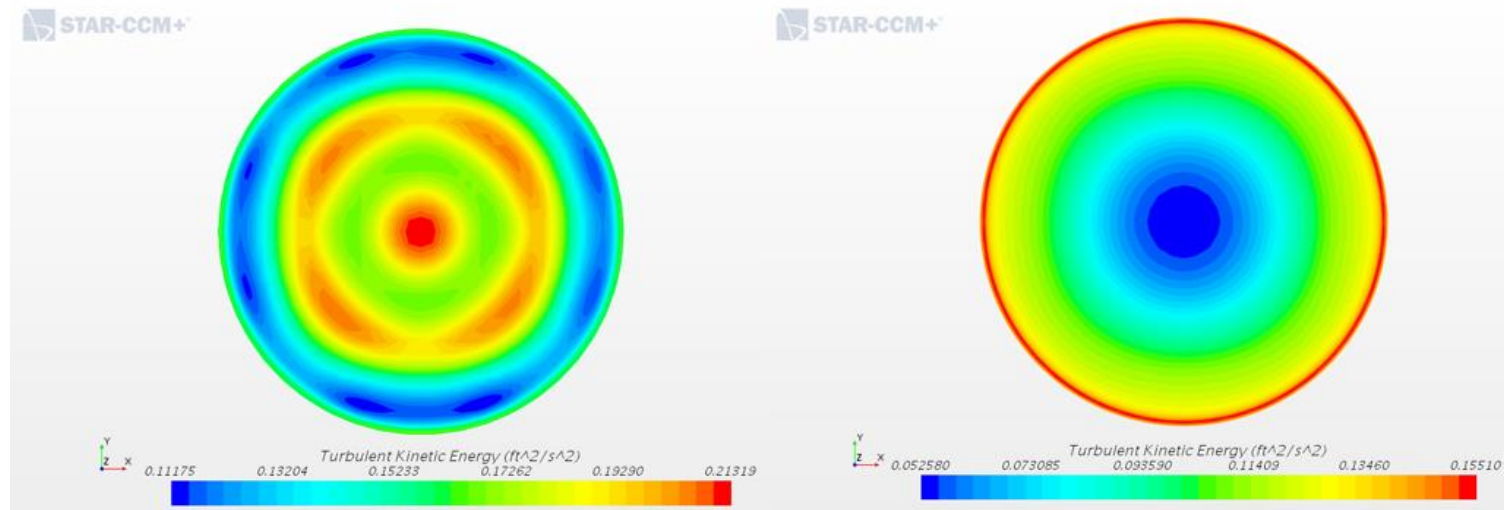

Figure 65. $5 \mathrm{ft} / \mathrm{s}$ TKE at 3D with and without Flow Conditioner

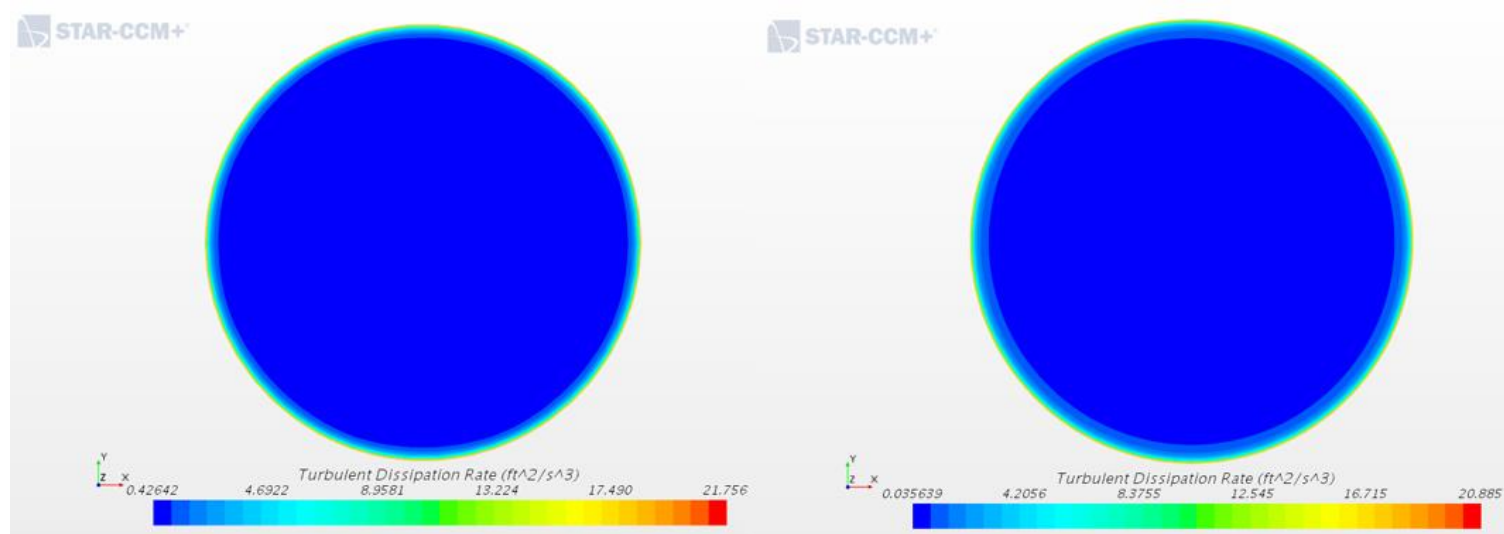

Figure 66. $5 \mathrm{ft} / \mathrm{s}$ TDR at 3D with and without Flow Conditioner 

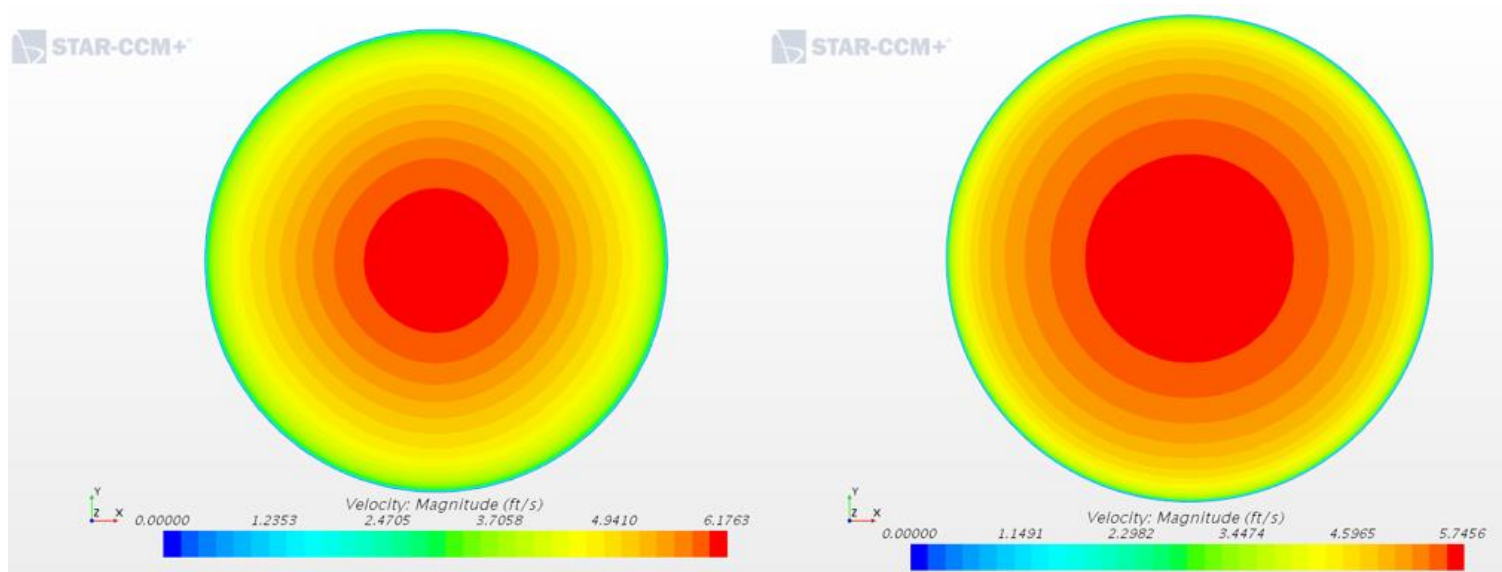

Figure $67.5 \mathrm{ft} / \mathrm{s}$ Velocity at 5D with and without Flow Conditioner
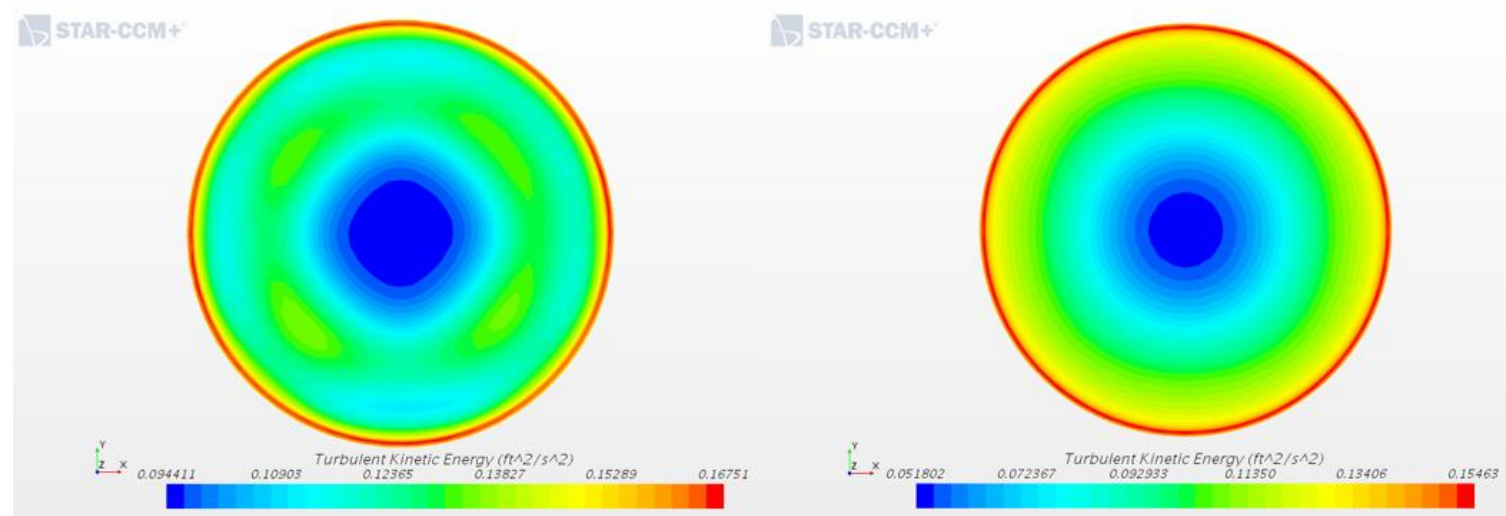

Figure $68.5 \mathrm{ft} / \mathrm{s}$ TKE at 5D with and without Flow Conditioner
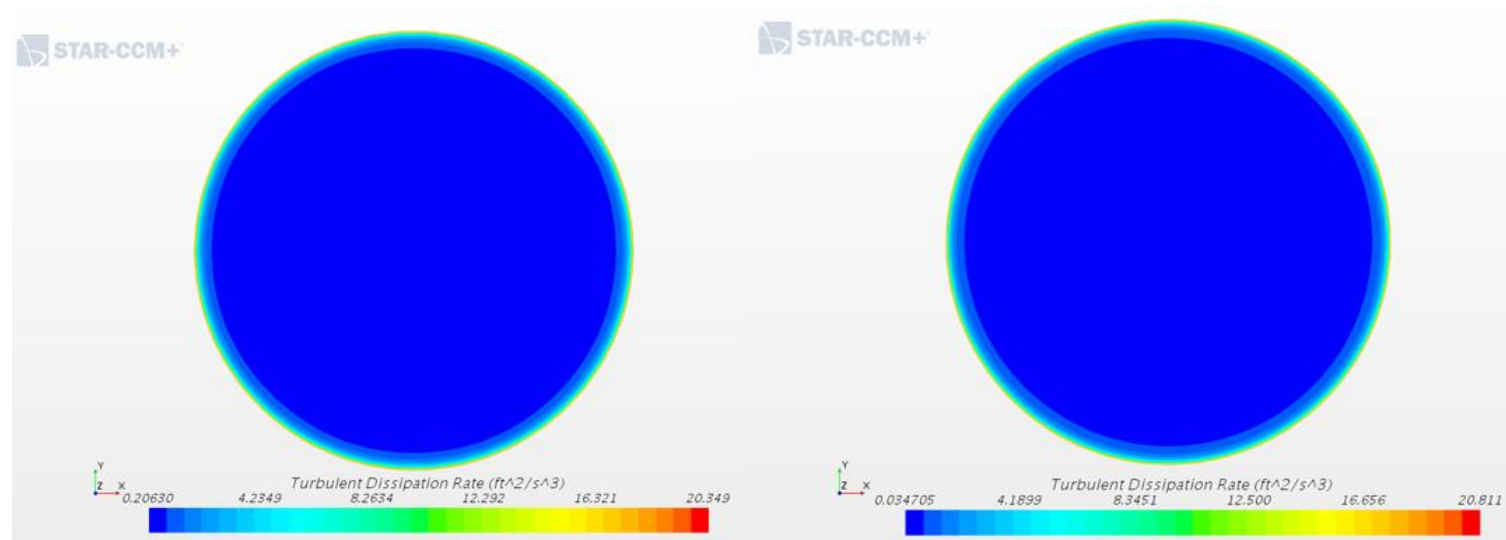

Figure 69. $5 \mathrm{ft} / \mathrm{s}$ TDR at 5D with and without Flow Conditioner 

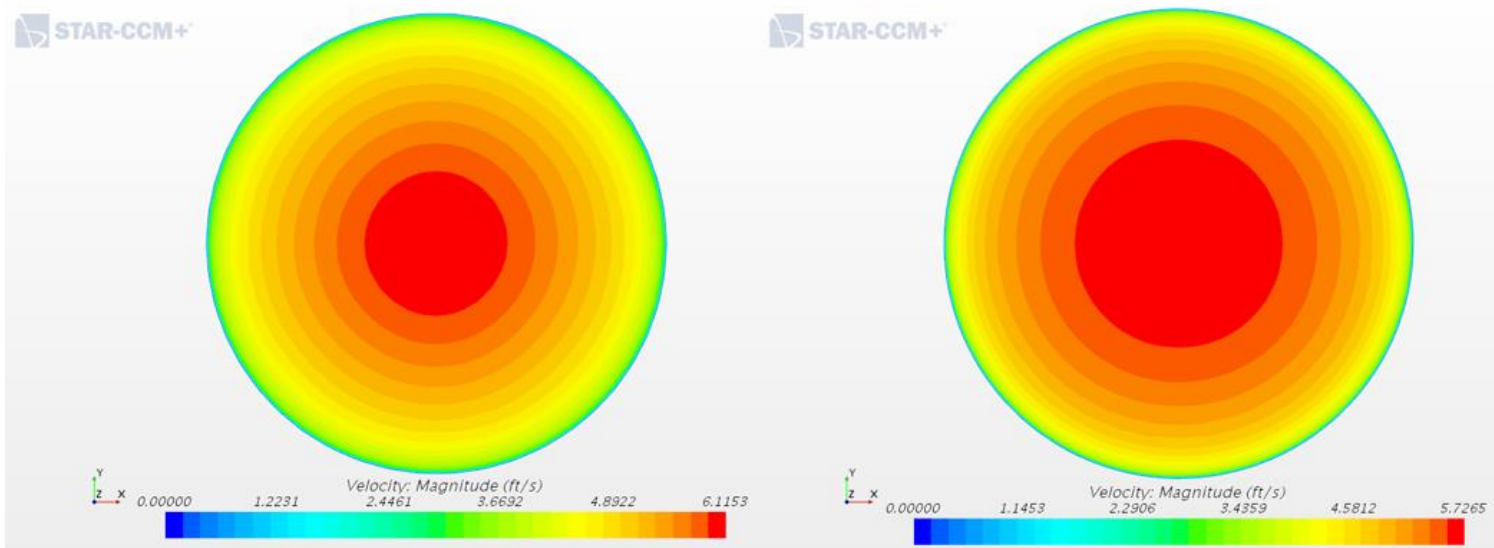

Figure 70. $5 \mathrm{ft} / \mathrm{s}$ Velocity at 10.4D with and without Flow Conditioner
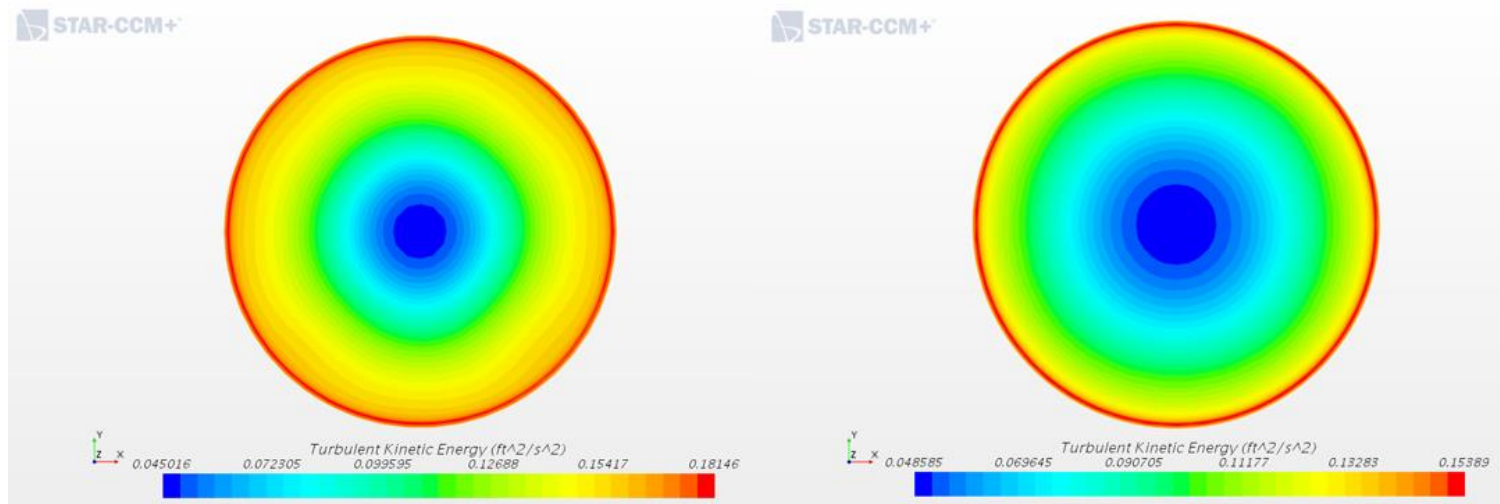

Figure 71. $5 \mathrm{ft} / \mathrm{s}$ TKE at 10.4D with and without Flow Conditioner
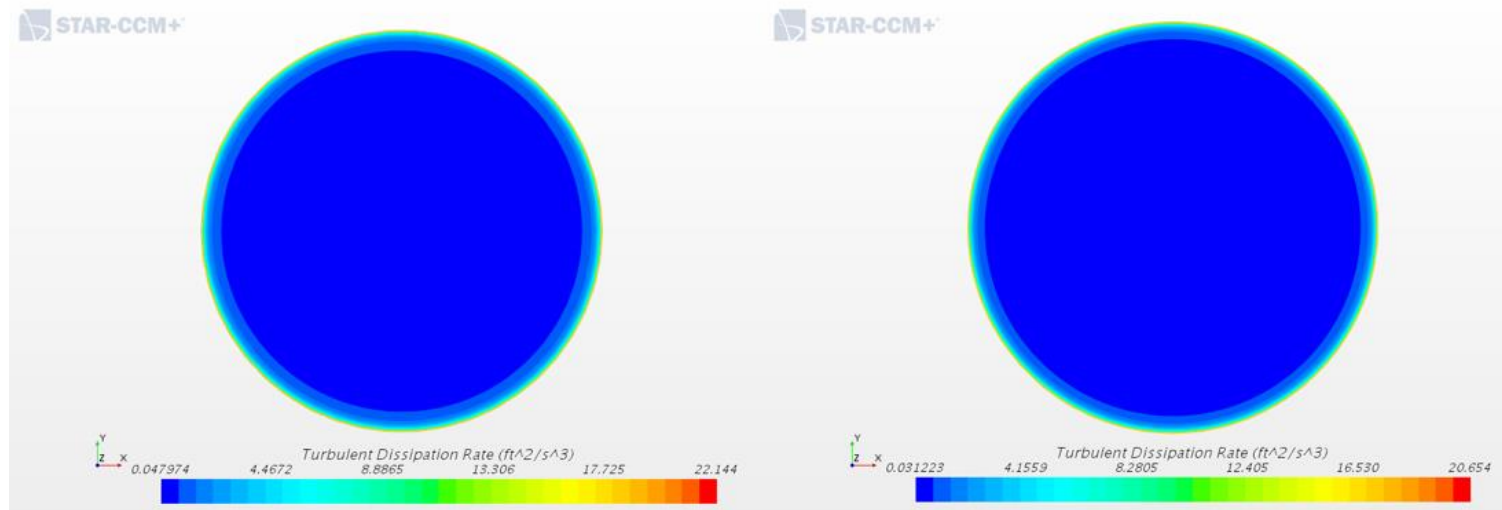

Figure 72. $5 \mathrm{ft} / \mathrm{s}$ TDR at 10.4D with and without Flow Conditioner 


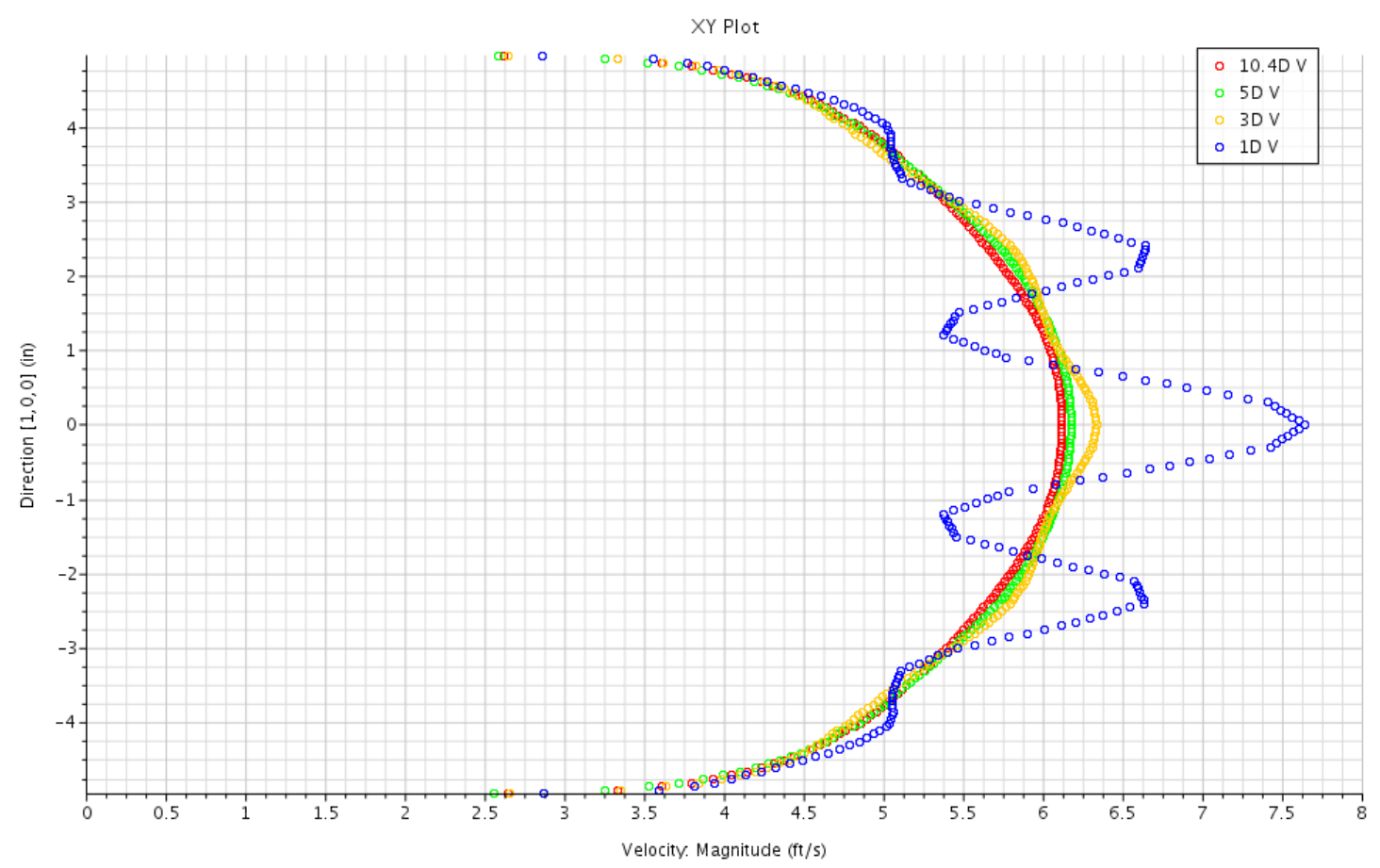

Figure 73. 5 ft/s Velocity Profiles with Flow Conditioner

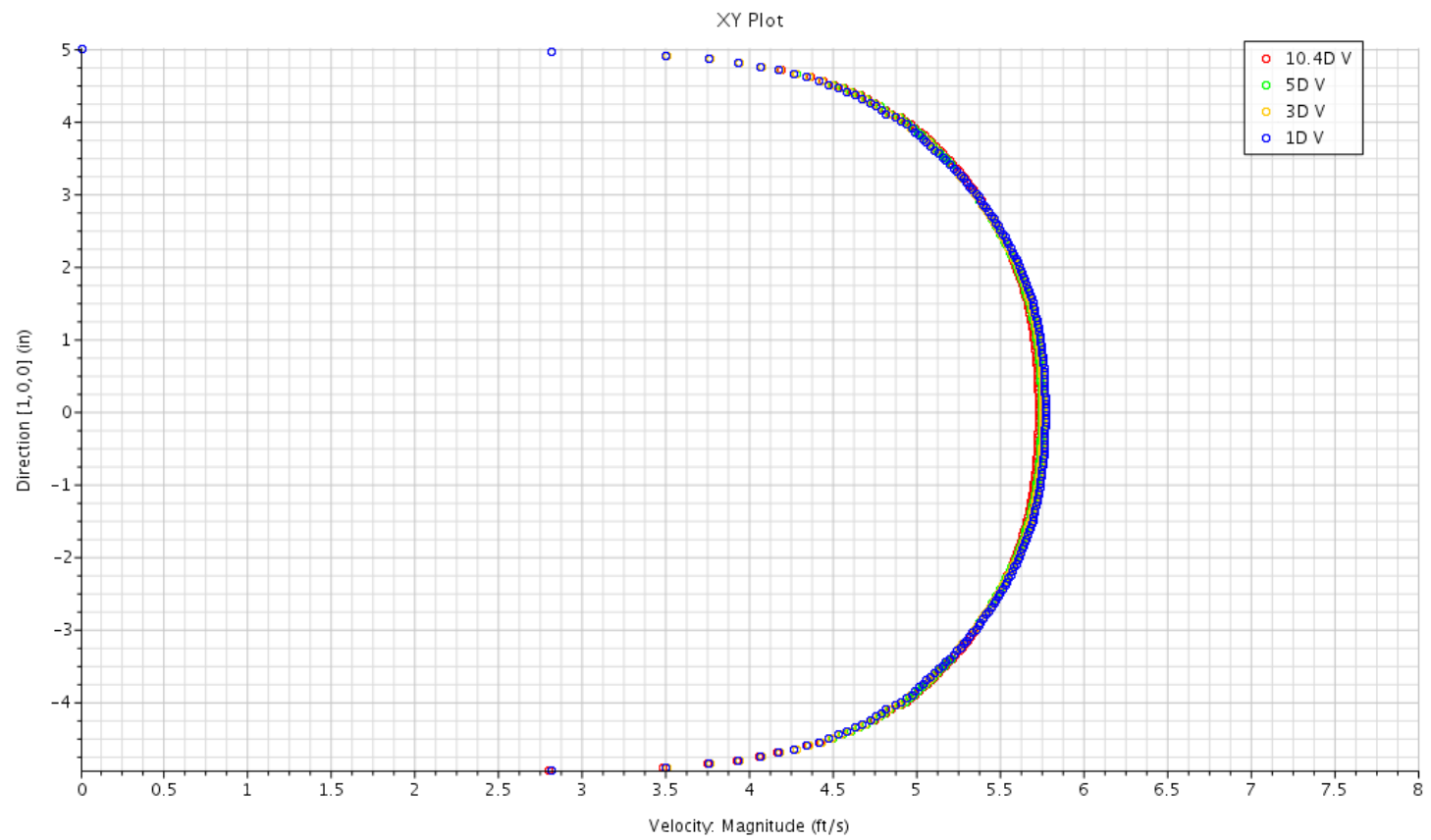

Figure 74. 5 ft/s Velocity Profiles without Flow Conditioner 
$9 \mathrm{ft} / \mathrm{s}$ CFD Simulation Results

Table 12. CFD Results for $9 \mathrm{ft} / \mathrm{s}$ with Flow Conditioner

\begin{tabular}{|c|c|c|c|c|c|c|}
\hline \multicolumn{7}{|c|}{ With Flow Conditioner } \\
\hline $\begin{array}{c}\text { Distance } \\
\text { Between Flow } \\
\text { Conditioner } \\
\text { and Cross } \\
\text { Section }\end{array}$ & $\begin{array}{c}\text { Average } \\
\text { Velocity } \\
(\mathrm{ft} / \mathrm{s})\end{array}$ & $\begin{array}{c}\text { Max } \\
\text { Velocity } \\
(\mathrm{ft} / \mathrm{s})\end{array}$ & $\begin{array}{c}\text { Average } \\
\text { TKE } \\
\left(\mathrm{ft}^{\wedge} 2 / \mathrm{s}^{\wedge} 2\right)\end{array}$ & $\begin{array}{c}\operatorname{Max} \\
\text { TKE } \\
\left(\mathrm{ft}^{\wedge} 2 / \mathrm{s}^{\wedge} 2\right)\end{array}$ & $\begin{array}{c}\text { Average } \\
\text { TDR } \\
\left(\mathrm{ft}^{\wedge} 2 / \mathrm{s}^{\wedge} 3\right)\end{array}$ & $\begin{array}{c}\operatorname{Max} \\
\text { TDR } \\
\left(\mathrm{ft}^{\wedge} 2 / \mathrm{s}^{\wedge} 3\right)\end{array}$ \\
\hline 1D & 9.00 & 13.39 & 1.37 & 2.05 & 27.27 & 539.09 \\
\hline $3 \mathrm{D}$ & 9.00 & 11.01 & 0.48 & 1.23 & 7.89 & 361.18 \\
\hline $5 \mathrm{D}$ & 9.00 & 10.82 & 0.34 & 1.17 & 6.18 & 332.36 \\
\hline $10.4 \mathrm{D}$ & 9.00 & 10.77 & 0.33 & 1.20 & 6.20 & 346.68 \\
\hline
\end{tabular}

Table 13. CFD Results for $9 \mathrm{ft} / \mathrm{s}$ without Flow Conditioner

\begin{tabular}{|c|c|c|c|c|c|c|}
\hline \multicolumn{7}{|c|}{ Without Flow Conditioner } \\
\hline $\begin{array}{c}\text { Distance } \\
\text { Between Flow } \\
\text { Conditioner } \\
\text { and Cross } \\
\text { Section } \\
\end{array}$ & $\begin{array}{c}\text { Average } \\
\text { Velocity } \\
\text { (ft/s) }\end{array}$ & $\begin{array}{c}\text { Max } \\
\text { Velocity } \\
\text { (ft/s) }\end{array}$ & $\begin{array}{c}\text { Average } \\
\text { TKE } \\
\left(\mathrm{ft}^{\wedge} 2 / \mathrm{s}^{\wedge} 2\right)\end{array}$ & $\begin{array}{c}\text { Max } \\
\text { TKE } \\
\left(\mathrm{ft}^{\wedge} 2 / \mathrm{s}^{\wedge} 2\right)\end{array}$ & $\begin{array}{c}\text { Average } \\
\text { TDR } \\
\left(\mathrm{ft}^{\wedge} 2 / \mathrm{s}^{\wedge} 3\right)\end{array}$ & $\begin{array}{c}\text { Max } \\
\text { TDR } \\
\left(\mathrm{ft}^{\wedge} 2 / \mathrm{s}^{\wedge} 3\right)\end{array}$ \\
\hline 1D & 8.98 & 10.30 & 0.31 & 1.22 & 6.26 & 353.47 \\
\hline $3 \mathrm{D}$ & 8.98 & 10.30 & 0.30 & 1.22 & 6.22 & 352.14 \\
\hline $5 \mathrm{D}$ & 8.98 & 10.30 & 0.30 & 1.21 & 6.19 & 351.02 \\
\hline $10.4 \mathrm{D}$ & 8.98 & 10.29 & 0.29 & 1.21 & 6.15 & 349.58 \\
\hline
\end{tabular}



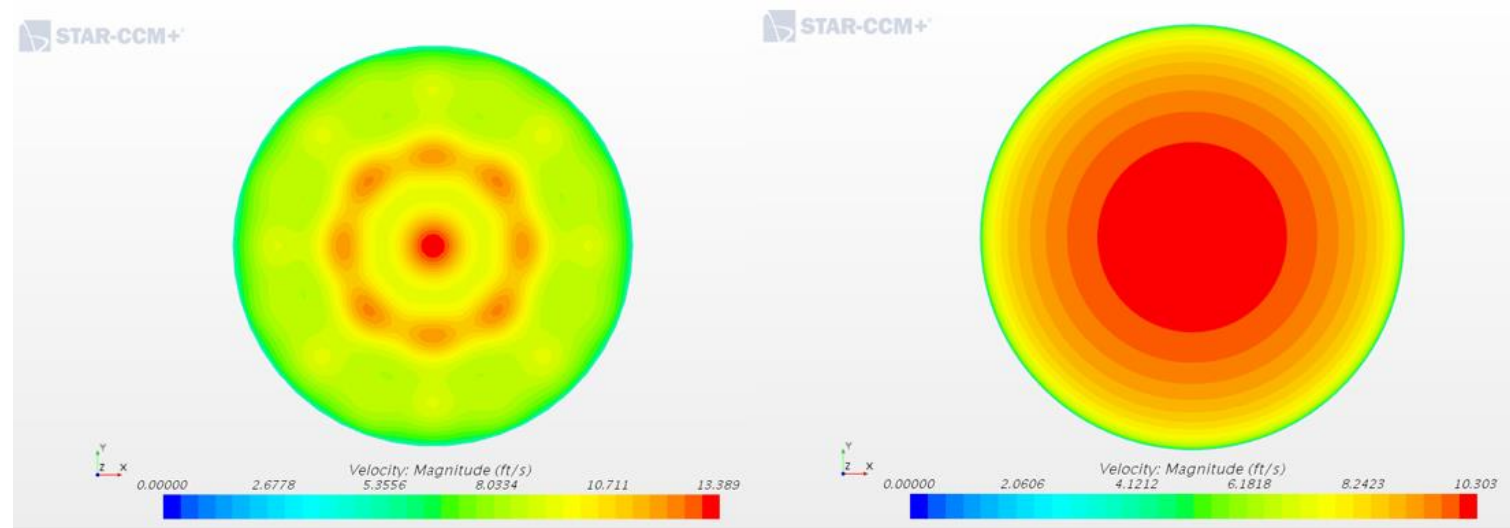

Figure 75. $9 \mathrm{ft} / \mathrm{s}$ Velocity at $1 \mathrm{D}$ with and without Flow Conditioner
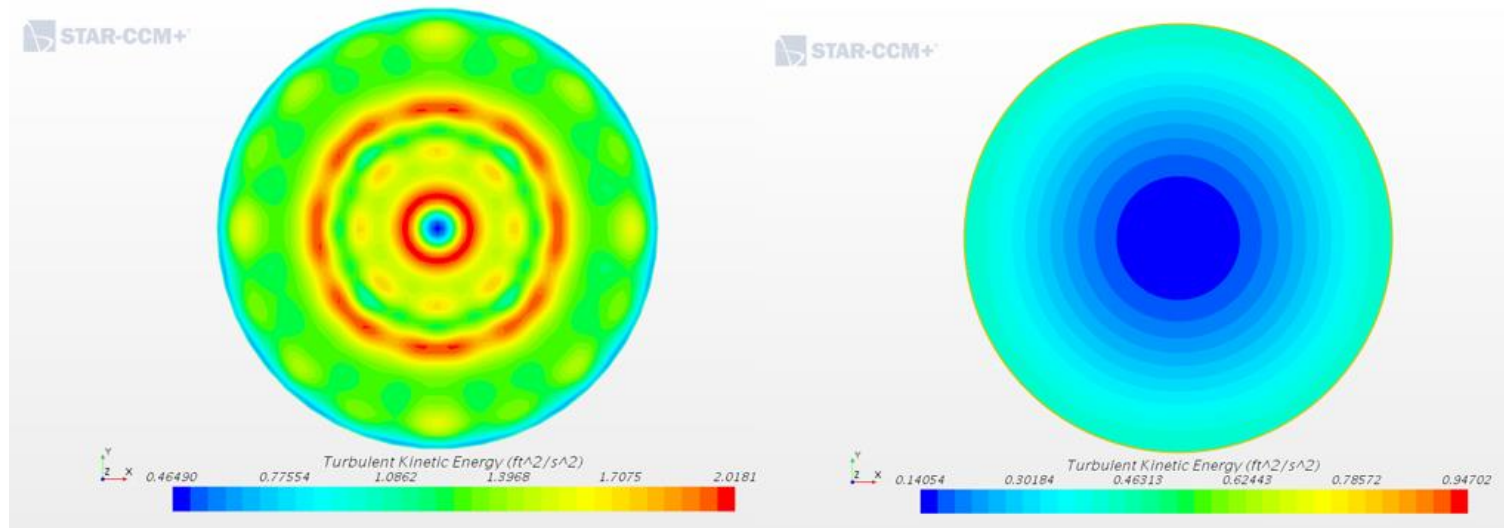

Figure 76. $9 \mathrm{ft} / \mathrm{s}$ TKE at 1D with and without Flow Conditioner
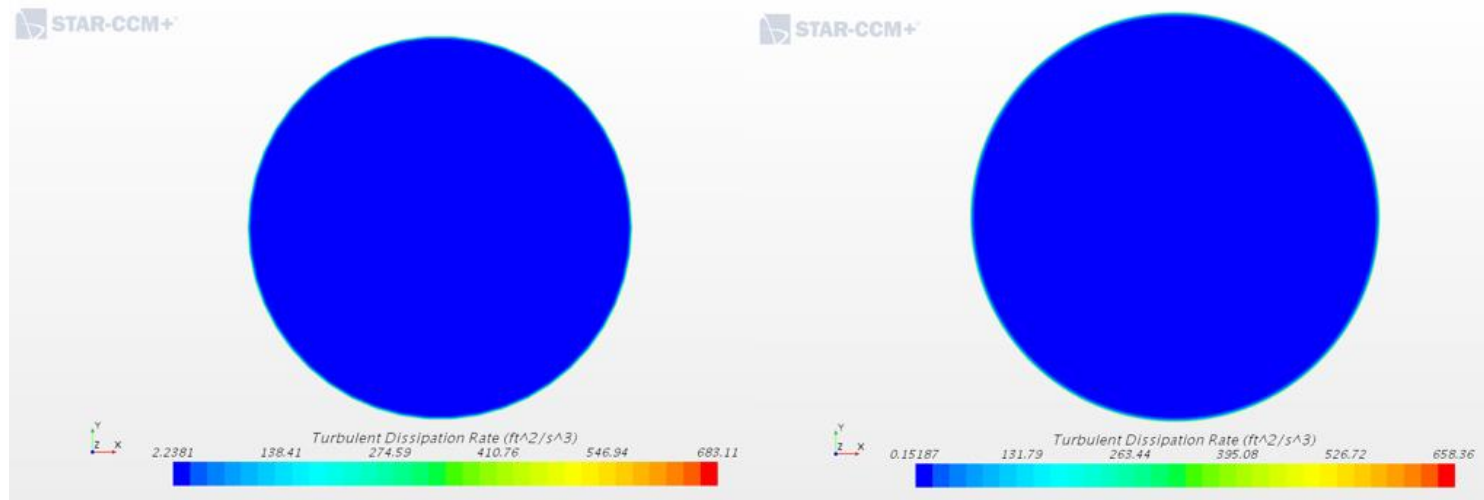

Figure 77. $9 \mathrm{ft} / \mathrm{s}$ TDR at 1D with and without Flow Conditioner 

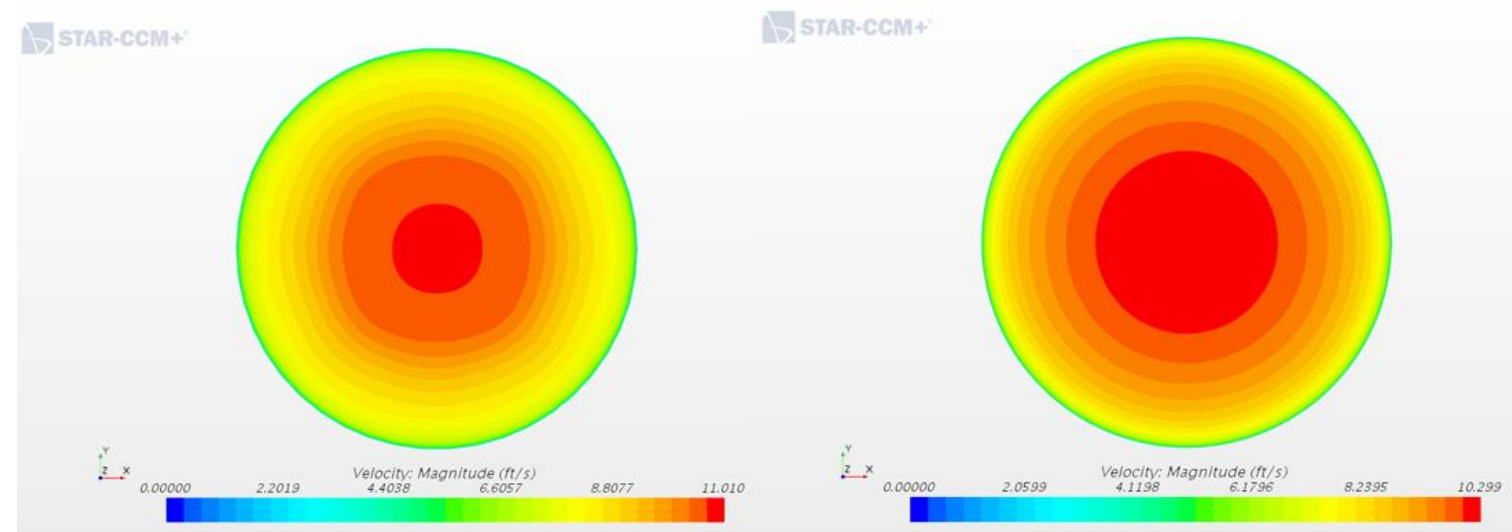

Figure 78. $9 \mathrm{ft} / \mathrm{s}$ Velocity at 3D with and without Flow Conditioner

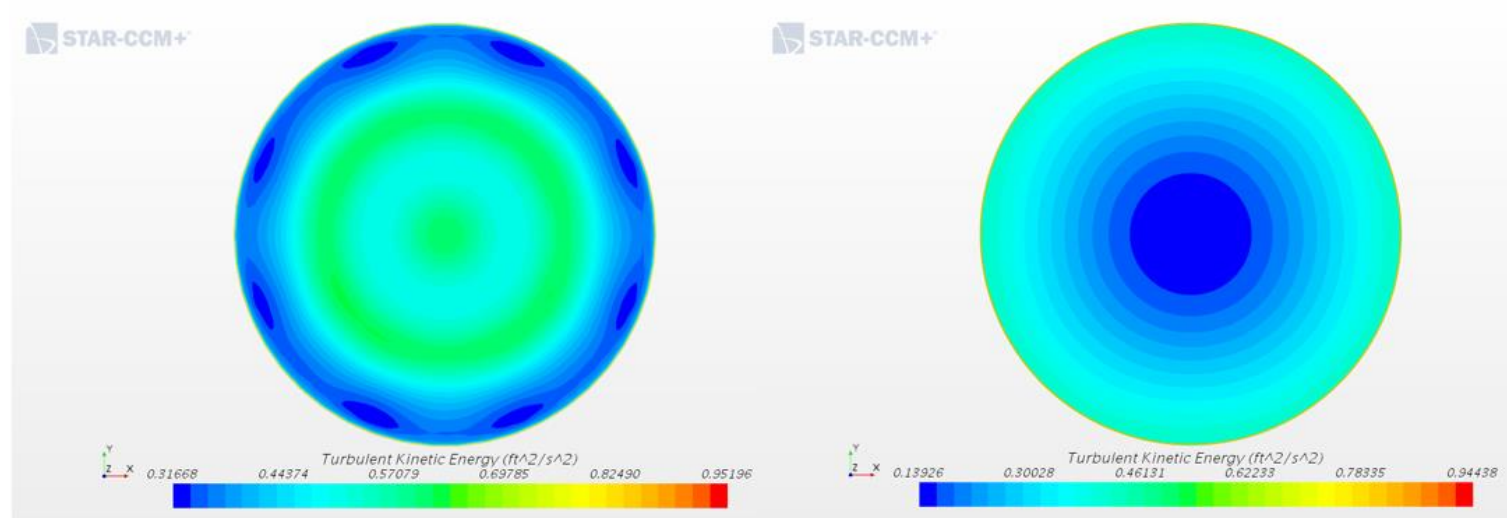

Figure 79. $9 \mathrm{ft} / \mathrm{s}$ TKE at 3D with and without Flow Conditioner
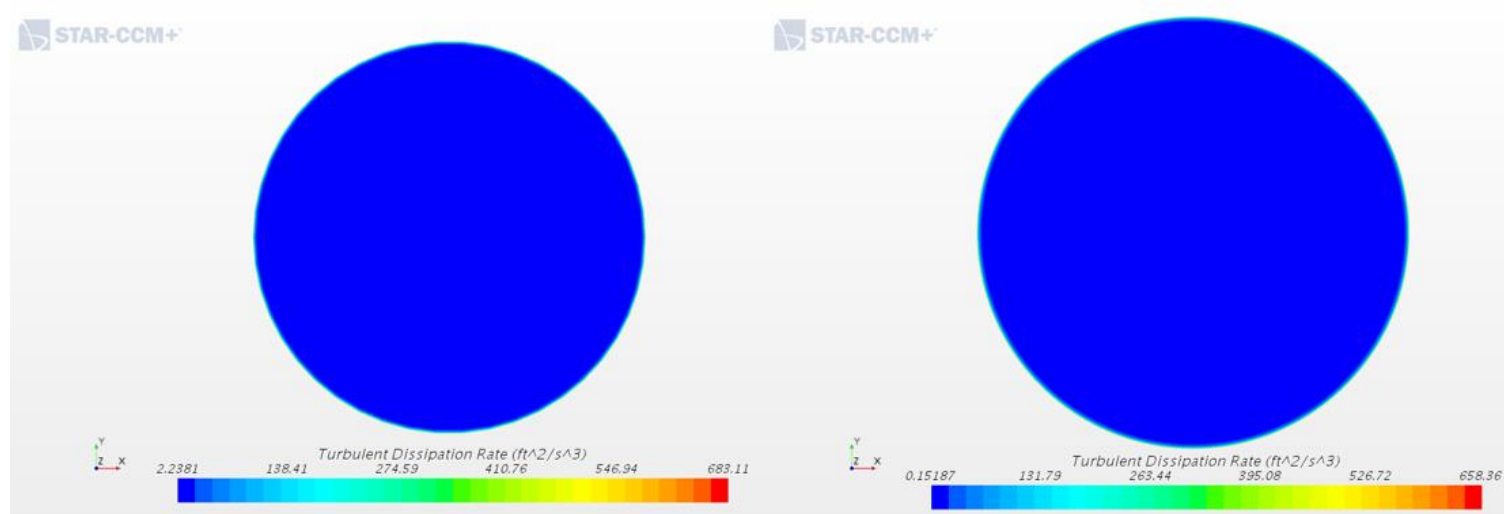

Figure 80. $9 \mathrm{ft} / \mathrm{s}$ TDR at 3D with and without Flow Conditioner 

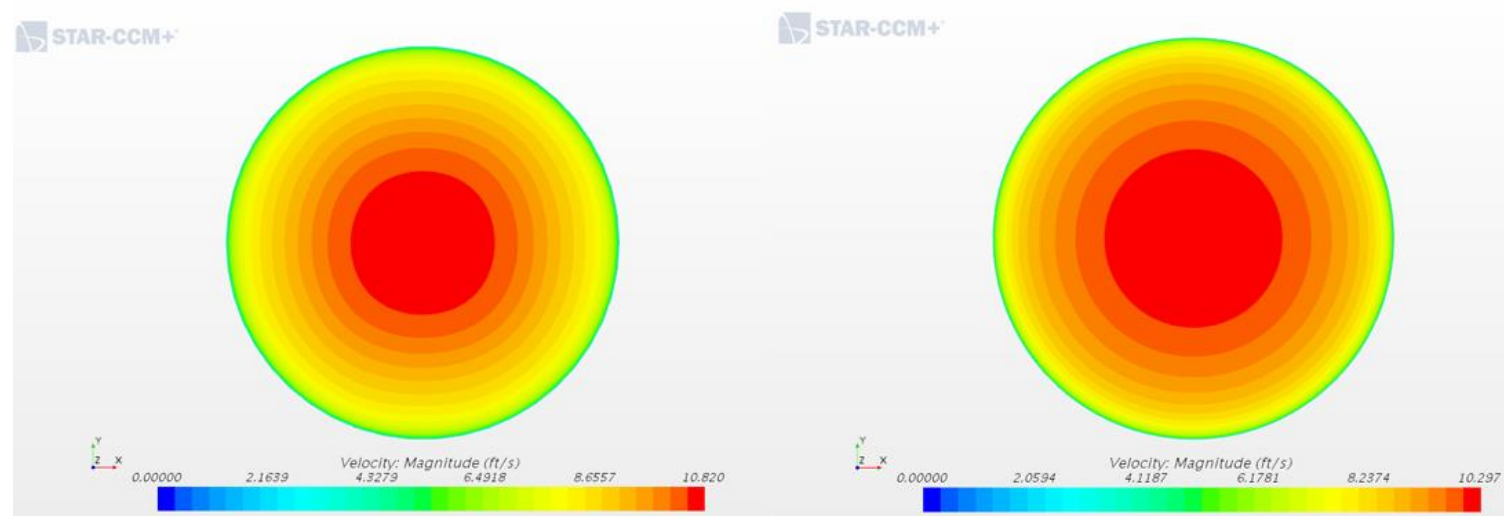

Figure $81.9 \mathrm{ft} / \mathrm{s}$ Velocity at 5D with and without Flow Conditioner
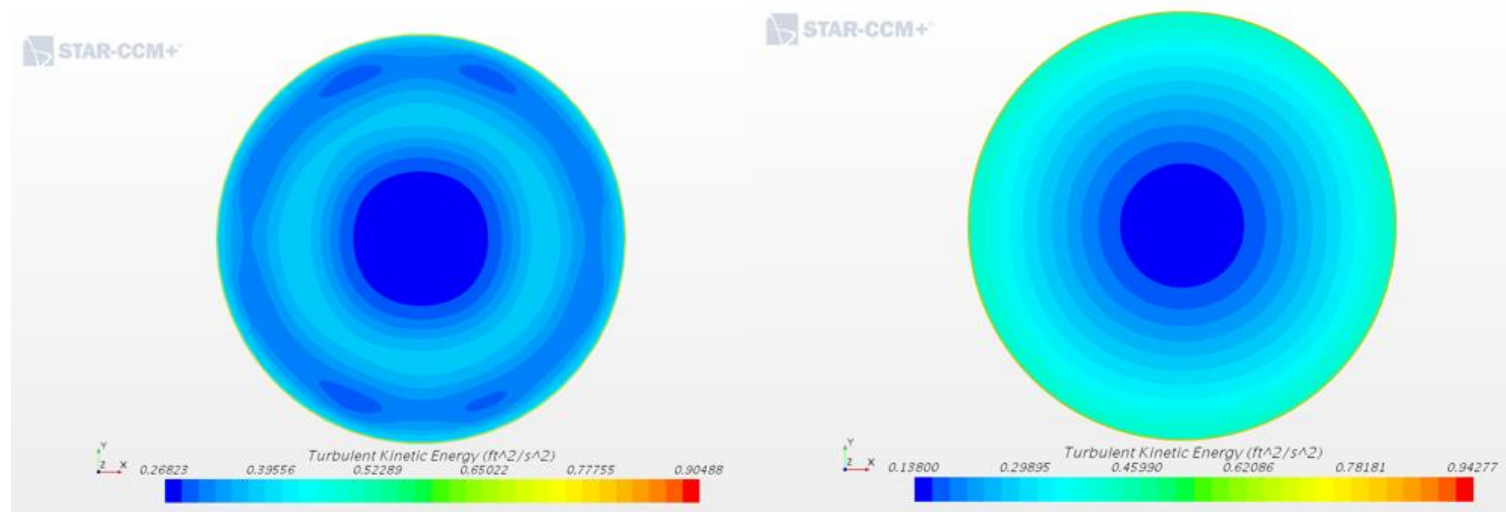

Figure 82. $9 \mathrm{ft} / \mathrm{s}$ TKE at 5D with and without Flow Conditioner

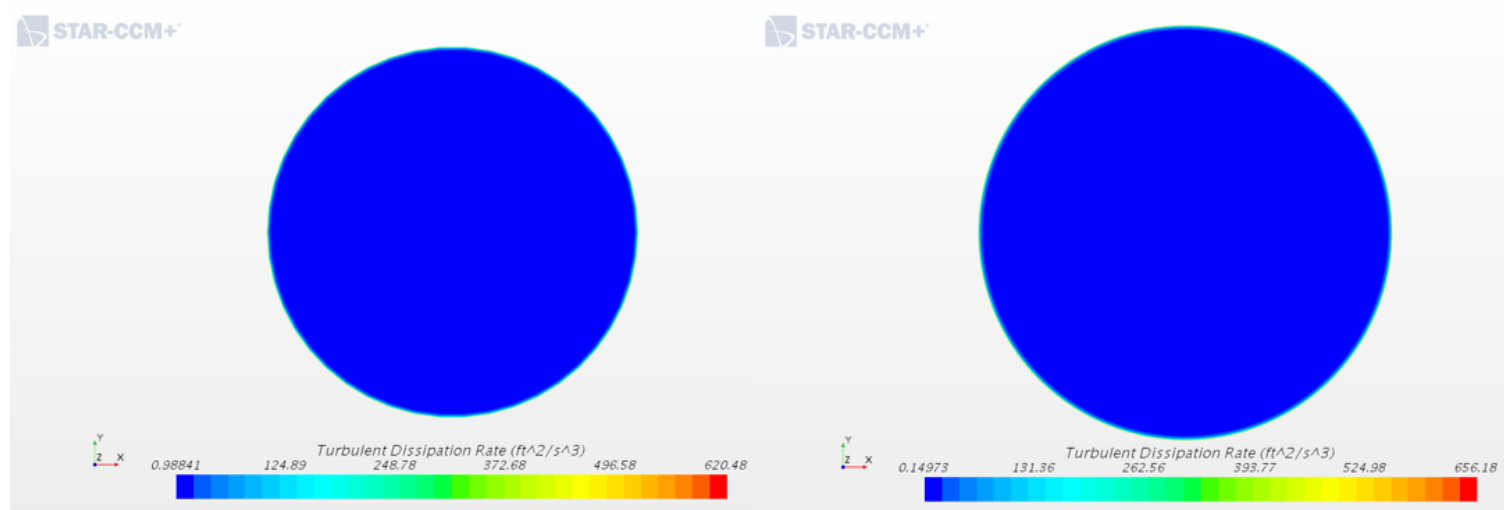

Figure 83. $9 \mathrm{ft} / \mathrm{s}$ TDR at 5D with and without Flow Conditioner 


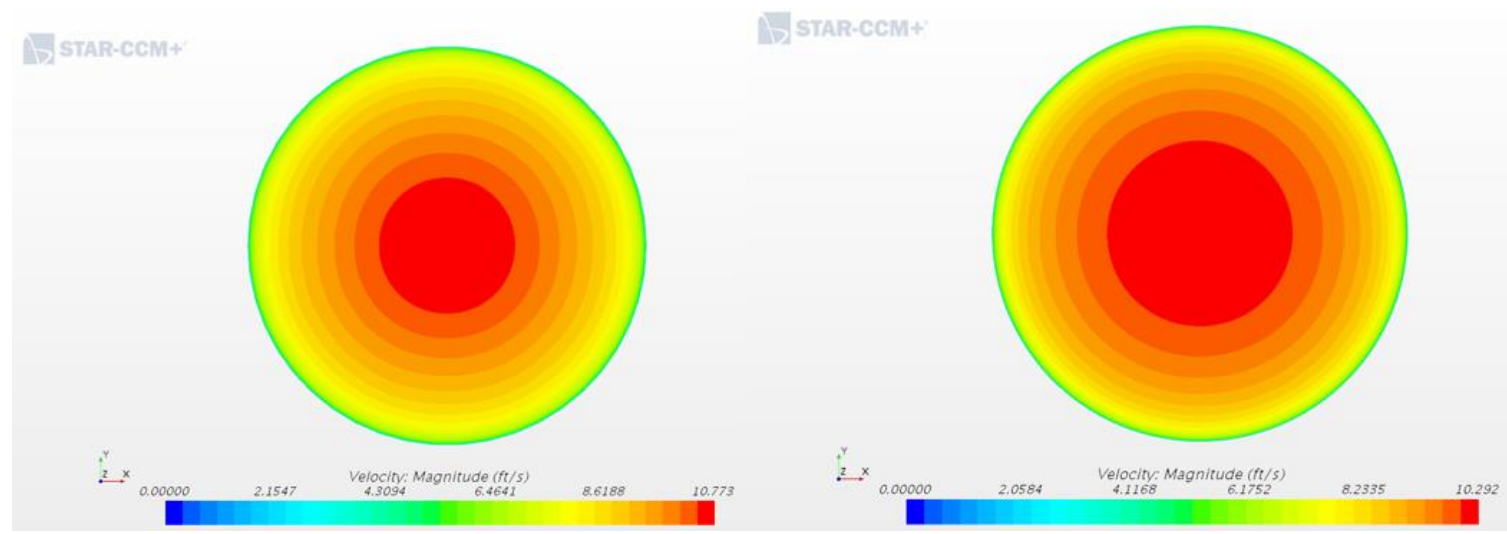

Figure 84. $9 \mathrm{ft} / \mathrm{s}$ at 10.4D with and without Flow Conditioner

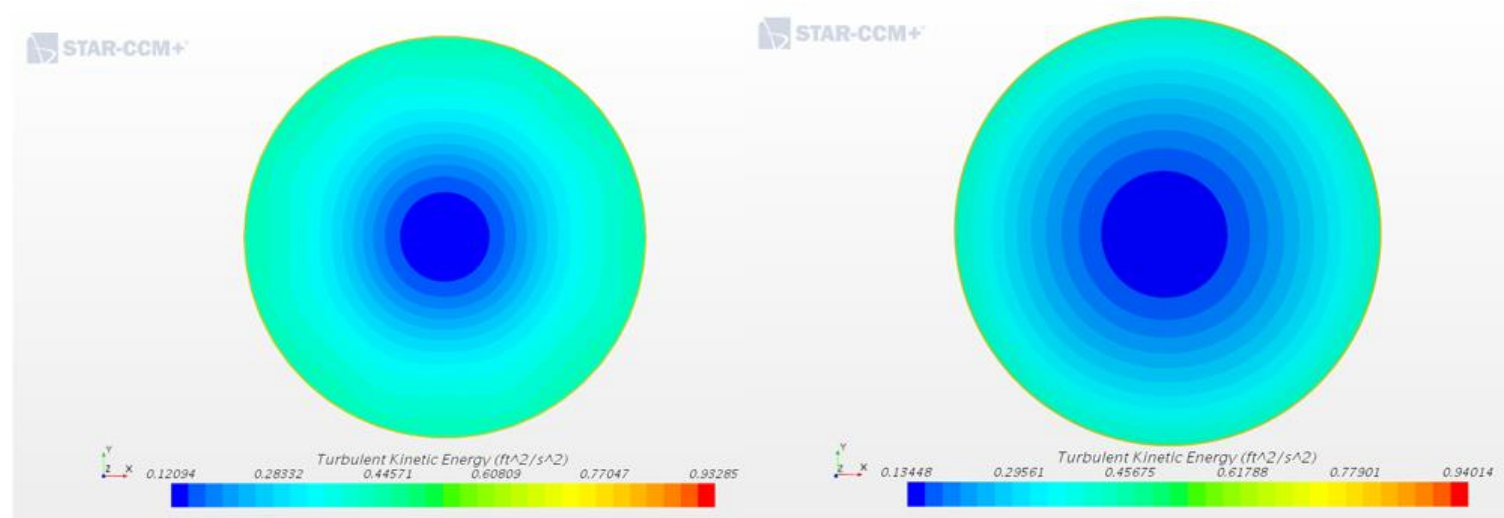

Figure 85. $9 \mathrm{ft} / \mathrm{s}$ TKE at 10.4D with and without Flow Conditioner
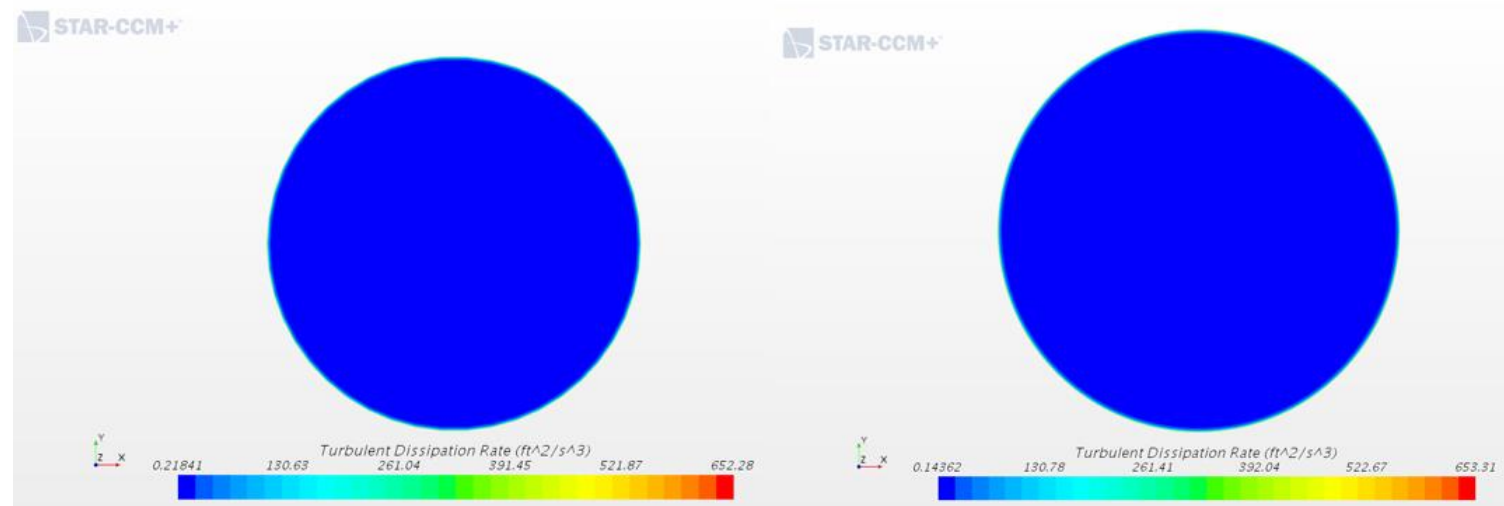

Figure 86. $9 \mathrm{ft} / \mathrm{s}$ TDR at 10.4D with and without Flow Conditioner 


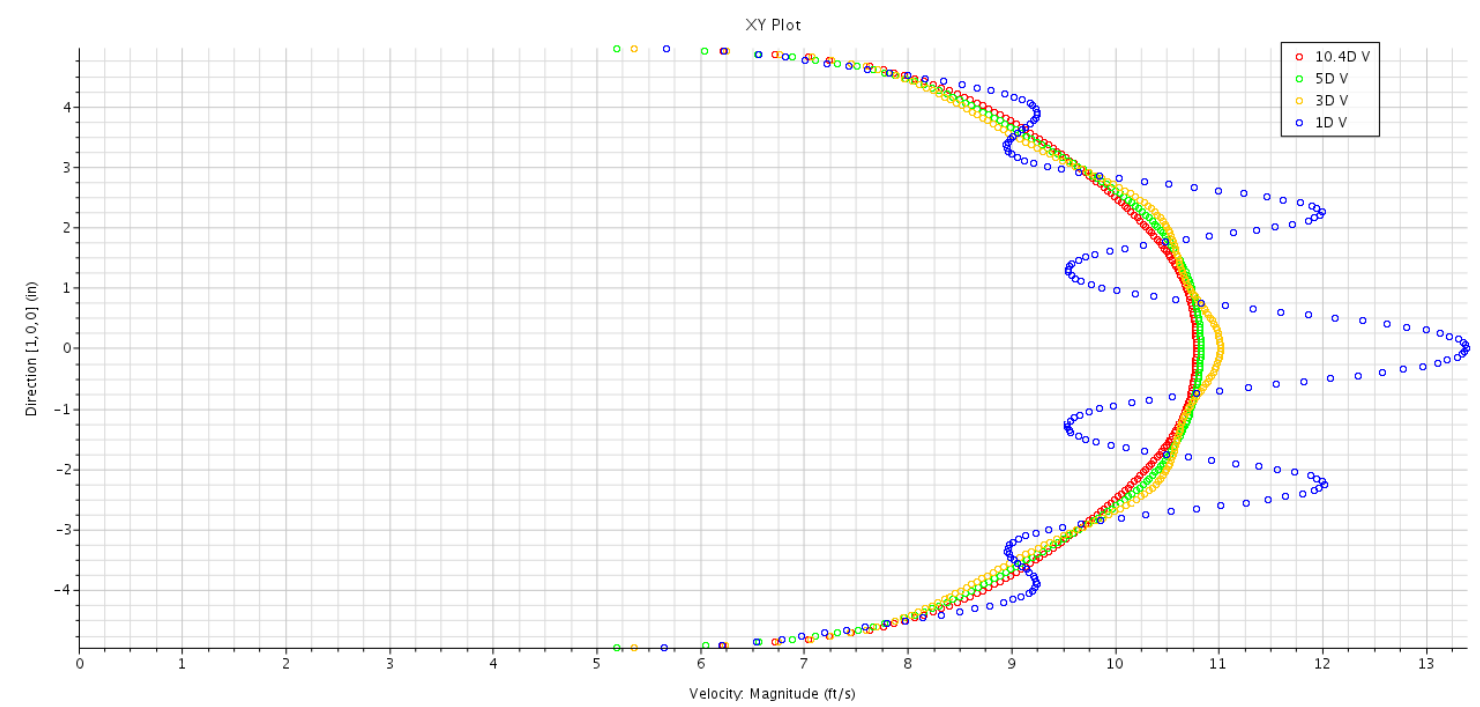

Figure 87. $9 \mathrm{ft} / \mathrm{s}$ Velocity Profiles with Flow Conditioner

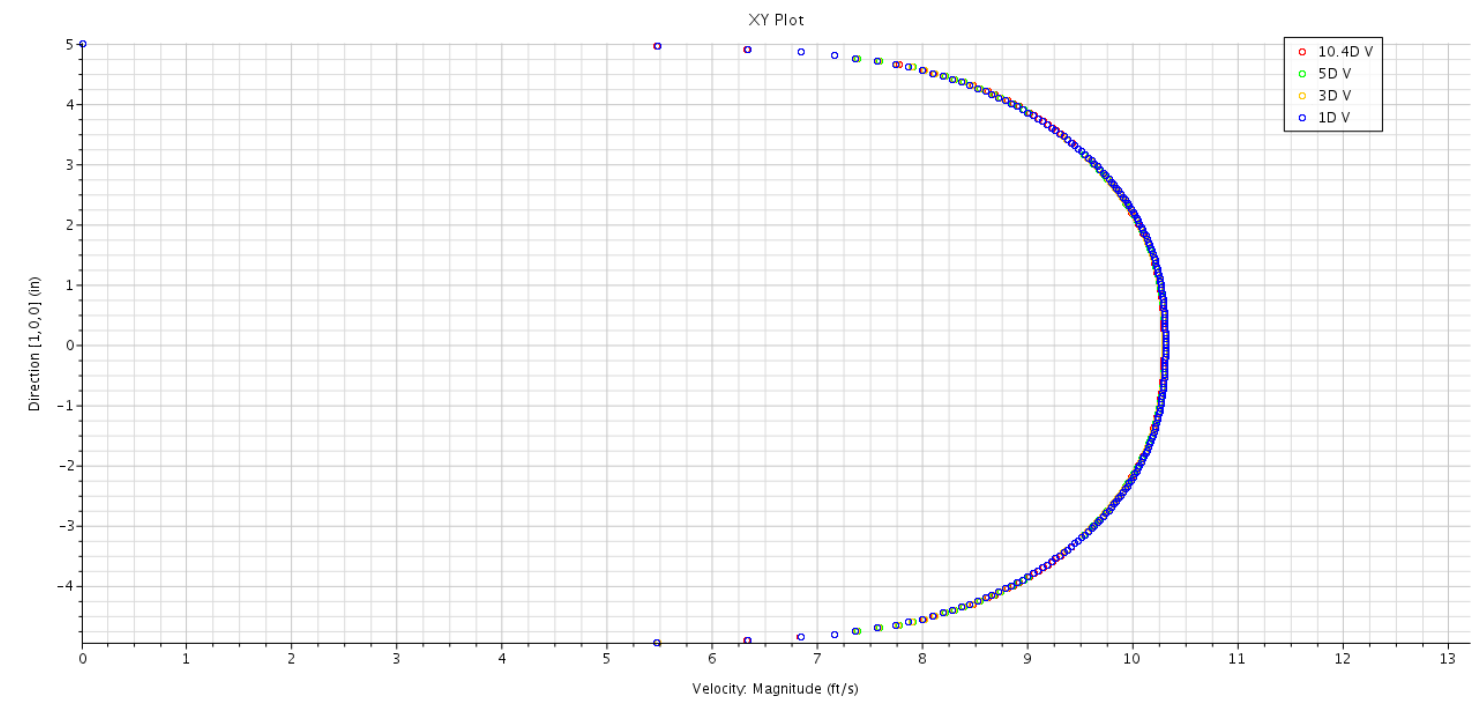

Figure 88. 9 ft/s Velocity Profiles without Flow Conditioner

\section{$14 \mathrm{ft} / \mathrm{s}$ CFD Simulation Results}

The 14 fps CFD simulation results were not included due to a mesh convergence problem. It is highly likely that the general trends of the $14 \mathrm{fps}$ simulations would match the other simulations with the only differences being in magnitudes. 